EDGAR APAZA HUALLPA

CARACTERIZAÇÃO DA TRANSFORMAÇÃO MARTENSÍTICA EM TEMPERATURAS CRIOGÊNICAS 


\section{CARACTERIZAÇÃO DA TRANSFORMAÇÃO MARTENSÍTICA EM TEMPERATURAS CRIOGÊNICAS}

Dissertação apresentada à Escola

Politécnica da Universidade de São Paulo para a obtenção do titulo de Mestre em Engenharia.

Área de concentração:

Engenharia Metalúrgica e de Materiais.

Orientador:

Prof. Dr. Hélio Goldenstein. 


\section{FICHA CATALOGRÁFICA}

\section{Huallpa, Edgar Apaza}

Caracterização da transformação martensítica em temperaturas criogênicas / E.A. Huallpa. --São Paulo, 2011.

$94 \mathrm{p}$.

Dissertação (Mestrado) - Escola Politécnica da Universidade de São Paulo. Departamento de Engenharia Metalúrgica e de Materiais.

1. Mudança de fase (Caracterização) 2. Baixa temperatura I. Universidade de São Paulo. Escola Politécnica. Departamento de Engenharia Metalúrgica e de Materiais II. t. 
DEDICO ESTE TRABAJO A MI FAMÍLIA, EDUARDO

LORENZA, EDWIN, JOSÉ, MARTHA, GIOVANNA Y ELVIO, POR SU CONSTANTE APOYO. 


\section{AGRADECIMENTOS}

A minha família sempre presente.

Ao Professor Doutor Hélio Goldenstein pela paciente orientação, amizade, conselhos e apoio durante todo o mestrado.

Aos amigos do Laboratório de Transformação de Fases da USP, Alexandre Farina, Paula Fernanda da Silva, Isaac Jamil, Paulo Ogata, Mario Ramirez, Eduardo Monlevade, Diego Rocha, Arthur Nishikawa, por seu constante apoio durante o mestrado.

Aos amigos do laboratório de LADIN em mecânica da USP, Freddy Franco, Manuel Alberteris, José Pérez, Linilson Padovese.

A Julio Capó pela co-orientação e discussões em assuntos de Barkhausen e outros. Ao Professor Dr. José Roberto Costa Guimarães, pelo fornecimento da liga Invar Fe$\mathrm{Ni}-\mathrm{C}$, e pelas discussões respeito à martensita.

A aço Villares pelo fornecimento do aço AISI D2

A Ernesto, Ivan e Renato do laboratório do grupo de transições de fase e supercondutividade do IF-USP, pela ajuda e confiança.

Ao bibliotecário técnicos e funcionários do PMT, especialmente a Rubens, Danilo, Rafael, Livio, Rafael, Ivo pela amizade e colaboração.

Aos amigos peruanos pela convivência grata durante o período de mestrado, Marvin, Juanca, Diego, Niko, Giancarlo, Erick, Dennis, Dany, Ronald, Johanna, JC, Karina, Lissie.

À amizade e apoio de Cleuza Fernandez, Alejandra Matiz.

A CNPq pela bolsa de estudos. 


\section{RESUMO}

$\mathrm{Na}$ atualidade, o estudo da transformação martensítica é de grande importância na área acadêmica e tecnológica, devido à aplicação de aços e ferros fundidos com estruturas martensíticas. $O$ estudo dos fenômenos da transformação martensítica envolve vários pesquisadores no mundo e é objeto de eventos como o ICOMAT e ESOMAT. O presente trabalho acompanhou a transformação martensítica por meio de técnicas experimentais a temperaturas sub-zero em um aço AISI D2 e uma liga Fe-Ni-C previamente austenitizadas. A literatura indica que $\mathrm{o}$ tratamento a temperaturas sub-zero pode melhorar propriedades dos aços temperados e revenidos. Foi explorado o uso dos métodos de ruído magnético de Barkhausen (MBN), para detectar a transformação de fase da austenita para a martensita durante o resfriamento sub-zero das amostras, usando três diferentes configurações: a emissão de ruído Barkhausen convencional estimulada por um campo magnético alternado; o método de Okamura que é a emissão de ruído magnético medido embaixo de um campo fixo (DC); e uma nova técnica experimental, que mede a emissão magnética espontânea durante a transformação na ausência de qualquer campo externo. Os fenômenos associados com a transformação de fase também foram medidos por resistividade elétrica e as amostras resultantes foram caracterizadas por microscopia óptica e eletrônica de varredura. Medições MBN no aço ferramenta AISI D2, austenitizadas a $1473 \mathrm{~K}\left(1200^{\circ} \mathrm{C}\right)$ e resfriadas a temperatura de nitrogênio líquido apresentaram uma mudança próximo de $225 \mathrm{~K}\left(-48^{\circ} \mathrm{C}\right)$ durante o resfriamento, que corresponde à temperatura Ms, como foi confirmado por medidas de resistividade. As medições da emissão de ruído magnético espontâneo, realizadas in situ durante o resfriamento da amostra imersa em nitrogênio líquido, mostraram que poderia ser detectado um fenômeno de "estouro" individual (burst), de forma similar às medições de emissão acústica ( $A E)$, o qual foi confirmado com a liga Fe-Ni-C. Este método de caracterização Spontaneous Magnetic Emission (SME) pode ser considerado uma nova ferramenta experimental para o estudo de transformações martensiticas em ligas ferrosas. Foi acompanhado o inicio da transformação martensítica por SME, em função do tamanho de grão, já que é conhecido pela literatura que o inicio da transformação martensítica (Ms), muda com a variação do tamanho de grão.

Palavras-chave: Martensita, Barkhausen, sub-zero. 


\section{ABSTRACT}

CHARACTERIZATION OF THE MARTENSITIC TRANSFORMATION AT CRYOGENIC TEMPERATURES

Martensitic transformations are of special interest both as an academic topic and as a technological issue, due to importance of steels and cast irons with martensitic structures. Studies of martensite transformation phenomena involve researchers all over the world and specific conferences and meetings, as ICOMAT and ESOMAT. The present work followed the martensitic transformation using different experimental techniques, during cooling at cryogenic temperatures samples of a AISI D2 cold work tool steel and also a Fe-Ni-C, previously austenitized. There are plenty of references in the literature suggesting that sub-zero cooling treatments could ameliorate the properties of quenched and tempered steels. The Magnetic Barkhausen Noise (MBN) method was applied during cooling to subzero temperatures of austenitic samples of a AISI D2 cold work tool steels (previously quenched from $1200^{\circ} \mathrm{C}$ ) and to a Invartype Fe-Ni-C alloy. MBN is a non-destructive technique based on the detection of the signal generated when ferromagnetic materials are subjected to an oscillating external magnetic field. In order to study the austenite to martensite transformation, three different configurations were tested: conventional Barkhausen using an oscillating magnetic field, a method proposed by Okamura, which uses a fixed magnetic field and a new method that detects spontaneous magnetic emissions (SME) on the absence of any applied magnetic field. Other phenomena associated with the transformation were followed using electrical resistivity measurements, optical microscopy and X-ray diffraction. MBN measurements on a cold work tool steel AISI D2, austenitized at $1473 \mathrm{~K}\left(1200^{\circ} \mathrm{C}\right)$ and quenched to room temperature, made during further cooling to liquid nitrogen temperature, presented a clear change of signal intensity near $225 \mathrm{~K}\left(-48^{\circ} \mathrm{C}\right)$, corresponding to Ms temperature, as confirmed by resistivity measurements. The SME in situ measurements during cooling of samples in liquid nitrogen were able to detect single "burst" (landslide nucleation and growth) phenomena, in a manner similar to the Acoustic Emission (AE) measurements; these results have been confirmed also with measurements on a Fe$\mathrm{Ni}-\mathrm{C}$ alloy. The new Spontaneous Magnetic Emission (SME) characterization method can be considered a new experimental tool for the study of martensitic transformations in ferrous alloys. The beginning temperature for the martensitic 
transformation detected using SME, electric resistivity and MBN were compared with estimates using the Andrews empirical equation (linear, 1965) for the Ms temperature. The effect of the austenite grain size on the beginning of the martensitic transformation was studied using SME, as it is known that the Ms temperature depends on the austenite grain size.

Key Words: Martensitic transformation; magnetic Barkhausen noise, subzero treatments. 


\section{LISTA DE FIGURAS}

Figura 1 - Formação de uma lamela de martensita, ilustrando ambos os tipos de

deformação do reticulado: a) escorregamento; b) maclação (KELLY; NUTTING, 1960)..........4

Figura 2 - Efeito do carbono nos parâmetros do reticulado da austenita e da

martensita(COHEN, 1962).

Figura 3 - A dependência das constantes do reticulado da martensita com o teor de carbono do aço, de acordo com os dados de vários autores: $\square$ ) Kurdyumov e Kaminskii (1929), +)

Selyakov; Kuryumov e Gudtsov (1927). Extraído de Vintaikin e Nosova (1997).

6

Figura 4 - Durezas de microestruturas martensíticas em função do conteúdo de carbono nos aços ferríticos (KRAUSS, 1999).

Figura 5 - Martensita escorregada na forma de ripas e sua estrutura (MAKI; TSUZAKI;

TAMURA, 1980).

Figura 6 - Microestrutura de martensita escorregada num aço 4140 temperado a $150^{\circ} \mathrm{C}$, micrografia obtida por microscopia de transmissão (TEM)(KRAUSS, 1999).

Figura 7 - Crescimento de placas de martensita com incremento do resfriamento abaixo de Ms a) crescimento da placa de martensita interrompido pelo contorno de grão; b) propagação da martensita (PORTER; EASTERLING, 1992).

Figura 8 - Microestrutura de martensita em placas numa liga Fe-1.86wt\%C, apresentando microtrincas nos locais de "impignemet" com colisões entre placas, micrografia óptica(KRAUSS, 1999).

Figura 9 - Morfologia do Ms em função de concentração de carbono para aços carbono (ZHAO; NOTIS, 1995).

Figura 10 - Variação de Ms com a taxa de resfriamento (ZHAO; NOTIS, 1995).

Figura 11 - Variação de Ms com o tempo de austenitização de uma liga Fe-0.75\%C, mostrando o efeito de descarbonetação (ZHAO; NOTIS, 1995).

Figura 12 - Temperatura Ms de ligas binárias a base de ferro compiladas por Liu et al. (2001).

Figura 13 - Temperatura Ms de ligas binárias a base de ferro, conforme determinado por vários pesquisadores 1) Gilbert e Owen (1962), 2) Swanson e Parr (1964) apud Liu et al. (2001), 3) Pascover e Radcliffe (1968) apud Liu et al. (2001), 4) Gomersall e Parr (1965) apud Liu et al. (2001), 5) Parr (1967) apud Liu et al. (2001), 6) Kaufman e Cohen (1958), 7) Owen e Wilson (1965), 8) Wilson (1965) apud Liu et al. (2001) e 9) Goodenow e Helemann (1965).

Figura 14 - Dados experimentais de Yang e Badheshia (2009) plotados no modelo de Guimarães na equação 4 com $T_{\text {off }}$ substituído por Ms, e $V_{V_{\text {off }}}=1$ (GUIMARÃES; RIOS, 2010). 
Figura 15 - Parede de Dominio de $180^{\circ}$ (CULLITY; GRAHAM, 2009).

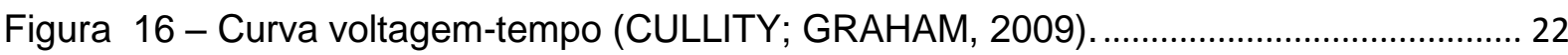

Figura 17 - Efeito de Barkhausen (BOZORTH, 1993) ................................................................ 23

Figura 18 - Mudança na resistividade elétrica durante o resfriamento e aquecimentos das ligas $\mathrm{Fe}-\mathrm{Ni}$ e $\mathrm{Au}-\mathrm{Cd}$, ilustrando a histerese entre a reação martensítica no resfriamento e a transformação inversa no aquecimento (KAUFMAN; COHEN, 1958)...................................... 25

Figura 19 - Resistividade elétrica resfriado desde 513K da liga Cu-Al-Zn............................. 26

Figura 20 - Difração de raios-X usando radiação de Mo. a) antes da transformação; b) após $20 \%$ de transformação. a refere-se à martensita, $y$ refere-se à austenita (ZHANG; KELLY; GATES, 1999).

Figura 21 - Tetragonalidade dependente do tempo (JABLONSKA et al., 2006). 28

Figura 22 - Variação da tetragonalidade máxima e mínima da martensita em função do tempo: a: Máximo; b: Mínimo de tetragonalidade registrada (c/a - 1) (JABLONSKA et al., 2006).

Figura 23 - Difração de raios-X para reflexões (011) e (110) da martensita (KAJIWARA; KIKUCHI, 1991).

Figura 24 - Mapa de fases para o aço AISI D2 calculado com o programa Thermo-Calc® aliado ao banco de dados TCFE. Nas ordenadas a escala é linear (fração mássica das fases).

Figura 25 - Mapa de fases para o aço AISI D2 calculado pelo programa Thermo-Calc® aliado ao banco de dados TCFE. Nas ordenadas a escala é logarítmica (fração mássica das fases).

Figura 26 - Mapa de fases para a liga Fe-Ni-C calculado pelo programa Thermo-Calc® aliado ao banco de dados TCFE. Nas ordenadas a escala é linear (fração mássica das fases).

Figura 27 - Mapa de fases para a liga Fe-Ni-C calculado pelo programa Thermo-Calc® aliado ao banco de dados TCFE. Nas ordenadas a escala é logarítmica (fração mássica das fases).

Figura 28 - Dimensões das amostras de Fe-Ni-C e AISI D2.

Figura 29 - Equipamento de lixamento "Disk-Grinder" as amostras foram colados com adesivo de poliacrilato e soltos com Acetona.

Figura 30 - Diagrama do esquema da medição de ruído magnético de Barkhausen. 40

Figura 31 - Amostras AISI D2 temperadas em óleo e atacadas com Villela. 43

Figura 32 - Amostras Fe-Ni-C temperadas em água e atacadas com nital 2\%. 44 
Figura 33 - Amostras de ampliação de 200x e 500x respectivamente para ser testadas no ImageJ.

Figura 34 - Mapa de fases para o aço AISI D2 calculado pelo programa Thermo-Calc® aliado ao banco de dados TCFE. Nas ordenadas a escala é linear e logarítmica

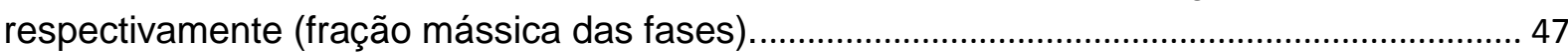

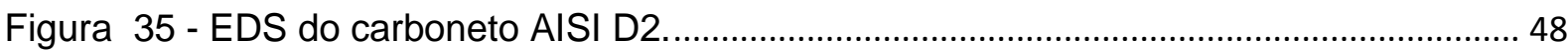

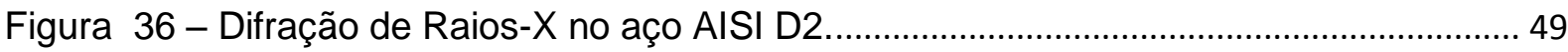

Figura 37 - Resistividade elétrica em função da temperatura............................................... 50

Figura 38 - Resistividade elétrica no dedo frio no ciclo de resfriamento. ............................... 52

Figura 39 - Resistividade elétrica no dedo frio no ciclo de aquecimento. ............................. 52

Figura 40 - Resistividade elétrica com variação de corrente. .................................................. 53

Figura 41 - Resistividade elétrica na liga Fe-Ni-C no ciclo de resfriamento. ......................... 54

Figura 42 - Arranjo experimental para o Barkhausen e resistividade em função da temperatura.

Figura 43 - Forno / câmara criogênica GRION. 55

Figura 44 - Ruído de Barkhausen medido em quatro temperaturas durante o resfriamento da amostra.

Figura 45 - Distribuição de probabilidades de MBN em 4 temperaturas durante o resfriamento do AISI D2.

Figura 46 - RMS do ruído de Barkhausen medido em diferentes temperaturas durante o resfriamento da amostra.

Figura 47 - Resistividade elétrica e emissão de sinal magnético medido em diferentes temperaturas durante o resfriamento da amostra.

Figura 48 - Arranjo experimental para o Barkhausen no decorrer do tempo. 59

Figura 49 - Sinais típicos de Barkhausen com decorrer do tempo. 60

Figura 50 - Distribuição de probabilidades com o tempo

Figura 51 - Dependência do MBN (RMS Voltagem) em função do tempo.

Figura 52 - Dependência do MBN (RMS Voltagem) em função do tempo, mostrando os picos magnéticos devido à transformação martensítica na liga $\mathrm{Fe}-\mathrm{Ni}-\mathrm{C}$.

Figura 53 - Ruído de Barkhausen medido durante a transformação martensítica. 64

Figura 54 - Distribuição de probabilidades da quantidade de eventos MBN no tempo. 65 
Figura 55 - Fotografia do arranjo experimental usado para reproduzir o experimento de Okamura apud Nishiyama (1978).

Figura 56 - (a) registro fotográfico do ruído captado pelo pick-up antes do resfriamento da amostra. Fig. 8 (b) sinal de ruído durante o resfriamento, os picos correspondem a avalanches magnéticas, devido ao movimento de paredes de Bloch. A variação do espectro do ruído pode ser observado na parte inferior da figura.

Figura 57 - Diagrama do esquema de medição da Emissão Magnética Espontânea (SME).

Figura 58 - Fotografia do arranjo experimental usado no SME.

Figura 59 - a e b sinais da Emissão Magnética Espontânea (SME) capturados durante o resfriamento da amostra, do aço ferramenta AISI D2, previamente temperada de $1200^{\circ} \mathrm{C}$, e c contagem acumulativa das ocorrências de SME com intensidades acima de 0.02V, em um total de 405 ocorrências.

Figura 60 - Primeiras emissões termicamente ativadas.

Figura 61 - Sinais da Emissão Magnética Espontânea (SME) capturado durante o resfriamento da amostra, para uma liga ternaria $\mathrm{Fe}-32,27 \% \mathrm{Ni}, 0,035 \% \mathrm{C}$, previa tempera de $750^{\circ} \mathrm{C}$, e o contagem de ocorrências de 486 acima de $0.25 \mathrm{~V}$,

Figura 62 - Micrografias típicas do material Fe-Ni-C: a.após têmpera à temperatura ambiente,300K apenas austenita, b. Transformada parcialmente em temperatura de $-60^{\circ} \mathrm{C}$ (213K) usando uma mistura de LN2 e etanol pa, c. Transformada na temperatura de $--^{196^{\circ} \mathrm{C}}$ $(77 \mathrm{~K})$

Figura 63 - Micrografias do aço AISI D2 obtidos nos 3 procedimentos e atacadas com vilela.

Figura 64 - Martensita em placas do Fe-Ni-C testadas no SME, atacadas com nital. 77

Figura 65 - Mudança no tamanho de grão na fase da austenita onde Grao $01<$ Grao $02<$ Grao $03<$ Grao 04.

Figura 66 - SME para o Grão 01, e 501 ocorrências acima de 1V. ......................................... 79

Figura 67 - SME para o Grão 02, e 1201 ocorrências acima de 1V. ........................................ 80

Figura 68 - SME para o Grão 03 e 384 ocorrências acima de 2V........................................... 81

Figura 69 - SME para o Grão 04 e 457 ocorrências acima de 1,5V . .................................... 82

Figura 70 - Inicio da transformação em função do tamaño de grão da austenita na liga Fe$\mathrm{Ni}-\mathrm{C}$.

Figura 71 - SME sem o sensor de temperatura para as ligas Fe-Ni-C. 84

Figura 72 - Tempo de Ms em função do tempo. 
Figura 73 - MBN antes e depois da transformação em função do tamanho de grão austenítico.

Figura 74 - MBN em função do tamanho de grão austenítico transformado.

86

Figura 75 - Aço D2 solubilizadas a $1200^{\circ} \mathrm{C}$ e temperado em óleo com presença de martensita. 


\section{LISTA DE TABELAS}

Tabela 1 - Tabulação cronológica das formulas para calcular as temperaturas Ms e aplicação ao ferro puro (LIU et al., 2001).

Tabela 2 - Composição química do aço AISI D2, \% em massa (ASTM A681-08). 31

Tabela 3 - Principais carbonetos formados no sistema ternário Fe-C-Cr (BENZ; ELLIOTT; CHIPMAN, 1974).

Tabela 4 - Composição química AISI D2 fornecido por Villares Metals. 32

Tabela 5 - Informações sobre a Liga Fe-Ni. 33

Tabela 6 - Composição química de equilíbrio (fração mássica dos componentes) da fase austenítica (FCC_A1\#1) presentes a $1200^{\circ} \mathrm{C}$, calculadas pelo Thermo-Calc $\AA$ aliado ao banco de dados TCFE.

Tabela 7 - Ms empíricos para o aço AISI D2 a $1200^{\circ} \mathrm{C}$, calculados com diferentes equações empíricas e os resultados obtidos através do Thermo-Calc®.

Tabela 8 - Apresenta a composição química de equilíbrio (fração mássica dos componentes) da fase austenítica (FCC_A1\#1) presentes a $750^{\circ} \mathrm{C}$, calculadas pelo ThermoCalc $\AA$ aliado ao banco de dados TCFE

Tabela 9 - Ms empíricos para o aço Fe-Ni-C a $750^{\circ} \mathrm{C}$, calculados com diferentes equações empíricas e os resultados obtidos através do Thermo-Calc®.

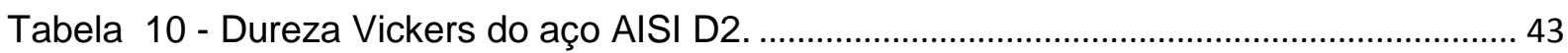

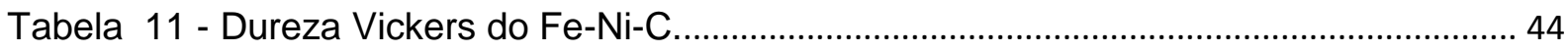

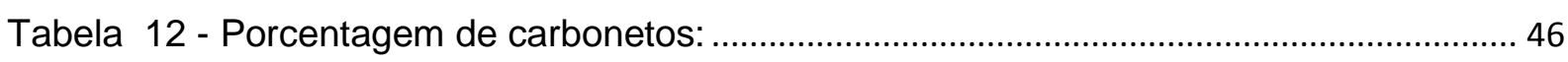

Tabela 13 - Porcentagem em massa das fases calculadas para o aço AISI D2 a $1200^{\circ} \mathrm{C}$, pelo Thermo-Calc $\AA$ aliado ao banco de dados TCFE............................................................... 47

Tabela 14 - Resultados de difração de raios-X no LNLS do aço AISI D2 ................................ 50

Tabela 15 - Fração experimental da martensita transformada num aço AISI D2, obtido nos 3 procedimentos. 


\section{SUMÁRIO}

1 INTRODUÇÃ

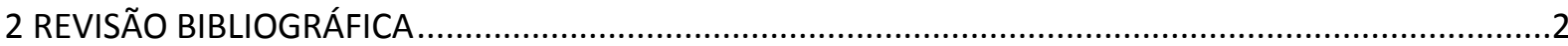

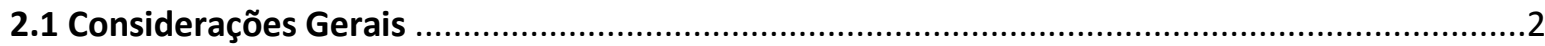

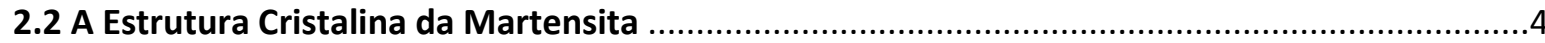

2.3 Influência do teor de carbono na austenita ...........................................................................

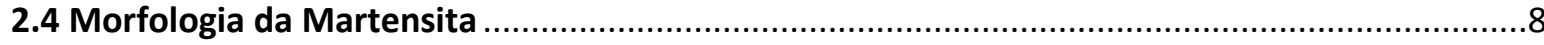

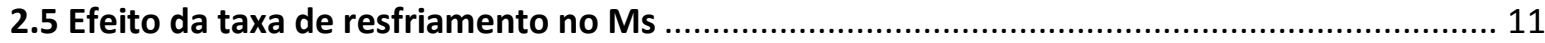

2.6. Os efeitos dos elementos de liga na temperatura Ms. ....................................................... 14

2.7 Fórmulas empíricas para o cálculo de temperaturas Ms ...................................................... 16

2.8 Temperatura de Ms e o tamanho de grão da austenita ...................................................... 19

2.9 Técnicas experimentais para estudar a transformação martensítica durante o resfriamento 21

2.9.1 Fenômeno de Ruido Magnetico de Barkhausen ............................................................... 21

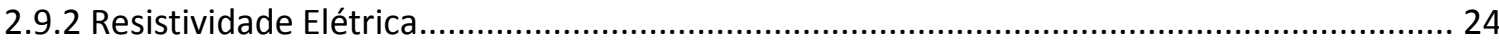

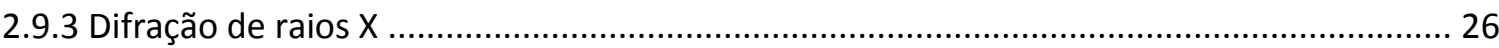

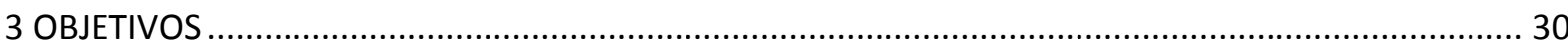

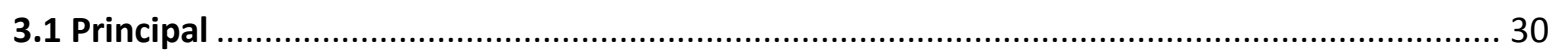

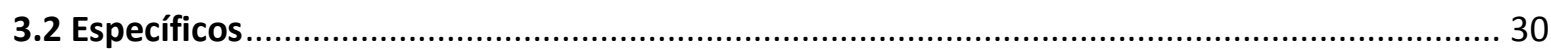

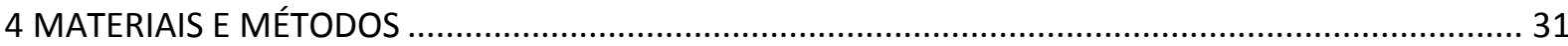

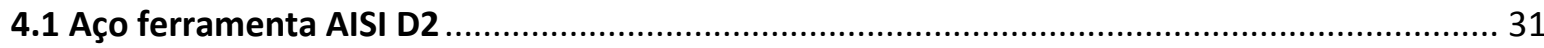

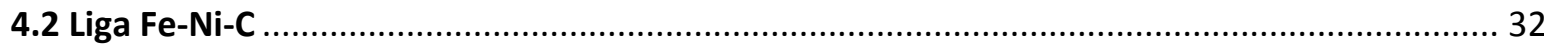

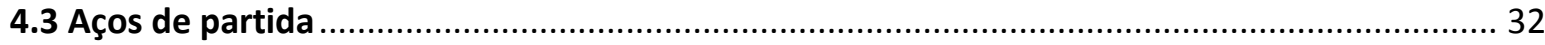

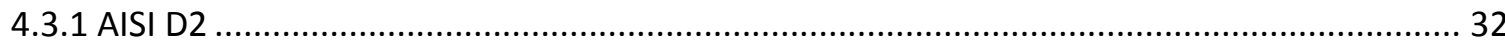

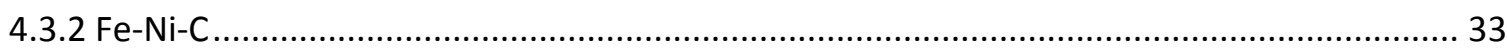

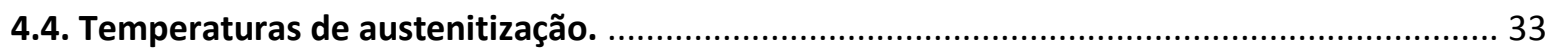

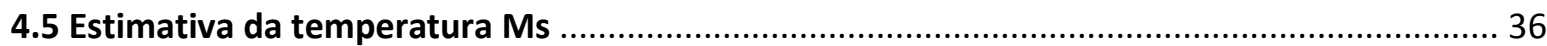




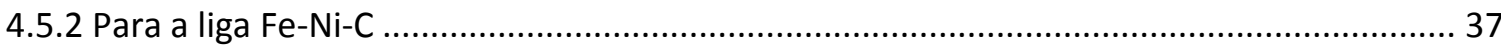

Os resultados mais razoáveis e confiáveis são os obtidos com a equação de Andrews Linear........ 38

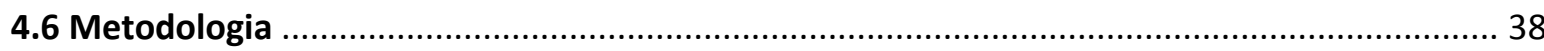

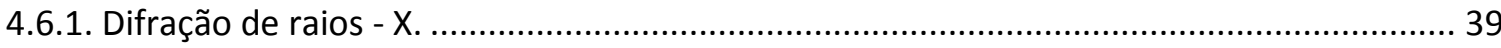

4.6.2 Medição da resistividade elétrica ................................................................... 39

4.6.3 Medições magnéticas de Barkhausen................................................................. 40

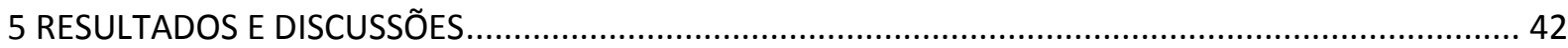

5.1 Caracterização das amostras como temperadas ................................................. 42

5.2 Porcentagens do carboneto do aço AISI D2 ......................................................... 45

5.2.1 Porcentagem por metalografia quantitativa..................................................... 45

5.2.2 Porcentagem de carbonetos obtida a partir de cálculos no Thermo-Calc ${ }^{\circledR} \ldots \ldots \ldots \ldots \ldots \ldots \ldots . . . . . . . . .47$

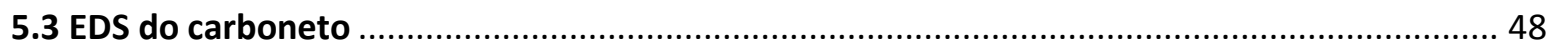

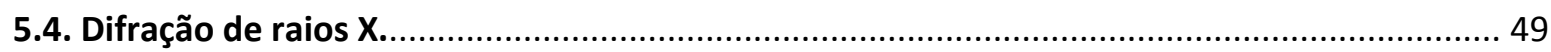

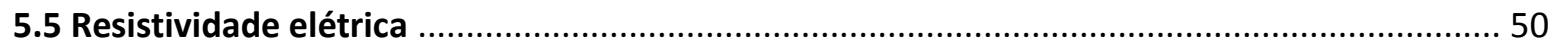

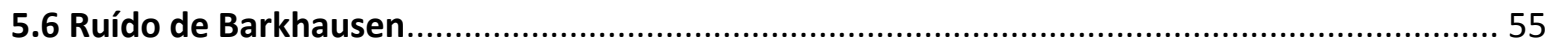

5.6.1 Ruído de Barkhausen no decorrer da temperatura ................................................ 55

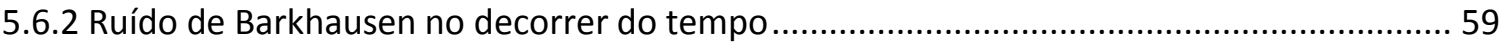

5.7. Emissão magnética espontânea (SME) por transformação de fase ...............................66

5.8 Variação do inicio da transformação martensítica em função do tamanho de grão por

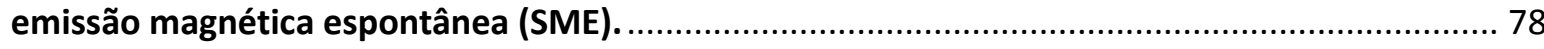

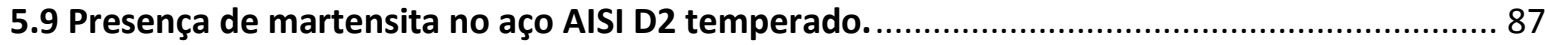

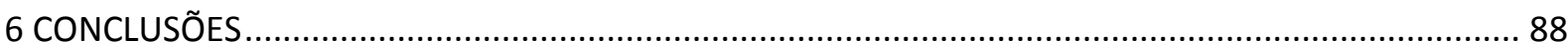

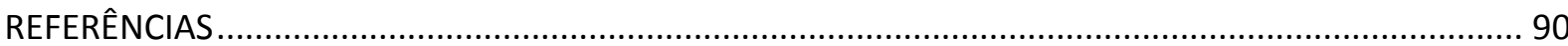




\section{INTRODUÇÃO}

O presente trabalho estudou a transformação martensítica em temperaturas subzero da austenita de um aço AISI D2 e de uma liga Fe-Ni-C. Para este fim foram desenvolvidas técnicas experimentais que permitissem acompanhar a transformação martensítica durante o resfriamento.

A justificativa tecnológica para a realização de tratamentos criogênicos é que estes: aumentam a dureza do aço por meio da redução da austenita retida, conseguindo aumentar a resistência ao desgaste graças à precipitação de carbonetos finos no revenido subseqüente, e melhorando a estabilidade dimensional.

Explorando as possibilidades da utilização da emissão de ruído magnético de Barkhausen, a fim de detectar a transformação de fase da austenita para a martensita, durante o resfriamento a temperaturas sub-zero de materiais ferrosos austeníticos encontrou-se um novo método de medição do início da transformação martensítica (Ms), o qual foi nomeado Spontaneous Magnetic Emission (SME), (HUALLPA et al., 2010).

Foi verificada a mudança do inicio da transformação martensítica com o tamanho de grão austenítico.

Este trabalho faz parte de um projeto de pesquisa mais amplo, coordenado pelo Professor Hélio Goldenstein, em relação ao estudo das transformações que ocorrem em aços e ligas ferrosas quando são submetidas a temperaturas sub-zero, após a tempera, até temperatura ambiente. 


\section{REVISÃO BIBLIOGRÁFICA}

\subsection{Considerações Gerais}

A arte e a tecnologia associadas com o endurecimento de "ferro aquecido" eram conhecidas pelos ferreiros desde o início da idade do ferro, faz uns 3000 anos. Até muito recentemente, no entanto, os artesãos não compreendiam o real motivo de tal fenômeno. A partir de 1861 Sorby, seguido por Martens e Osmond utilizaram o microscópio para identificar os microcomponentes dos aços, e foi a partir desse momento que se estabeleceu as bases para começar a compreender este comportamento.

A martensita implica uma mudança de fase de uma estrutura cristalina para outra por meio de processos de cisalhamento, acompanhados de uma mudança sistemática de forma na região transformada. O nome é agora comumente utilizado de forma genérica para se referir a transformações similares em todos os sistemas puros ou ligas. A cinética e outras propriedades da martensita podem ser muito diferentes e ter uma definição precisa ainda é difícil (MACKENZIE, 1970).

Segundo Zhao e Notis (1995), as transformações martensíticas são divididas em dois grupos principais: Martensita Atérmica (incluindo burst martensita, também chamada de umklapp) e Martensita Isotérmica (também chamada schiebung). A primeira cresce atermicamente, ou seja, a reação prossegue como resultado da mudança da temperatura e a quantidade de martensita formada depende só da temperatura, é independente do tempo. A segunda cresce isotermicamente, isto é a transformação prossegue com o tempo.

Existem evidencias da ocorrência da transformação "martensítica isotérmica" em aços de alta liga, no entanto na maioria dos aços ocorre martensita atérmica (ZHAO; NOTIS, 1995).

A velocidade de resfriamento requerida para a transformação depende dos elementos da liga presentes no aço, é mais baixa quanto maior for a concentração total desses elementos (BHADESHIA; HONEYCOMBE, 2006). 
A transformação martensítica é produzida por meio de um processo de nucleação heterogênea, já que esta tem lugar, preferencialmente, em contornos de grão e/ou defeitos e um posterior crescimento da fase previamente nucleada é extremamente rápido, com velocidades da ordem de grandeza do som no metal (NISHIYAMA, 1978). As interfaces estão constituídas por um plano macroscopicamente invariante, denominado plano de hábito, isto significa que dois vetores quaisquer sobre ele mantêm seus módulos e orientação relativa, constantes durante o avanço da transformação.

No caso das martensitas ferrosas, admite-se que por meio da deformação de Bain é obtido o reticulado da martensita a partir da austenita, uma transformação do reticulado original (cúbica de faces centradas) em tetragonal de corpo centrado, já que essa deformação corresponde aos menores deslocamentos atômicos, e energia de deformação mínima. Esta deformação global homogênea, combinada com uma não-homogênea em escala atômica (reticulado invariante), permite obter uma interface não distorcida com bom ajuste atômico. Admite-se ainda que, a deformação não-homogênea do reticulado invariante resulta do movimento de discordâncias associado com deformação por escorregamento ou por maclação. Qualquer um desses processos é capaz de acomodar o desajuste atômico, que de outro modo, teria que ocorrer na interface austenita/martensita por força da deformação, deixando de ser interface não distorcida, provocando a alteração macroscópica de forma. Na Figura 1 esquematizam-se os dois tipos de deformação de reticulado invariante, que ocorrem em uma lamela de martensita. Percebe-se que a ripa de martensita formada origina um relevo na superfície e que, o plano de hábito é preservado pela acomodação conseguida por escorregamento (Figura 1a) ou por maclação (Figura 1b). O resultado é uma interface macroscopicamente plana, que contém irregularidades em uma escala microscópica (BHADESHIA; HONEYCOMBE, 2006). 

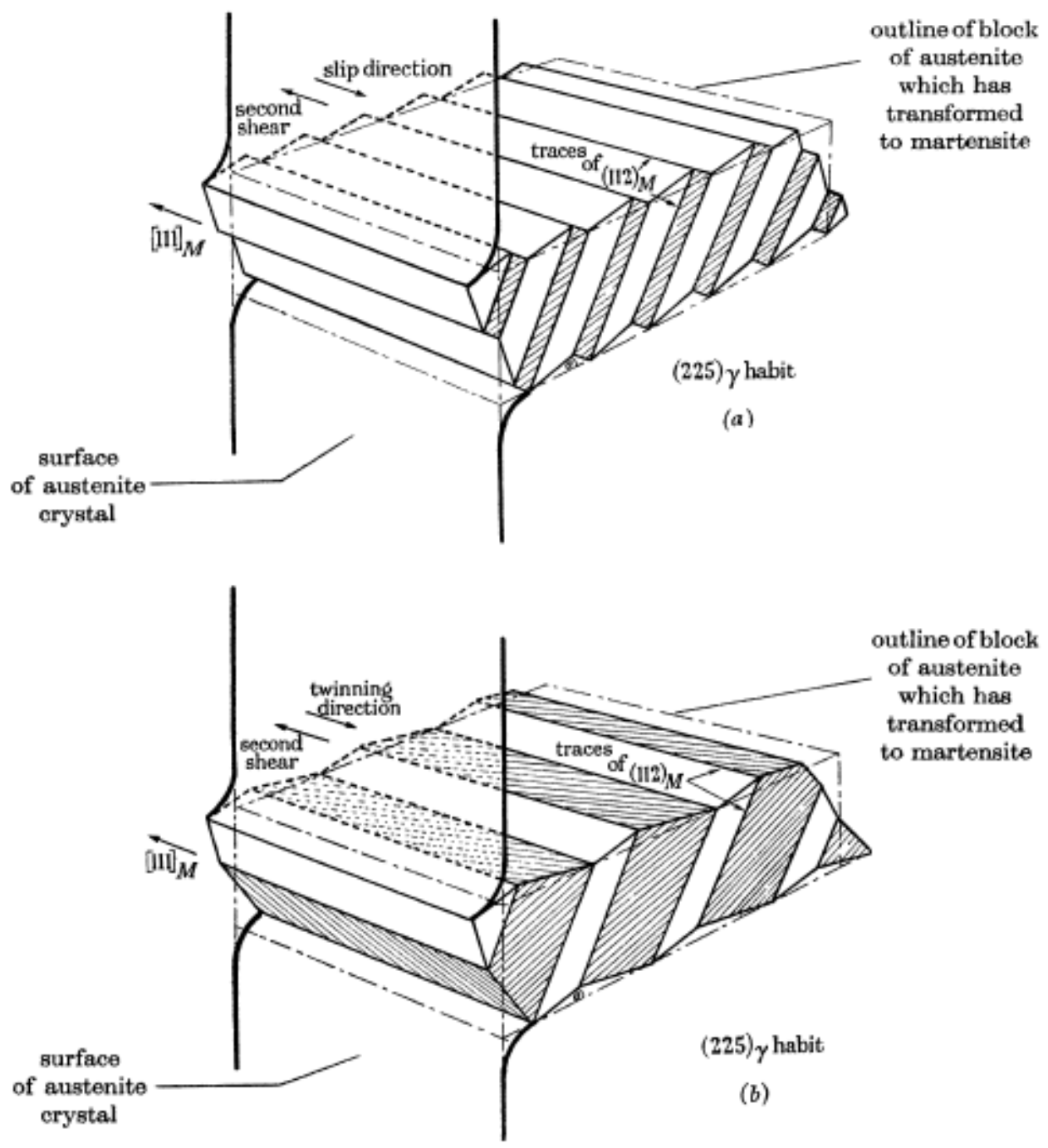

Figura 1 - Formação de uma lamela de martensita, ilustrando ambos os tipos de deformação do reticulado: a) escorregamento; b) maclação (KELLY; NUTTING, 1960).

\subsection{A Estrutura Cristalina da Martensita}

A martensita nas ligas ferrosas é usualmente uma solução sólida supersaturada de carbono no ferro e tem uma estrutura tetragonal de corpo centrado (tcc), que é uma forma distorcida da ferrita com estrutura cúbica de corpo centrado (ccc). A tetragonalidade pode ser medida pelo quociente c/a entre os eixos, como apresentado na eq.(1), e aumenta com o teor de carbono (BHADESHIA; HONEYCOMBE, 2006). 


$$
\frac{c}{a}=1+0,045 \% p C
$$

Onde a e c são as dimensões do reticulado da martensita, \%p é porcentagem em peso.

A eq.(1) implica que para um teor nulo de carbono a estrutura é ccc, sem qualquer distorção. O efeito do carbono no parâmetro do reticulado da austenita e nos parâmetros c e a da martensita estão indicados na Figura 2.

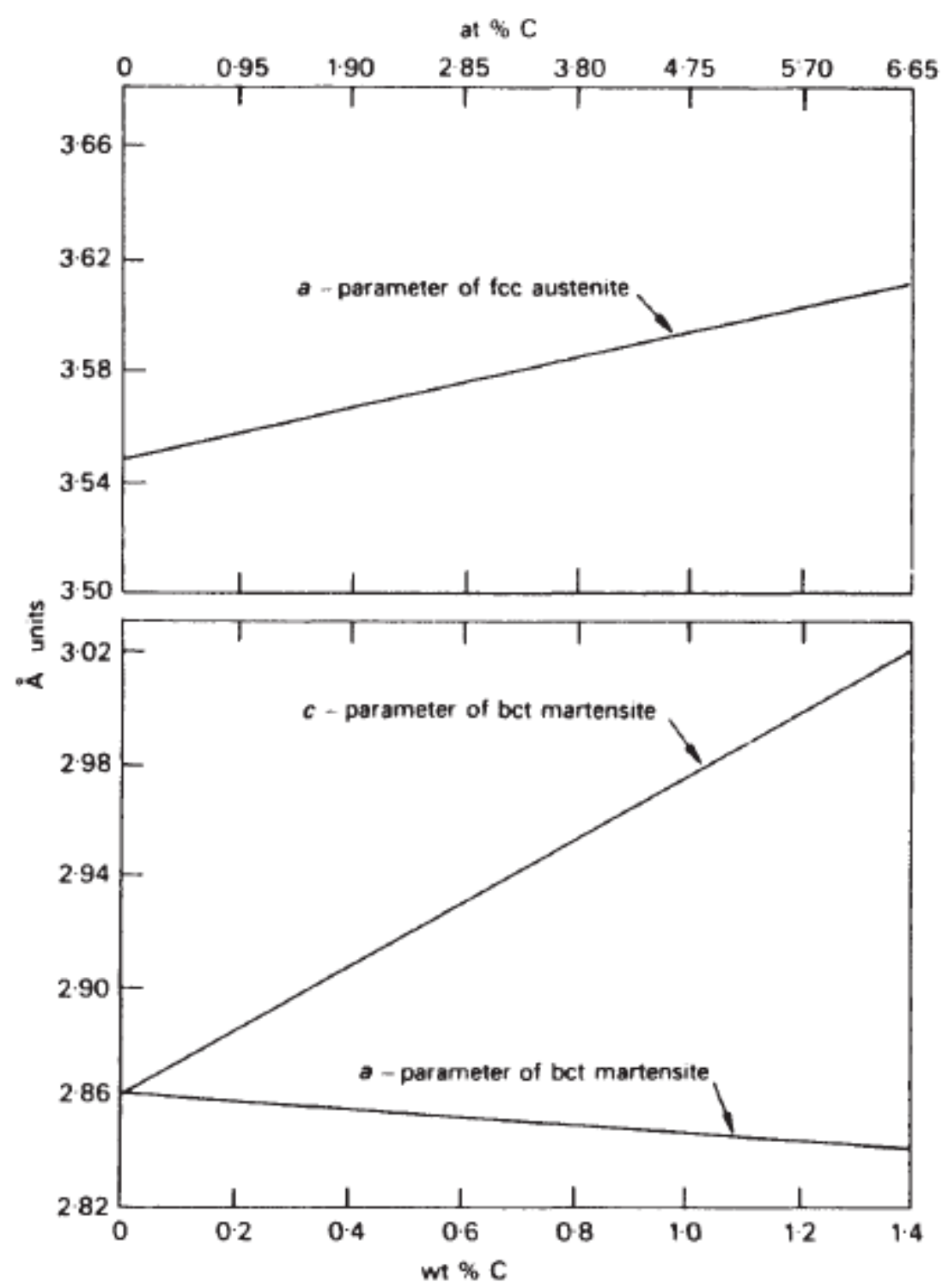

Figura 2 - Efeito do carbono nos parâmetros do reticulado da austenita e da martensita(COHEN, 1962). 
Vintaikin e Nosova (1997) fizeram uma revisão da dependência das constantes de reticulados da martensita com o teor de carbono do aço. Os primeiros pesquisadores que utilizaram raios-X, Selyakov; Kurdyumov e Gudtsov (1927) apud Vintaikin e Nosova (1997) mostraram que a martensita endurecida está formada por uma solução sólida de fase única de carbono em $\mathrm{Fe}-\alpha$ com um reticulado cristalino tetragonal de corpo centrado. Em 1929, Kurdyumov e Kaminskii apud Vintaikin e Nosova (1997) estudaram a concentração de dependência das constantes de reticulado da martensita em aços com conteúdos acima de $0,6 \% \mathrm{pC}$ dependência esta que foi verificada em outros estudos (Figura 3 ).

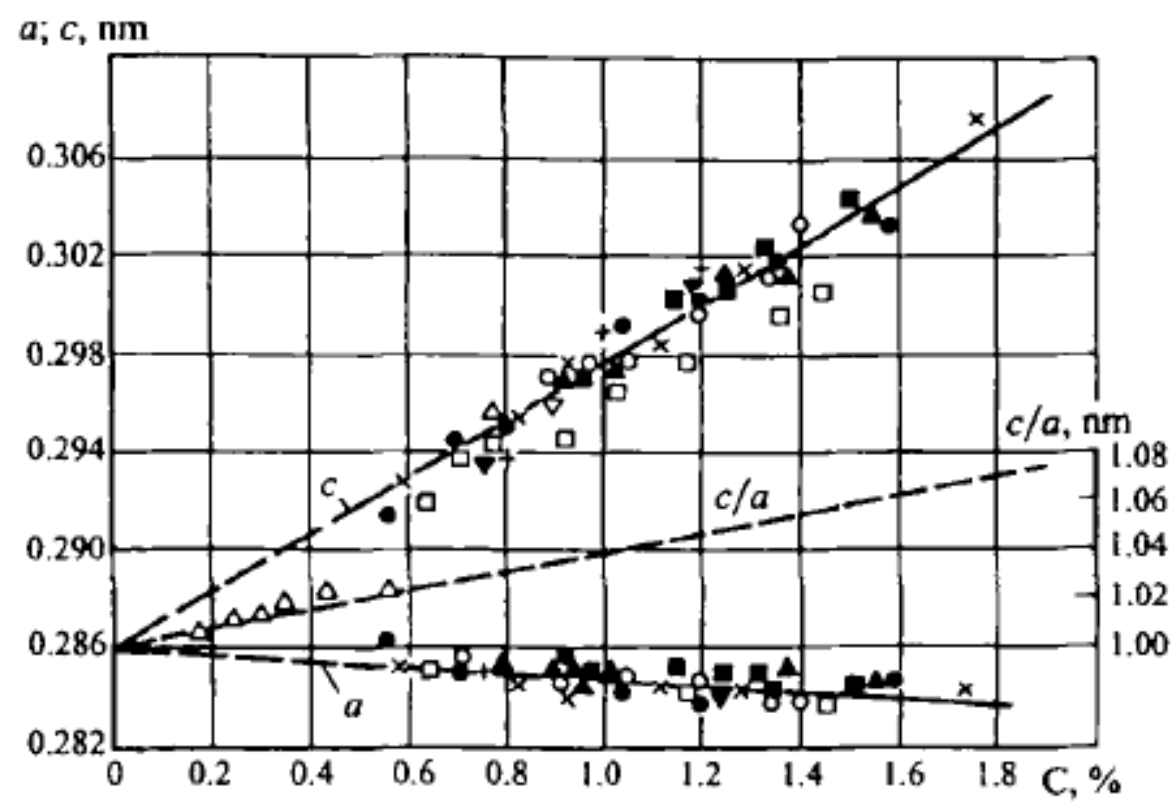

Figura 3 - A dependência das constantes do reticulado da martensita com o teor de carbono do aço, de acordo com os dados de vários autores: $\square$ ) Kurdyumov e Kaminskii (1929), +) Selyakov; Kuryumov e Gudtsov (1927). Extraído de Vintaikin e Nosova (1997).

A explicação dada à tetragonalidade por Zener (ZENER, 1946) é baseada, na minimização da energia livre de origem elástica causada pela distorção do reticulado pelos átomos de C. O reticulado de ferrita com carbono dissolvido intersticialmente adquire automaticamente a estrutura com energia livre mínima, e esta é menor na estrutura tetragonal do que na estrutura cúbica, isto é, a energia livre dos átomos de carbono ordenados é menor do que se eles tivessem uma distribuição ao acaso. Hillert (1986) faz uma observação ao trabalho de Zener (1946) a fim de explicar a tetragonalidade da martensita, em uma deformação todos os átomos de carbono 
encontram-se em lugares que têm todos os seus átomos de ferro mais próximos e na mesma direção da deformação, o que é denominado como Ordenação de Zener.

\subsection{Influência do teor de carbono na austenita}

No começo da década dos anos 30, com o desenvolvimento de conceitos de temperabilidade, observou-se que a dureza da martensita aumenta de uma forma relativamente linear com o teor de $\mathrm{C}$, de aproximadamente 0,05 até 0,5\%pC. Na Figura 4 são mostrados os pontos experimentais de dureza em relação à porcentagem de carbono, obtidos por diferentes pesquisadores, os quais foram analisados por Krauss (1999). Litwinchuk; Kaiser e Baker (1976) entre outros demonstraram uma queda da dureza com concentrações de carbono acima de 0,9\% que é resultado do incremento da fração do volume da austenita retida.

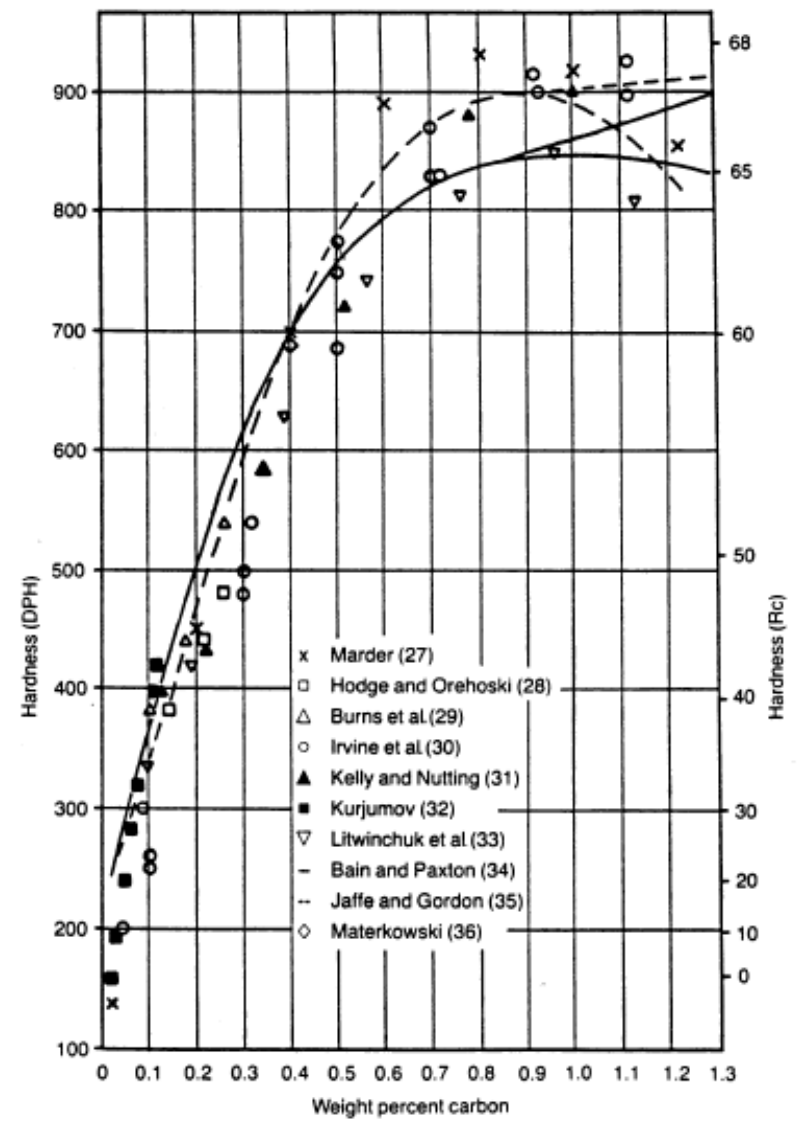

Figura 4 - Durezas de microestruturas martensíticas em função do conteúdo de carbono nos aços ferríticos (KRAUSS, 1999). 


\subsection{Morfologia da Martensita}

Dependendo do conteúdo de carbono da fase matriz austenítica, a martensita será escorregada (baixo carbono nas Figura 5 e Figura 6 ) ou na forma de placas (alto carbono nas Figura 7 e Figura 8); a martensita também se pode formar como uma mistura das duas morfologias. Existe ainda uma relação entre a temperatura Ms e a morfologia da martensita, como se vê na Figura 9. Em geral a martensita escorregada esta associada com alta dureza e ductilidade, porém menor resistência mecânica. As estruturas de martensita em placas têm altas resistências mecânicas, mas não são dúcteis, e freqüentemente contém microtrincas decorrentes do impacto entre placas, que podem iniciar falhas subseqüentes(VOORT, 2009). Em ligas sem intersticiais, a martensita em placas pode ser dúctil e de baixa dureza.

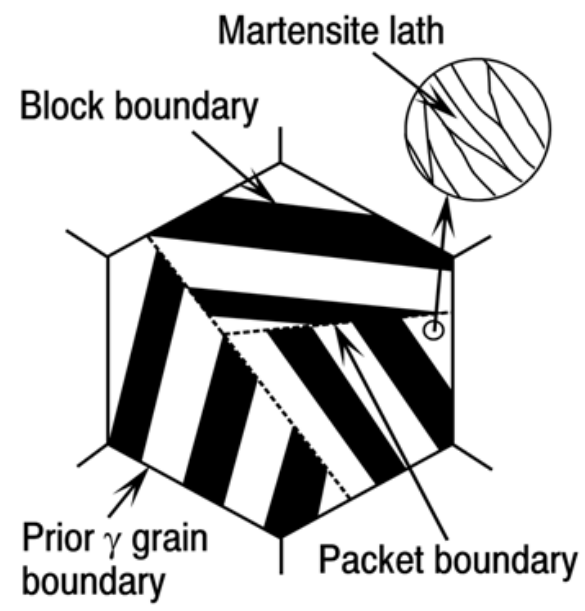

Packet: a group of laths with the same habit plane $(\sim\{111\} \gamma)$

Block: a group of laths with the same orientation (the same K-S variant)

\begin{tabular}{|c|c|c|c|c|}
\hline \multicolumn{5}{|c|}{ Carbon Content $(w t \%)$} \\
\hline $0.1 \sim 0.2 \%$ & $0.3 \%$ & $0.4 \%$ & $0.6 \%$ & $0.8 \%$ \\
\hline
\end{tabular}

Figura 5 - Martensita escorregada na forma de ripas e sua estrutura (MAKI; TSUZAKI; TAMURA, 1980). 


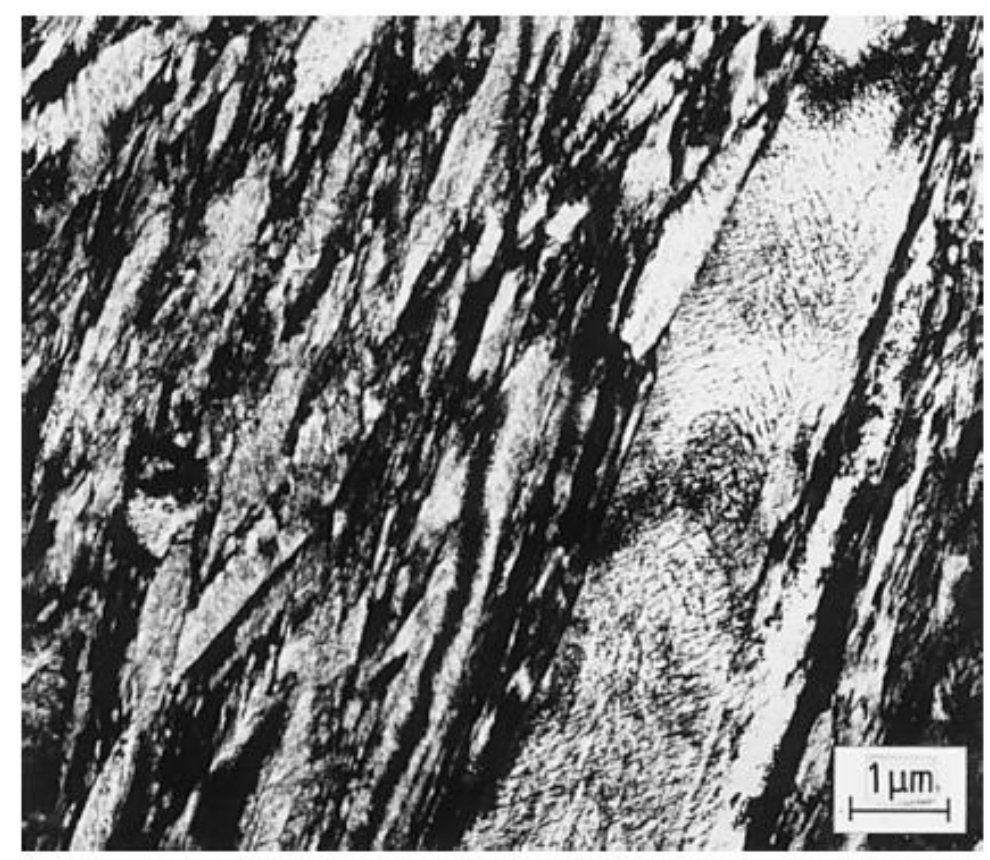

Figura 6 - Microestrutura de martensita escorregada num aço 4140 temperado a $150^{\circ} \mathrm{C}$, micrografia obtida por microscopia de transmissão (TEM)(KRAUSS, 1999).

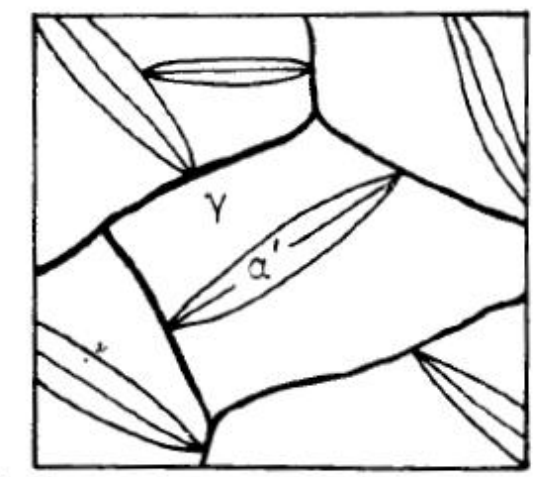

(a)

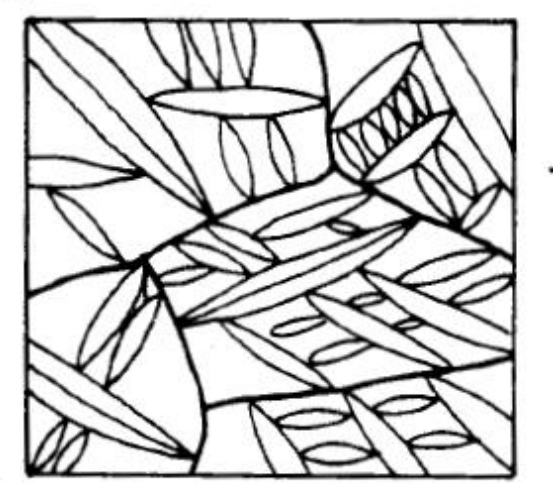

(b)

Figura 7 - Crescimento de placas de martensita com incremento do resfriamento abaixo de Ms a) crescimento da placa de martensita interrompido pelo contorno de grão; b) propagação da martensita (PORTER; EASTERLING, 1992). 


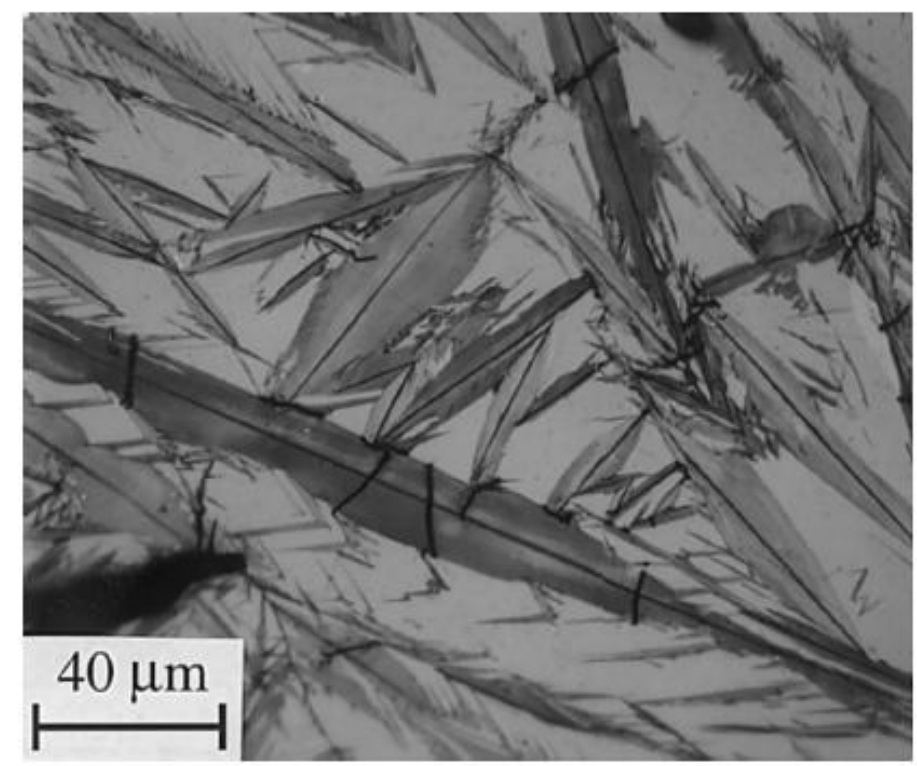

Figura 8 - Microestrutura de martensita em placas numa liga Fe-1.86wt\%C, apresentando microtrincas nos locais de "impignemet" com colisões entre placas, micrografia óptica(KRAUSS, 1999).

Segundo Zhao e Notis (1995) para aços de baixos teores de carbono e/ou baixa liga o processo de transformação é complexo, a temperatura de inicio da transformação da martensita escorregada durante o resfriamento de ferro puro deve ser $540^{\circ} \mathrm{C}$, ao invés de ir até altas temperaturas perto de $720^{\circ} \mathrm{C}$ que é realmente o inicio da transformação bainitica (Bs). 


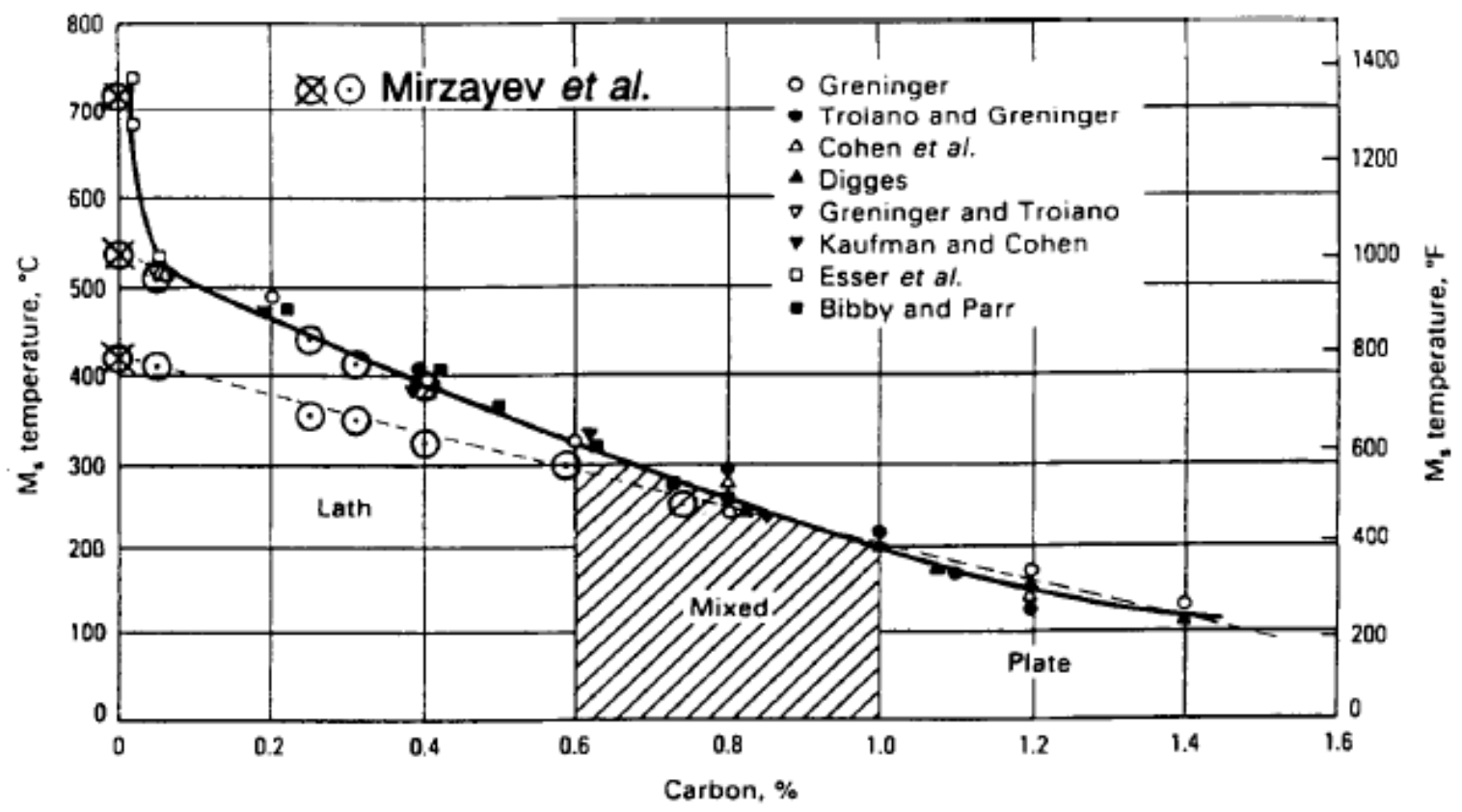

Figura 9 - Morfologia do Ms em função de concentração de carbono para aços carbono (ZHAO; NOTIS, 1995).

\subsection{Efeito da taxa de resfriamento no Ms}

Afirmaram-se erroneamente que o Ms aumenta com a taxa de resfriamento (ANSELL; DONACHIE; MESSLER, 1971) mostrado na Figura 10a, segundo Zhao e Notis (1995) o aumento de Ms era devido a descarbonetação das amostras durante a austenitização.

Para verificar a hipóteses, Zhao e Notis (1995) repetiram o experimento de Ansell; Donachie e Messler (1971) em uma liga Fe-0.75C. Três diferentes amostras com espessuras de 0,15 0,33 e 0,45mm, testados em três diferentes taxas de resfriamento $25 \times 103,12 \times 103$ e $8 \times 103{ }^{\circ} \mathrm{Cs}-1$, os resultados são apresentados nas Figura 10b e Figura 10c. 


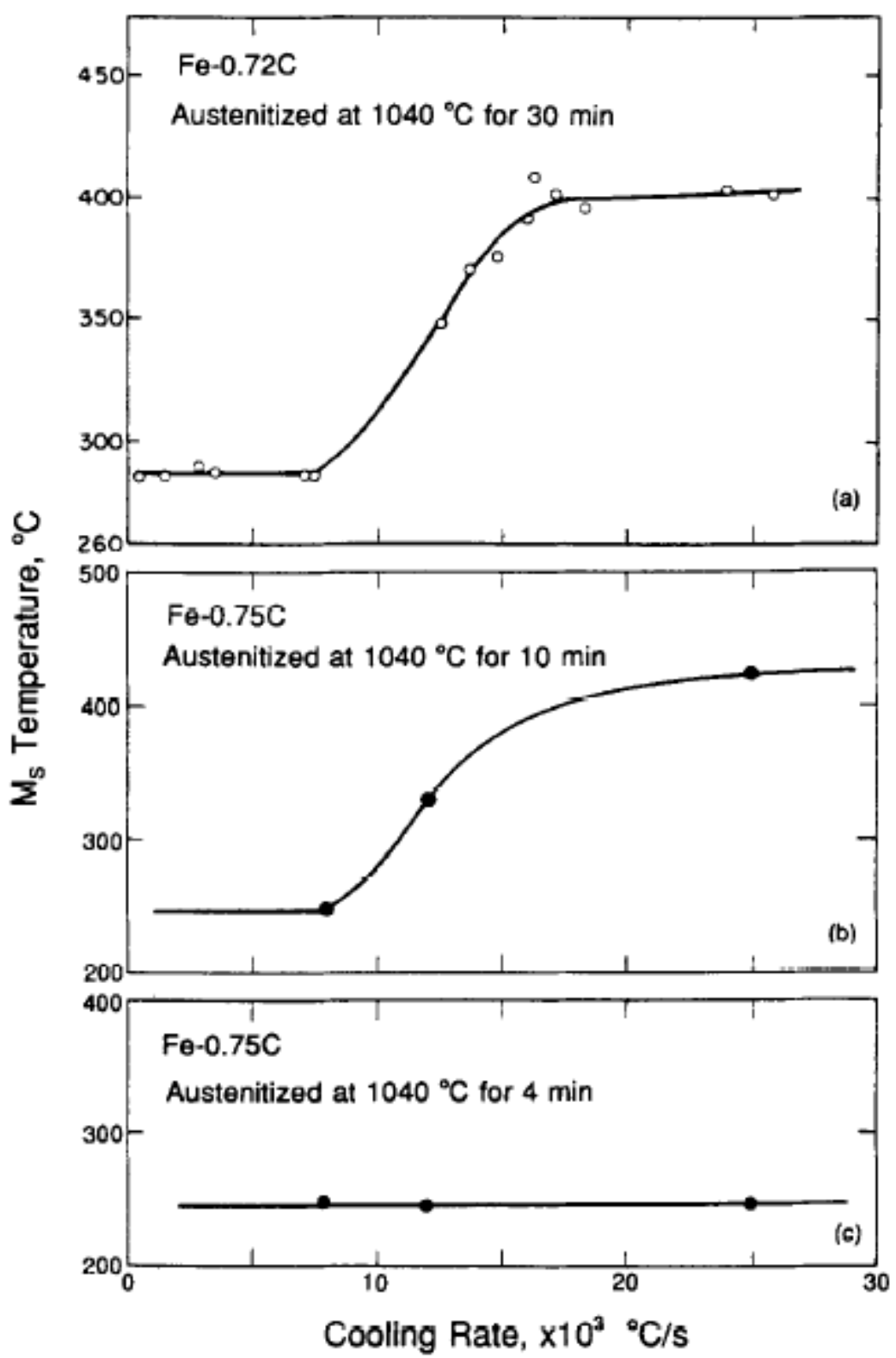

Figura 10 - Variação de Ms com a taxa de resfriamento (ZHAO; NOTIS, 1995).

A influência do tempo de austenitização sobre o ponto de Ms é apresentada na Figura 11, considerando as três fases descritas anteriormente. 


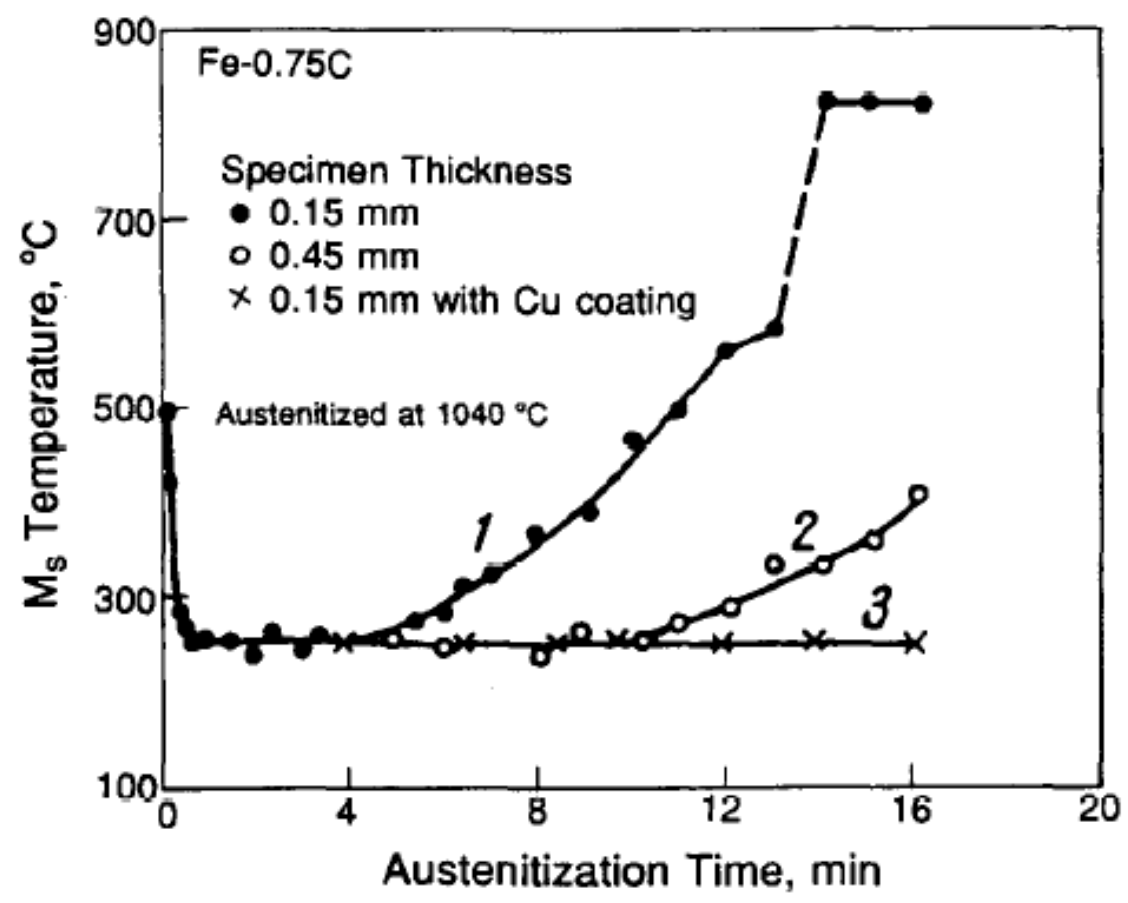

Figura 11 - Variação de Ms com o tempo de austenitização de uma liga Fe-0.75\%C, mostrando o efeito de descarbonetação (ZHAO; NOTIS, 1995).

$\mathrm{Na}$ primeira etapa, na faixa dos 20 aos 30 s, o Ms tem uma queda drástica, provavelmente, devido à homogeneização da austenita. Na segunda etapa, o Ms é independente da espessura da amostra e do tempo de austenitização; a duração desta fase é reduzida de 10 a 4 min como a espessura das amostras de 0,45 a $0,15 \mathrm{~mm}$. Na terceira etapa, o Ms incrementou-se (amostra com espessura $0,45 \mathrm{~mm}$ ) com o tempo de austenitização, devido à descarbonetação. Pode-se verificar que Ms independe do tempo de austenitização pelo fato de que a amostra mais fina $(0,15 \mathrm{~mm})$ é revestida com Cu para evitar descarbonetação durante a austenitização, o que fez que o Ms se tornasse independente do tempo de austenitização, como mostrado na Figura 11. Portanto, o Ms é independente da taxa de resfriamento, quando a composição da amostra não é alterada durante o processo de austenitização e, quanto menor o teor de C maior é o Ms (ZHAO; NOTIS, 1995).

Para garantir que a medida dos pontos Ms é a sua temperatura real, leva-se em consideração: 1) a taxa de resfriamento deve ser utilizada dentro da faixa de formação da martensita entre $\dot{T}_{L}^{M}$ (limite critico inferior de taxa de resfriamento para a formação de martensita durante o resfriamento) e $\dot{T}_{U}{ }^{M}$ (limite critico superior de 
taxa de resfriamento para a formação de martensita durante o resfriamento, a partir do qual a transformação martensítica atermica será suprimida), dentro do patamar de martensita em diagramas CCT (transformação de resfriamento continuo) ou $T_{t}-\dot{T}$ (temperatura de transformação versus taxa de resfriamento); e 2) não deve existir mudança da composição química durante a austenitização e resfriamento (por exemplo descarbonetação). Devido à grande taxa critica para a formação da martensita, não é recomendado usar uma única taxa de resfriamento para o levantamento dos pontos de Ms (ZHAO; NOTIS, 1995).

\subsection{Os efeitos dos elementos de liga na temperatura Ms.}

No trabalho de Liu et al. (2001) são apresentadas duas figuras: na primeira figura; Izumiyama; Tsuchiya e Imai (1974) apud Liu et al. (2001) relataram o efeito de cada um dos elementos de liga na temperatura Ms para ligas ferrosas binárias com até 13 elementos (Figura 12), seus resultados mostram que o $\mathrm{Al}, \mathrm{Ti}, \mathrm{V}, \mathrm{Nb}$ e Co aumenta a temperatura $\mathrm{Ms}$, enquanto $\mathrm{Si}, \mathrm{Cu}, \mathrm{Cr}, \mathrm{Ni}, \mathrm{Mn}$ e $\mathrm{C}$ diminui a temperatura $\mathrm{Ms}$, no entanto, o estudo de Liu (1981) apud Liu et al. (2001) mostra que todos os elementos de liga ( $\mathrm{Mn}, \mathrm{V}, \mathrm{Ni}, \mathrm{Cr}, \mathrm{Mo}, \mathrm{Cu}, \mathrm{W}, \mathrm{Si}$ ), exceto $\mathrm{Al}$ e Co diminuem a temperatura Ms (Figura 12). Na segunda figura também é apresentada a influencia dos elementos de liga na temperatura Ms de ligas binárias a base de ferro determinado por outros pesquisadores (Figura 13).

Pode-se ver que o efeito da temperatura Ms do mesmo elemento é diferente, já que foram usadas diferentes condições: de processamento (austenitização e taxas de resfriamento), o conteúdo de impurezas (especialmente de nitrogênio -diz-se que o nitrogênio tem um efeito similar na temperatura Ms como o $\mathrm{C}$ ) e diferentes tamanhos de grão. A taxa de resfriamento critica é muito sensível ao tamanho de grão (ZHAO, 1992). 


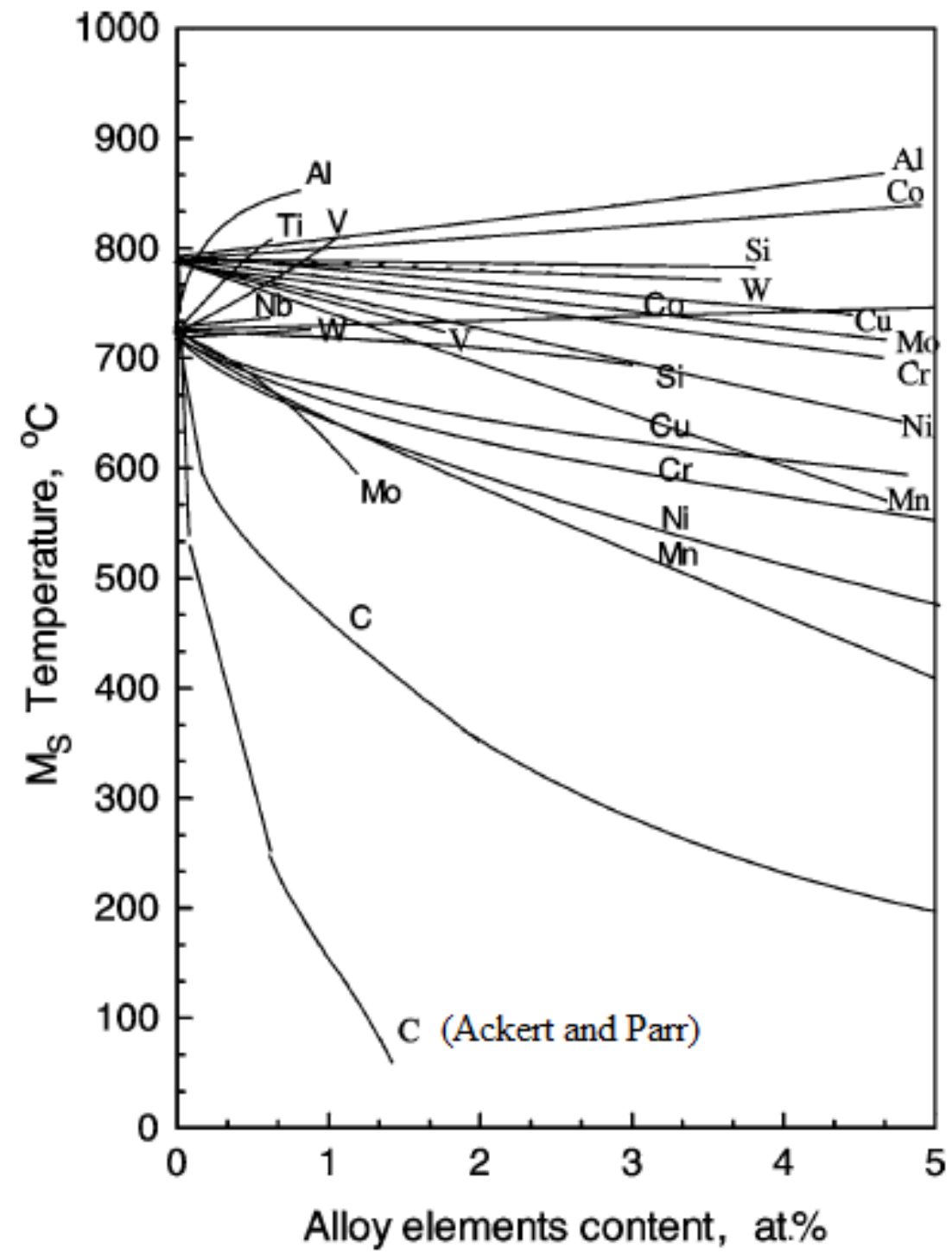

Figura 12 - Temperatura Ms de ligas binárias a base de ferro compiladas por Liu et al. (2001). 


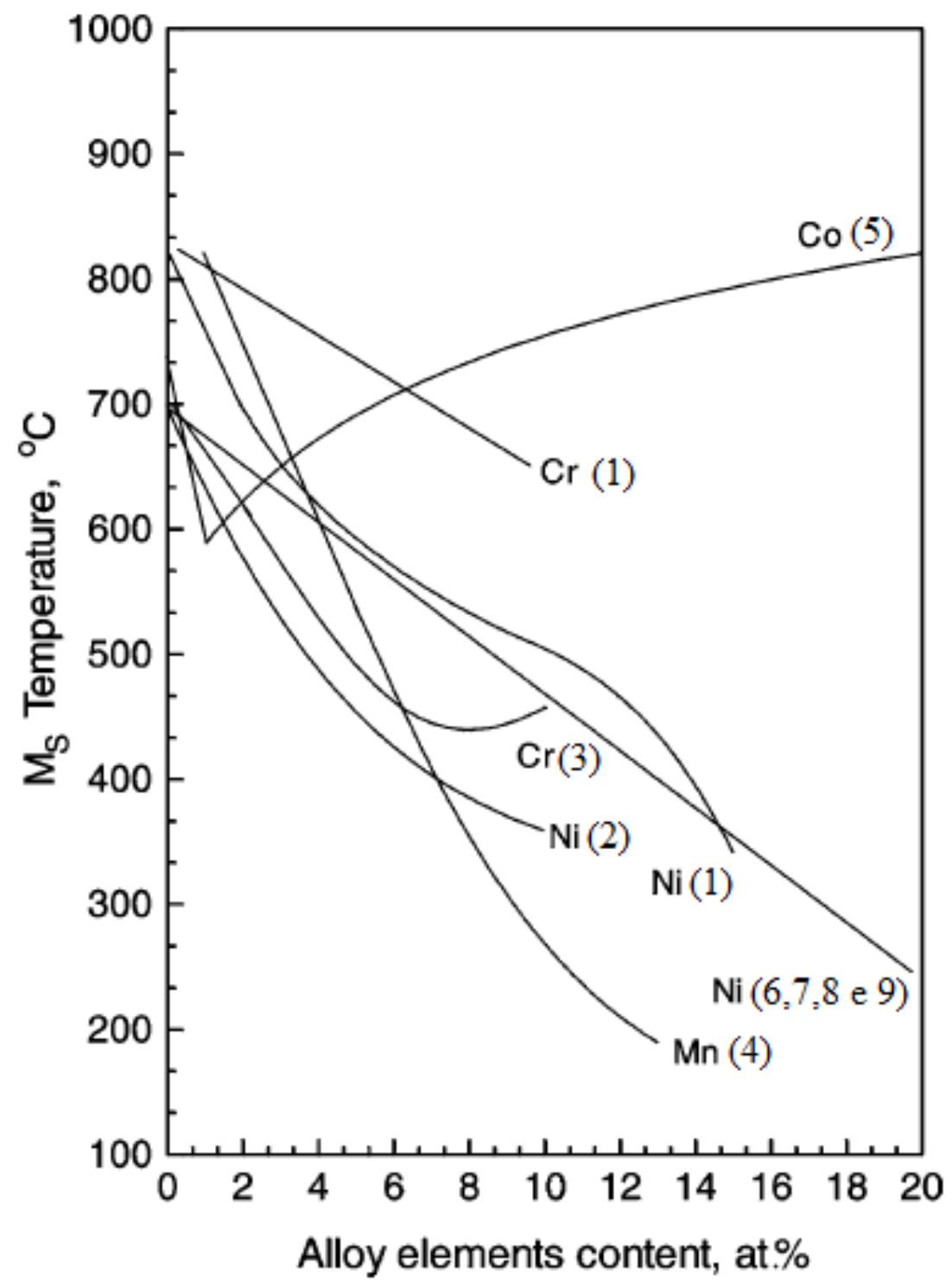

Figura 13 - Temperatura Ms de ligas binárias a base de ferro, conforme determinado por vários pesquisadores 1) Gilbert e Owen (1962), 2) Swanson e Parr (1964) apud Liu et al. (2001), 3) Pascover e Radcliffe (1968) apud Liu et al. (2001), 4) Gomersall e Parr (1965) apud Liu et al. (2001), 5) Parr (1967) apud Liu et al. (2001), 6) Kaufman e Cohen (1958), 7) Owen e Wilson (1965), 8) Wilson (1965) apud Liu et al. (2001) e 9) Goodenow e Helemann (1965).

\subsection{Fórmulas empíricas para o cálculo de temperaturas Ms}

Liu et al. (2001) fizeram uma revisão de formulas empíricas de calculo de Ms com base na composição (Tabela 1) e não simplesmente a partir do teor de carbono. $O$ carbono tem o maior efeito, porém a influência dos elementos de liga sobre a 
redução de Ms não pode ser ignorado. A temperatura Mf cai com o Ms, desse modo as fórmulas prevêem apenas a temperatura Ms.

Até 1982 a análise mais completa da temperatura Ms em função da composição foi descrito por Andrews (1965), que desenvolveu duas formulas: uma linear e a outra não linear ambos avaliados com 184 aços (KUNG; RAYMENT, 1982).

Neste trabalho, decidimos, com base nas recomendações do artigo de Kung e Rayment (1982), utilizar a equação de Andrews Linear (ANDREWS, 1965). 
Tabela 1 - Tabulação cronológica das formulas para calcular as temperaturas Ms e aplicação ao ferro puro (LIU et al., 2001).

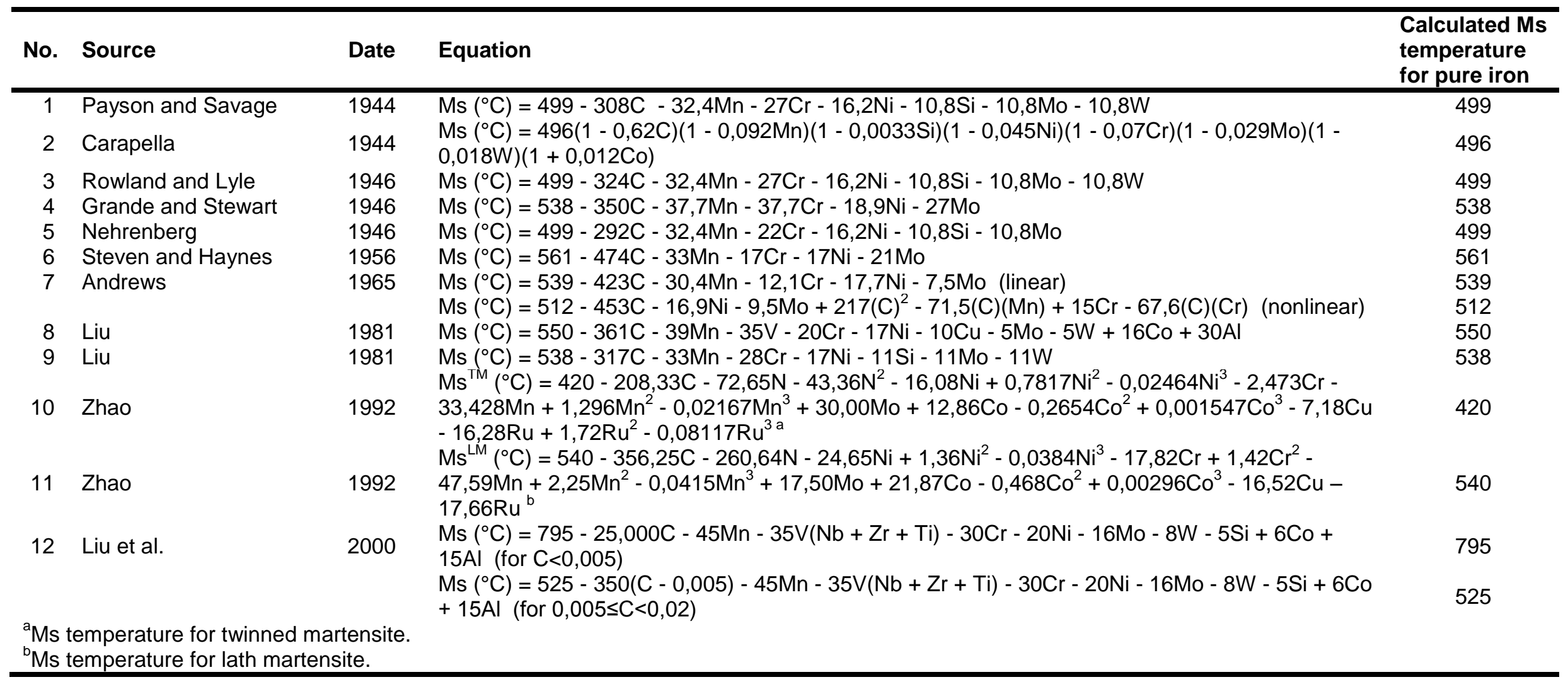




\subsection{Temperatura de Ms e o tamanho de grão da austenita}

A dependência da temperatura de início da martensita Ms, com respeito ao tamanho de grão da austenita, no modelo de Guimarães e Rios (2010) é baseado no fato de que os contornos de grãos proporcionam um ambiente adequado para a nucleação da martensita e, ao mesmo tempo, um pequeno tamanho de grão tem um efeito estabilizador na austenita, limitando o volume de unidades individuais de martensita.

Guimarães e Rios (2010) utilizaram os dados de Cech e Turnbull (1956), demonstrando a seguinte correlação:

$$
S_{V}^{-2}=\Gamma_{1} \times \frac{T^{*}-M s}{M s}
$$

Onde $\Gamma_{1}$ é definido por:

$$
\Gamma_{1}=\frac{n_{s}^{0} \times \lambda \times \varphi}{N_{V}^{M s}} \times \frac{\Delta S}{k}
$$

Onde Sv é um parâmetro estereológico padrão e depende inversamente da distância média de grãos de interceptação, e diminui com o aumento do tamanho de grão; $\varphi$ é um fator introduzido para a integridade, levando em consideração o aspecto conhecido autocatalítico da cinética da martensita; $n_{S}$ é o número de embriões por unidade de área do contorno de grão; o evento de nucleação tem uma espessura de $\lambda ; \Delta S$ é a variação da entropia para a transformação; $N_{V}^{M S}$ é o número total de unidades de martensita por unidade de volume formada inicialmente a Ms; k é a constante de Boltzmann.

Seja $T^{*}$ a temperatura alta onde locais de nucleação torna-se viável; $m$ a fração do volume de grão transformado pelas unidades inicialmente da martensita formada e assumindo que os grãos austeníticos tem forma de tetracaidecaedro, usando estas aproximações na Equação 3 encontra-se a seguinte relação entre o tamanho de grão da austenita, expressado como $S_{V}$, e Ms experimental, determinada pelo monitoramento das alterações de volume, torna-se: 
$S_{V}=\Gamma_{2} \times \frac{T^{*}-M s}{M s}$

Onde:

$\Gamma_{2}=\left(\frac{8}{3}\right)^{3} \times \frac{m \times n_{s}^{0} \times \lambda \times \varphi}{N_{V}^{\text {offset }}} \times \frac{\Delta S}{k}$

Aqui $N_{V}^{\text {offset }}$ é uma fração do volume compensado relacionado com a sensibilidade do experimento.

Para a validação da Equação 4, Guimarães e Rios (2010) utilizaram os resultados experimentais de Yang e Badheshia (2009) para um aço Fe-5\%pNi-2,3\%pMn$0,13 \%$ pC. A Figura 14 mostra os dados experimentais do trabalho de Yang e Badheshia (2009) plotados em conformidade ao modelo de Guimarães e Rios (2010) (equação 4).

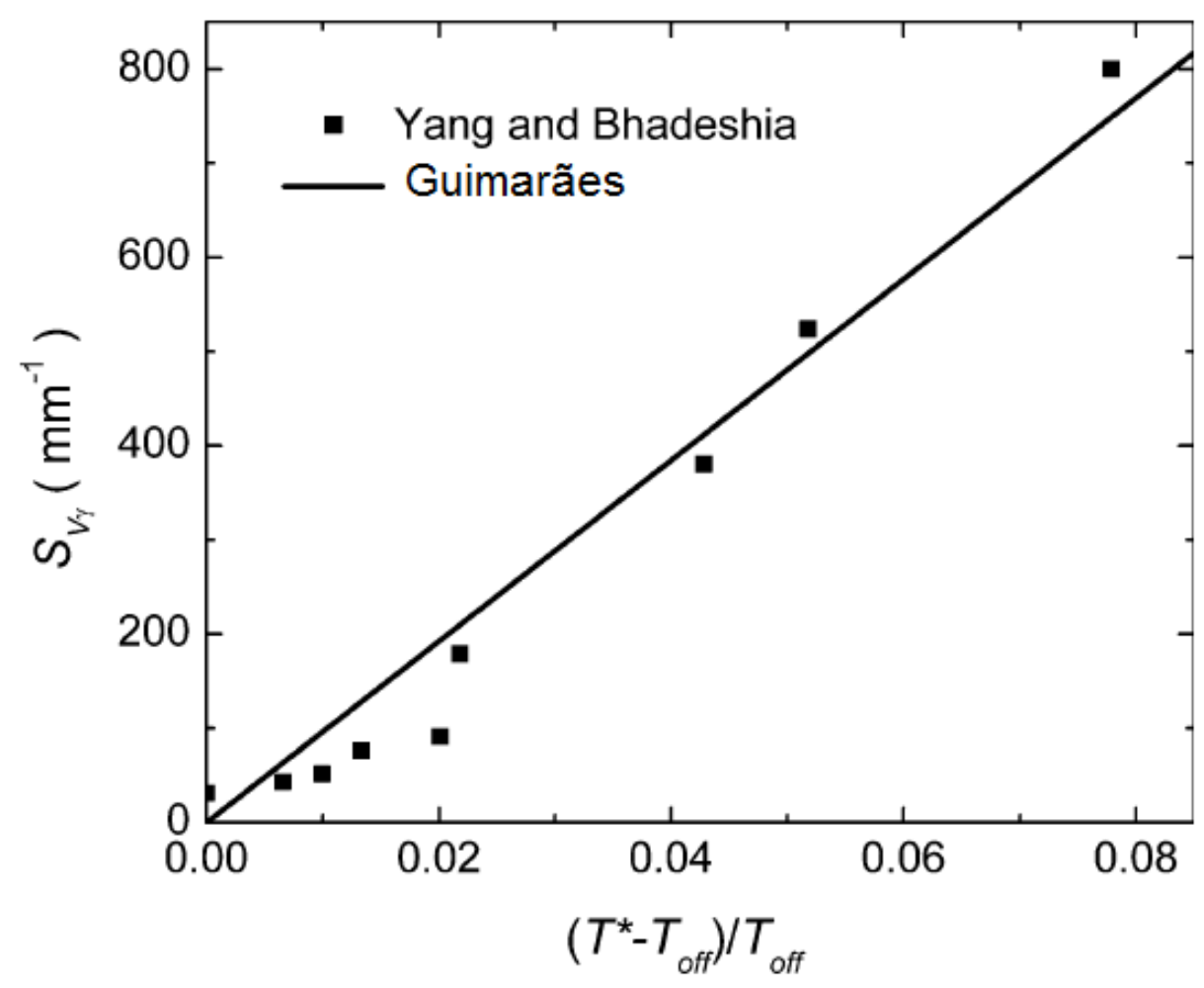

Figura 14 - Dados experimentais de Yang e Badheshia (2009) plotados no modelo de Guimarães na equação 4 com $T_{\text {off }}$ substituído por Ms, e $V_{V_{\text {off }}}=1$ (GUIMARÃES; RIOS, 2010). 


\subsection{Técnicas experimentais para estudar a transformação martensítica durante o resfriamento}

A medição experimental da temperatura Ms, é largamente influenciada pelo arranjo experimental, como foi demonstrado por Olson et al. (1987): valores de Ms obtidos com a emissão acústica $(\mathrm{AE})$ foram diferentes daqueles obtidos por métodos de resistividade elétrica. A determinação da temperatura de inicio da martensita Ms é geralmente obtida por um método indireto, que reflete uma mudança do volume do material, como dilatometria de alta resolução, saturação magnética, medidas de resistividade, observação do relevo sobre uma superfície polida, emissão acústica, entre outros. Como todos estes métodos dependem da detecção duma fração do volume inicial, eles precisam estabelecer um volume de deslocamento $\mathrm{V}^{\text {off }}$ que pode ser tão pequena como 0.002 (PATl; COHEN, 1969) ou tão grandes como 0.01 (YANG; BHADESHIA, 2009).

Outro problema fundamental para a compreensão do crescimento atérmico, com rápida transformação martensítica (burst), é a forma de caracterizar a velocidade de crescimento de placas de martensita individuais. Uma abordagem para este problema foi testada por Okamura apud Nishiyama 1978, medindo a duração dos pulsos de efeito de Barkhausen individual durante o resfriamento de uma amostra de aço Ni com um campo magnético fixo de 5500e, usando um osciloscópio. Técnicas semelhantes foram utilizadas posteriormente por Yu e Clapp (1989). Posteriormente este problema foi amplamente explorado usando picos de aumento de resistividade, uma técnica definida por Bunshad e Mehl (1953).

\subsubsection{Fenômeno de Ruido Magnetico de Barkhausen}

Ruido magnético de Barkhausen (MBN) baseia-se na detecção por indução de um sinal gerado em materiais ferromagnéticos submetido a um campo magnético externo. Na Figura 15 são apresentadas paredes de domínio magnético (paredes de Bloch) que são forçadas a recuar e avançar, quando são submetidas por um campo magnético externo oscilante. 


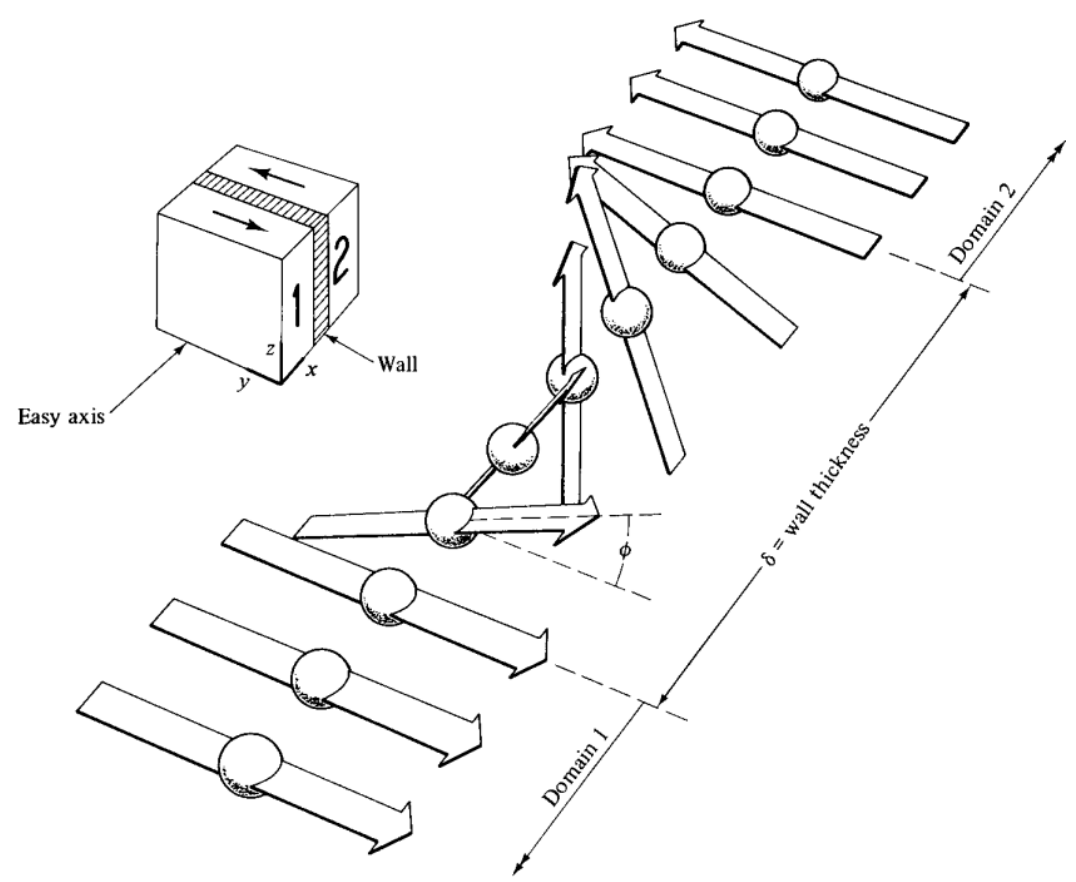

Figura 15 - Parede de Dominio de 180 (CULLITY; GRAHAM, 2009).

A mudança no campo magnético sofre resistência devido a barreiras dissipativas no movimento das paredes de Bloch. Assim, quando um grupo de paredes de domínio finalmente muda, é de forma abrupta e irreversível, superando as interações interatômicas dentro da rede cristalina. A energia interna de parede de domínio então atinge um nível alto, causando a emissão de picos repentinos ou pulsos de campo magnético, gerando pulsos de voltagem numa bobina de sensor colocado na superfície da amostra (Figura 16).

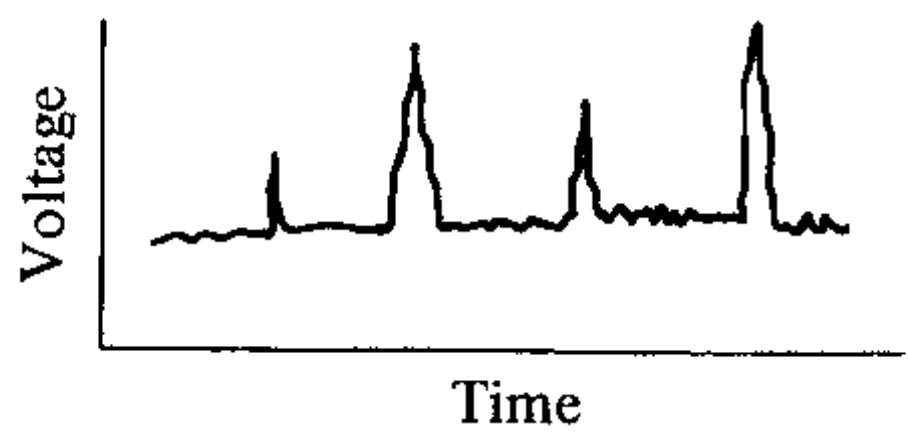

Figura 16 - Curva voltagem-tempo (CULLITY; GRAHAM, 2009). 
Estes pulsos são chamados MBN em honra de Heinrich Barkhausen, que descobriu este fenômeno em 1919. A Figura 17 apresenta uma curva de indução mostrando um detalhe da curva onde aparece o ruído de Barkhausen

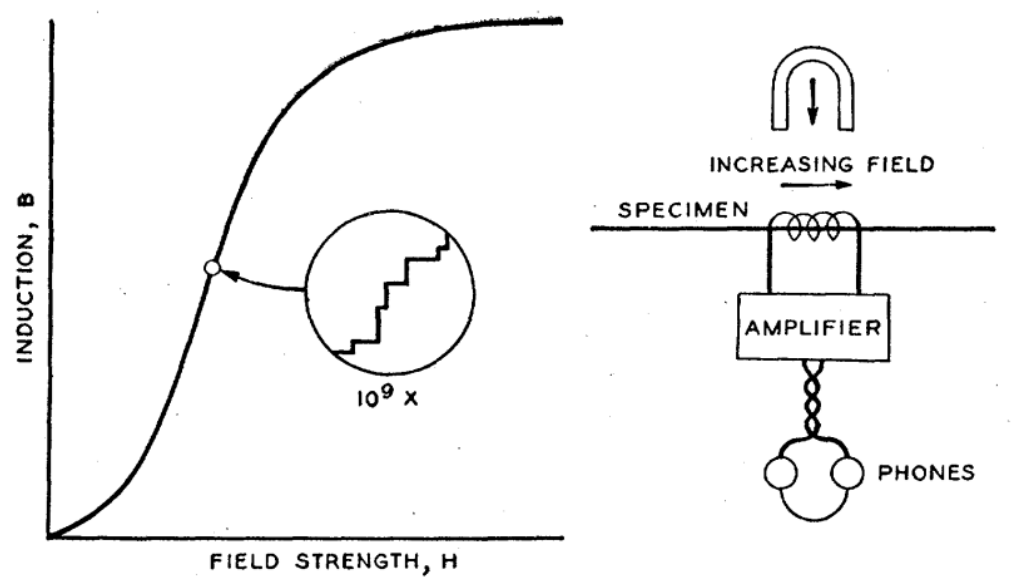

Figura 17 - Efeito de Barkhausen (BOZORTH, 1993)

Precipitados, contornos de grão, discordâncias e campos de tensão atuam como barreiras efetivas para o movimento da parede de domínio de modo que MBN é sensível à microestrutura, deformação elástica e plástica em materiais ferromagnéticos (BLAOW; EVANS; SHAW, 2005; ALBERTERIS et al., 2008). Também é fortemente influenciada pelos defeitos da estrutura, tais como poros, segundas inclusões de fases, as deslocações, ancoragem de imperfeições pontuais e tensões no material (JILES, 2000).

Recentemente técnicas de MBN se tornaram mais disponíveis, devido ao avanço em instrumentação eletrônica e a propagação do uso destas técnicas como ferramenta de ensaios não destrutivos, inspeção de materiais e estruturas de engenharia.

Artigos recentes começaram a usar MBN para a avaliação da proporção de fases em materiais de duas fases (KLEBER; HUG-AMALRIC; MERLIN, 2008), sendo ela utilizada para: caracterizar a quantidade de martensita formada durante a deformação de austenita metaestável em materiais TRIP, a formação de $\alpha^{\text {' }}$ martensita devido à carga de tração plástica a temperatura ambiente em aço inoxidável austenítico, os efeitos do trabalho a frio e tratamentos térmicos de recozimento dos aços. (MÉSZÁROS et al., 1996; VINCENT et al., 2005) usaram 
MBN para investigar a deformação induzida por a'-martensita durante um baixo ciclo de fadiga de aços inoxidáveis, Blachnio (2008) demonstrou que qualquer mudança na distribuição de discordâncias, aumento da desorientação de sub-grãos, assim como precipitados da austenita retida, afetam consideravelmente a intensidade de MBN. A possibilidade de detectar a formação de martensita induzida por tensão em ligas ferromagnéticas com memória de forma foi investigado por Okazaki et al. (2004). Ruído de Barkhausen também foi usado para detectar transformação martensítica induzida por deformação por jateamento (shot-peening) num aço 304L (KLEBER; BARROSO, 2010). Todos esses trabalhos foram realizados à temperatura ambiente.

\subsubsection{Resistividade Elétrica}

A transformação martensítica pode ser classificada em dois importantes grupos, a primeira que é a transformação martensitica termoelástica, com histereses de dezena de graus e mudança de volume pequena onde a transformação é produzida quando diminui a temperatura e a transformação é reversível, no sentido de que a martensita se revelte à fase matriz na orientação original em um aquecimento posterior, presente nos sistemas Ni-Ti, Cu-Zn-Al, Cu-Al-Ni, Au-Cd, Ni-Mn-Ga, etc., os quais são importantes tecnologicamente pelo efeito de memória de forma e outras

propriedades, apresentando baixas resistividades elétricas. A segunda é a transformação martensítica tipo burst (não-termoelástico) acontece em intervalos muito pequenos de temperatura e são menos reversíveis que as anteriores, a mudança de volume é notavelmente superior que as transformações termoelásticas, o que produz fortes irreversibilidades, tem histereses muito elevados (centenas de graus). Os sistemas que tipicamente são inclusos neste grupo são os aços: $\mathrm{Fe}-\mathrm{Ni}$, Fe-Cr, etc., que apresentam altas resistividades (com algumas exceções que tem comportamentos termoelasticos e apresentam o efeito de memória de forma). $\mathrm{Na}$ Figura 18 é apresentado uma transformação clássica termoelástica (Au-Cd) e um tipo burst (Fe-Ni) (KAUFMAN; COHEN, 1958). 


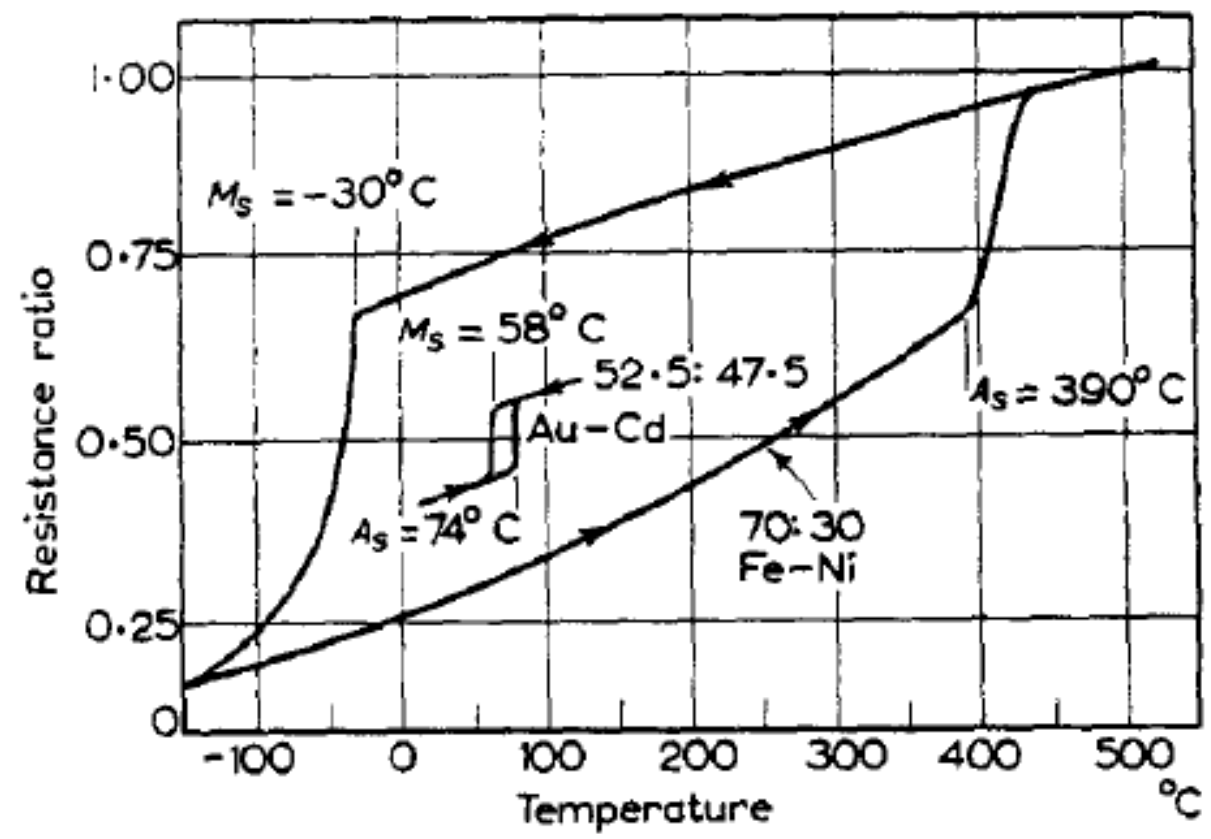

Figura 18 - Mudança na resistividade elétrica durante o resfriamento e aquecimentos das ligas $\mathrm{Fe}-\mathrm{Ni}$ e Au-Cd, ilustrando a histerese entre a reação martensítica no resfriamento e a transformação inversa no aquecimento (KAUFMAN; COHEN, 1958).

Existem vários métodos descritos na literatura para o calculo e a determinação da resistividade elétrica com corrente contínua (direct current DC) ou corrente alternada (alternating current $\mathrm{AC}$ ) o método mais usado é o método de quatro pontas para a determinação da resistividade elétrica de condutores metálicos e semicondutores, devido a sua aplicabilidade é muito utilizado para acompanhar a transformação martensítica entre eles: ligas Fe-Ni-C (HSU; JIAN; ZHENPENG, 1986), Fe-Ni-B (GUO et al., 1988), ligas de Fe-Ni (KAUFMAN; COHEN, 1958), Fe-Mn-Cr (TROIANI et al., 2009), etc.

$\mathrm{Na}$ transformação martensítica se apresentou anomalias na resistividade elétrica como é mostrado por Makita; Kobukata e Nagasawa (1986) em ligas Cu-Al-Zn como é mostrado na Figura 19, também foram mostrados em Co-Ni-Ga (CHEN et al., 2008), ligas de Ni-Ti-Cu (KATSUYAMA et al., 2004), ligas Ti-Ni-C (YIN et al., 2008). 


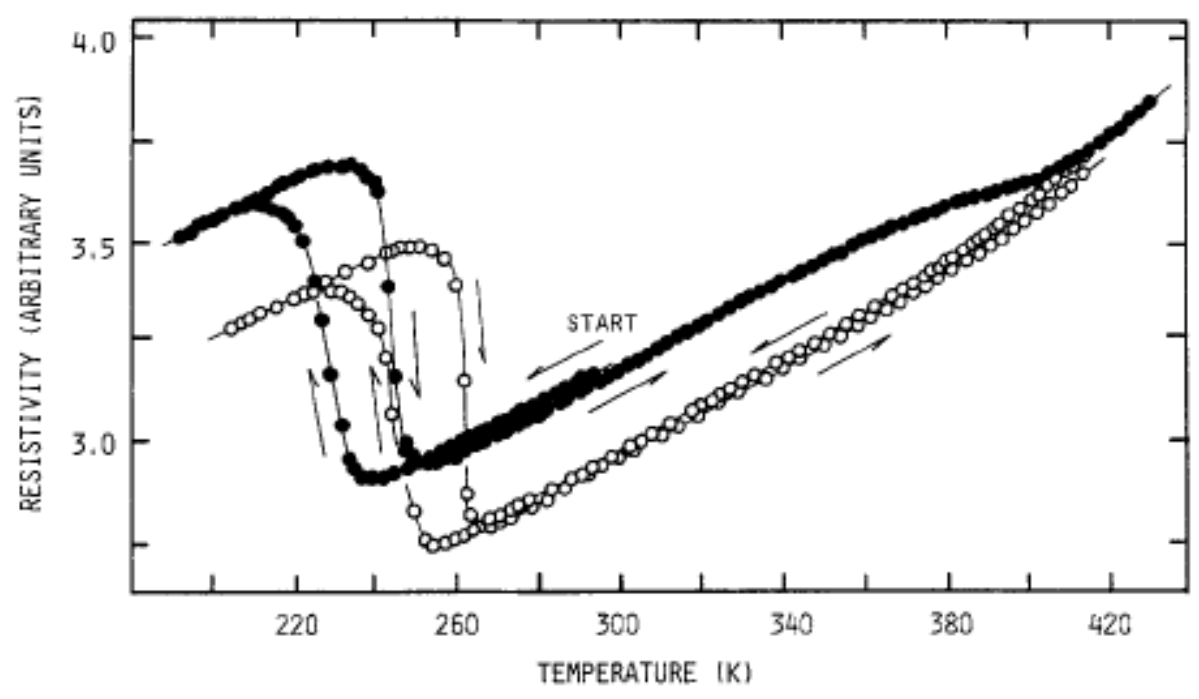

Figura 19 - Resistividade elétrica resfriado desde 513K da liga Cu-Al-Zn (MAKITA; KOBUKATA; NAGASAWA, 1986).

\subsubsection{Difração de raios $X$}

As relações entre a quantidade de martensita transformada, a mudança de volume e as deformações longitudinal e transversal causadas pela transformação martensítica foram estudados por Zhang; Kelly e Gates (1999). Num aço Fe-20\%pNi-0.8\%pC, sob compressão uniaxial, onde os grãos com orientações perto da direção <100> preferencialmente são transformados em martensita. Uma conseqüência dessa transformação preferencial foi a previsão do desenvolvimento de uma textura na austenita restante a baixas frações da martensita induzida por tensão $(<30 \%)$, onde a textura prevista na compressão foi confirmada por difração de raios-X (Figura 20). As intensidades $\{220\}$ da austenita é essencialmente o mesmo, enquanto a transformação induzido por tensão resultou na redução dos picos $\{200\}$ e $\{311\}$ da austenita. 

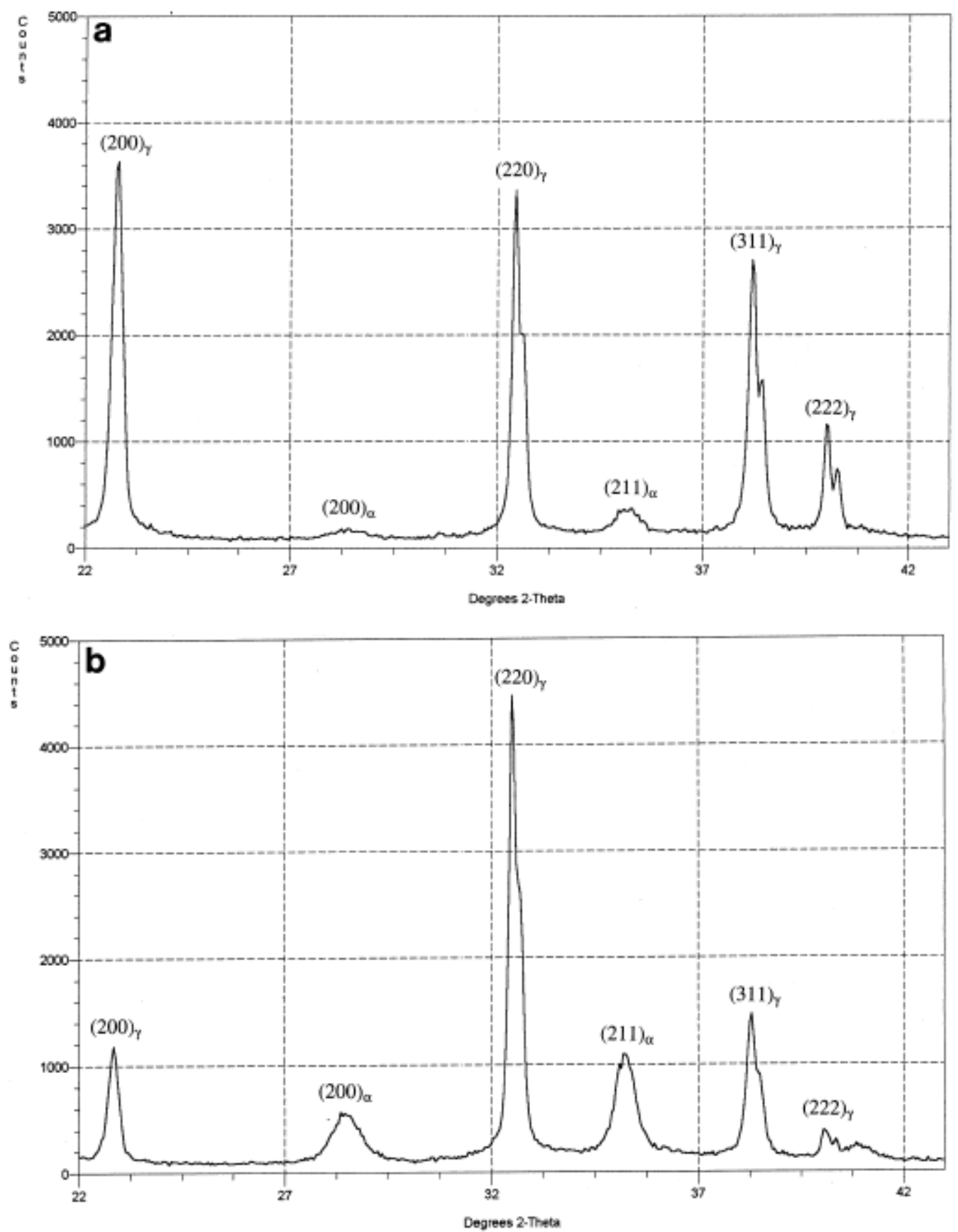

Figura 20 - Difração de raios-X usando radiação de Mo. a) antes da transformação; b) após 20\% de transformação. a refere-se à martensita, y refere-se à austenita (ZHANG; KELLY; GATES, 1999).

Jablońska et al. (2006) fizeram medições de raios-X de um ferro puro ARMCO, que depois de temperado foi armazenado na temperatura do nitrogênio liquido, onde as intensidades dos picos $<112>$ e $<121+211>$ foram medidos, a duração de cada medição foi de 20 min., cada amostra foi submetida a dez medições sucessivas 
(Figura 21). O mesmo procedimento foi repetido seis vezes, com novas amostras, imersas em nitrogênio líquido no intervalo de 35 dias (Figura 22).

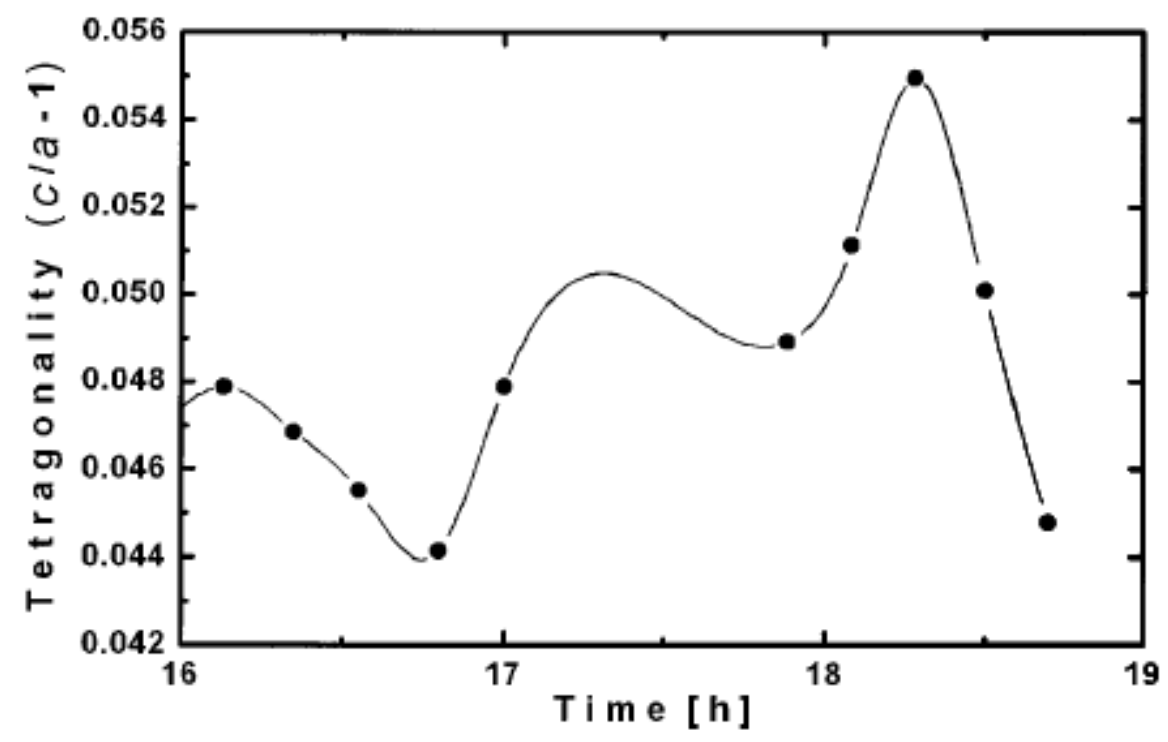

Figura 21 - Tetragonalidade dependente do tempo (JABLONSKA et al., 2006).

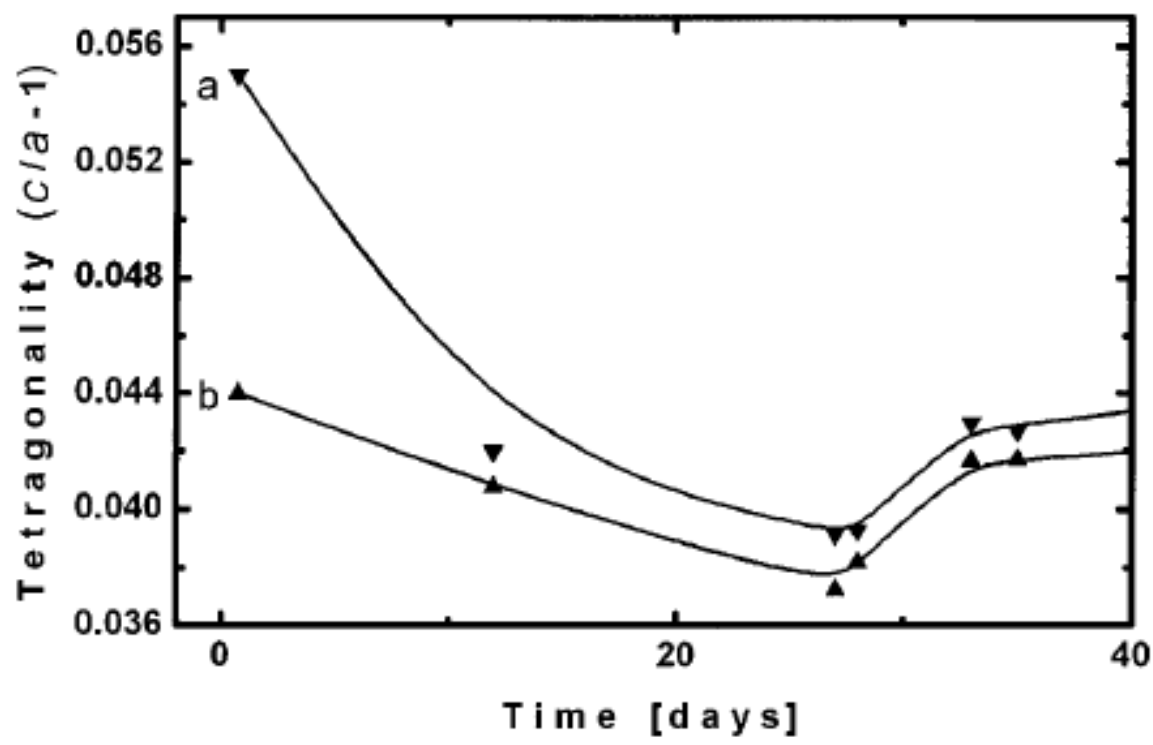

Figura 22 - Variação da tetragonalidade máxima e mínima da martensita em função do tempo: a: Máximo; b: Mínimo de tetragonalidade registrada (c/a - 1) (JABLONSKA et al., 2006).

Kajiwara e Kikuchi (1991) mostram o relaxamento de altas tensões internas no aço $\mathrm{Fe}-28 \% \mathrm{pNi}-0.6 \% \mathrm{pC}$ por difrações de raios- $\mathrm{X}$, onde os picos de difração de raios-X para reflexões de (011) e (110) de martensita a $90 \mathrm{~K}$ e aquecido a $293 \mathrm{~K}$ são 
mostrados na Figura 23, nesta figura valores nos picos a $90 \mathrm{~K}$ torna-se muito menor ao aquecimento a $293 \mathrm{~K}$, especialmente para picos de (110) (mudança considerável com um alvo de Co), e o pico (011) tem mudado pouco, a razão para isso não é claro, pode estar relacionado a algum arranjo especial de átomos de carbono na austenita.

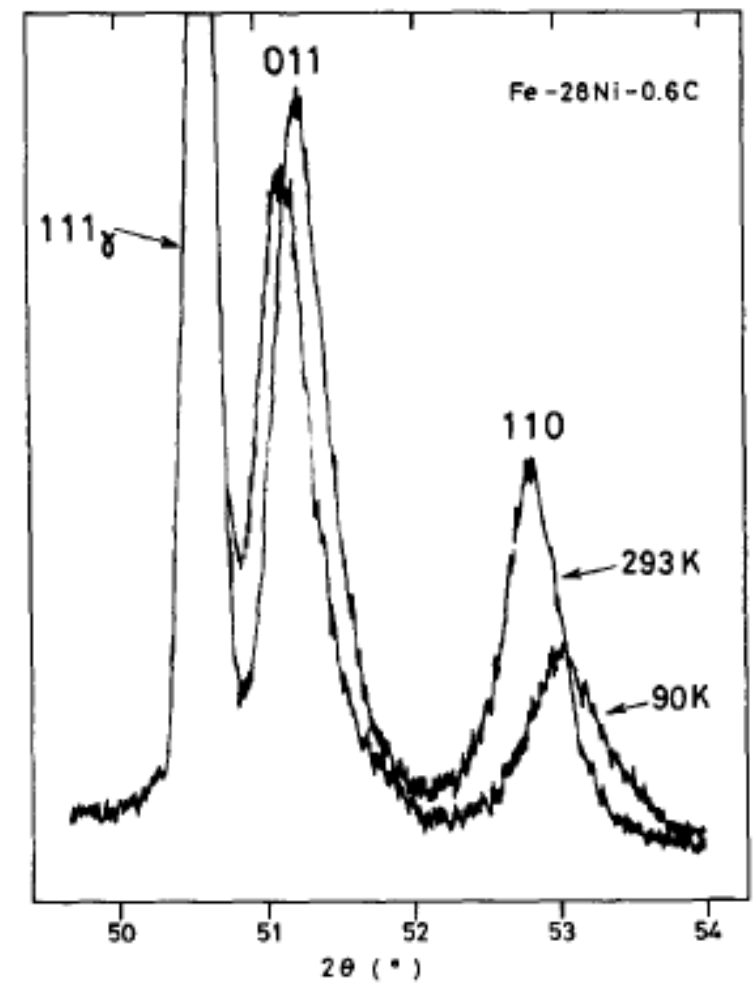

Figura 23 - Difração de raios-X para reflexões (011) e (110) da martensita (KAJIWARA; KIKUCHI, 1991). 


\section{OBJETIVOS}

\subsection{Principal}

O objetivo geral foi detectar o inicio da transformação martensítica Ms.

\subsection{Específicos}

Acompanhar a transformação martensítica por meio de técnicas experimentais a temperaturas sub-zero, em um aço para trabalho a frio austenitizado AISI D2 e uma liga Fe-Ni-C.

Explorar as possibilidades de utilização da emissão de ruído magnético de Barkhausen, a fim de detectar a transformação de fase de austenita para martensita durante o resfriamento a temperaturas sub-zero de materiais ferrosos austeniticos.

Utilizar a técnica para estudar o efeito do tamanho de grão da austenita na temperatura Ms. 


\section{MATERIAIS E MÉTODOS}

\subsection{Aço ferramenta AISI D2}

O aço AISI D2 tem composição química básica: 1,55\%C, $12 \% \mathrm{Cr}$, com adições dos elementos de liga de Mo e $V$ da ordem de 1\% (VILLARES METALS). Com esta composição, no sistema ternário $\mathrm{Fe}-\mathrm{C}-\mathrm{Cr}$ o aço D2 possui uma seqüência de solidificação que se inicia pela formação da austenita ( $(\mathrm{)})$, sofrendo uma reação eutética para $\mathrm{\gamma}+\mathrm{M} 7 \mathrm{C} 3$ (VOORT, 2004). Os elementos de liga Mo e V são adicionados para fornecer uma melhor resposta ao tratamento térmico de têmpera e revenimento, permitindo o fenômeno de endurecimento secundário.

A Tabela 2 mostra a composição química nominal do aço AISI D2. Na tabela 3 são mostradas as principais características dos carbonetos do sistema Fe-C-Cr.

Tabela 2 - Composição química do aço AISI D2, \% em massa (ASTM A681-08).

\begin{tabular}{cccccccc}
\hline $\mathbf{C}$ & $\mathbf{M n}$ & $\mathbf{P}$ & $\mathbf{S}$ & $\mathbf{S i}$ & $\mathbf{C r}$ & $\mathbf{V}$ & $\mathbf{M o}$ \\
\hline 1,40 & 0,1 & 0,03 & 0,03 & 0,10 & 11,00 & 0,50 & 0,70 \\
- & - & máx. & máx & - & - & - & - \\
1,60 & 0,6 & & & 0,60 & 13,00 & 1,10 & 1,20 \\
\hline
\end{tabular}

Tabela 3 - Principais carbonetos formados no sistema ternário Fe-C-Cr (BENZ; ELLIOTT; CHIPMAN, 1974).

\begin{tabular}{lllll}
\hline Carboneto & \multicolumn{1}{c}{$\begin{array}{c}\text { Estrutura } \\
\text { Cristalina }\end{array}$} & $\begin{array}{c}\text { Parâmetro de } \\
\text { Reticulado }\left(\mathbf{A}^{\circ}\right)\end{array}$ & \multicolumn{1}{c}{ Símbolo } & \multicolumn{1}{c}{ Observações } \\
\hline $\mathrm{M}_{3} \mathrm{C}$ & Ortorrômbica & $\begin{array}{l}\mathrm{a}=4,414 \mathrm{~b}=5,079 \\
\mathrm{c}=6,730\end{array}$ & $\mathrm{~K}_{\mathrm{C}}$ & $\begin{array}{l}\text { Dissolve até } 18 \% \text { de } \\
\text { cromo. } \\
\mathrm{M}_{23} \mathrm{C}_{6}\end{array}$ \\
Cúbica & $\mathrm{a}=10,640$ & $\mathrm{~K}_{1}$ & $\begin{array}{l}\text { Dissolve até } 35 \% \text { de } \\
\text { ferro. }\end{array}$ \\
$\mathrm{M}_{7} \mathrm{C}_{3}$ & Hexagonal & $\mathrm{a}=13,98 \mathrm{~b}=4,523$ & $\mathrm{~K}_{2}$ & $\begin{array}{l}\text { Dissolve entre } 30 \% \mathrm{a} \\
50 \% \text { de ferro. }\end{array}$ \\
\hline
\end{tabular}




\subsection{Liga Fe-Ni-C}

Em 1897, Charles Edouard Guillaume descobriu que as ligas com estrutura cúbica de faces centradas (cfc), de $\mathrm{Fe}$ e $\mathrm{Ni}$, com concentração de $\mathrm{Ni}$ ao redor de 35\%, apresentam baixo (quase zero) de expansão térmica sobre uma ampla faixa de temperatura, efeito conhecido como Invar. As ligas Invar têm teor de Ni na faixa 30$36 \%$, sendo o restante de $\mathrm{Fe}$, podendo ser acrescentados outros elementos, apresentando também outras propriedades anômalas. No modelo de Weiss (1963), existem dois estados possíveis para a estrutura cfc $(\gamma-\mathrm{Fe})$ : estado de alto volume ferromagnético e estado de baixo volume antiferromagnético.

\subsection{Aços de partida}

\subsubsection{AISI D2}

Material fornecido por Villares Metals com a composição química (Tabela 4).

Tabela 4 - Composição química AISI D2 fornecido por Villares Metals.

\begin{tabular}{lcr}
\hline Elem. & Sinal & \% Analise \\
\hline $\mathrm{C}$ & $=$ & 1,5200 \\
$\mathrm{Si}$ & $=$ & 0,3700 \\
$\mathrm{Mn}$ & $=$ & 0,4000 \\
$\mathrm{P}$ & $=$ & 0,0280 \\
$\mathrm{~S}$ & $<$ & 0,0010 \\
$\mathrm{Co}$ & $=$ & 0,0300 \\
$\mathrm{Cr}$ & $=$ & 11,8000 \\
$\mathrm{Mo}$ & $=$ & 0,8400 \\
$\mathrm{Ni}$ & $=$ & 0,3900 \\
$\mathrm{~V}$ & $=$ & 0,8200 \\
$\mathrm{~W}$ & $=$ & 0,1700 \\
$\mathrm{Cu}$ & $=$ & 0,0400 \\
$\mathrm{Ti}$ & $<$ & 0,0050 \\
$\mathrm{Nb}$ & $<$ & 0,0100 \\
$\mathrm{Al}$ & $=$ & 0,0240 \\
$\mathrm{~B}$ & $<$ & 0,0010 \\
$\mathrm{~Pb}$ & $<$ & 0,0025 \\
$\mathrm{Sn}$ & $<$ & 0,0050 \\
$\mathrm{~N}$ & $=$ & 0,0190 \\
\hline
\end{tabular}




\subsubsection{Fe-Ni-C}

Fornecido pelo Dr. José Roberto Costa Guimarães com a informação respectiva na Tabela 5.

Tabela 5 - Informações sobre a Liga Fe-Ni.

\section{Composição}

$\mathrm{Fe}-32,27 \% \mathrm{Ni}-0,035 \% \mathrm{C}$

Dimensões da amostra

comprimento ------ $50 \mathrm{cms}$

largura ------ $20 \mathrm{cms}$

espessura ----- $1,55 \mathrm{cms}$

Tratamento térmico

Recozido a $1100^{\circ} \mathrm{C}$ por 24 horas em $(10-5 \mathrm{mms} \mathrm{Hg})$ de vácuo seguido de tempera argônio.

\subsection{Temperaturas de austenitização.}

Foi calculado a mapa de fases utilizando o Thermo-Calc®, para escolher as temperaturas de austenitização para os aços trabalhados: 
AISI D2.

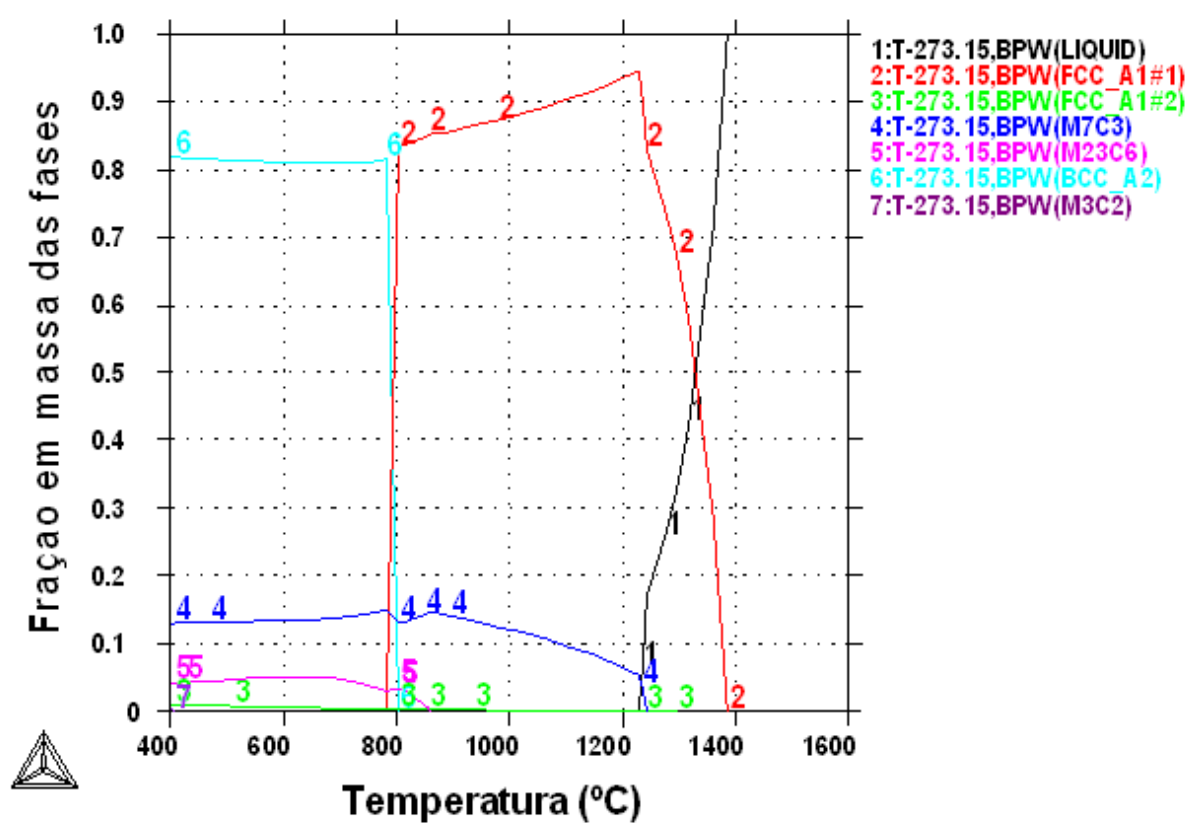

Figura 24 - Mapa de fases para o aço AISI D2 calculado com o programa Thermo-Calc® aliado ao banco de dados TCFE. Nas ordenadas a escala é linear (fração mássica das fases).

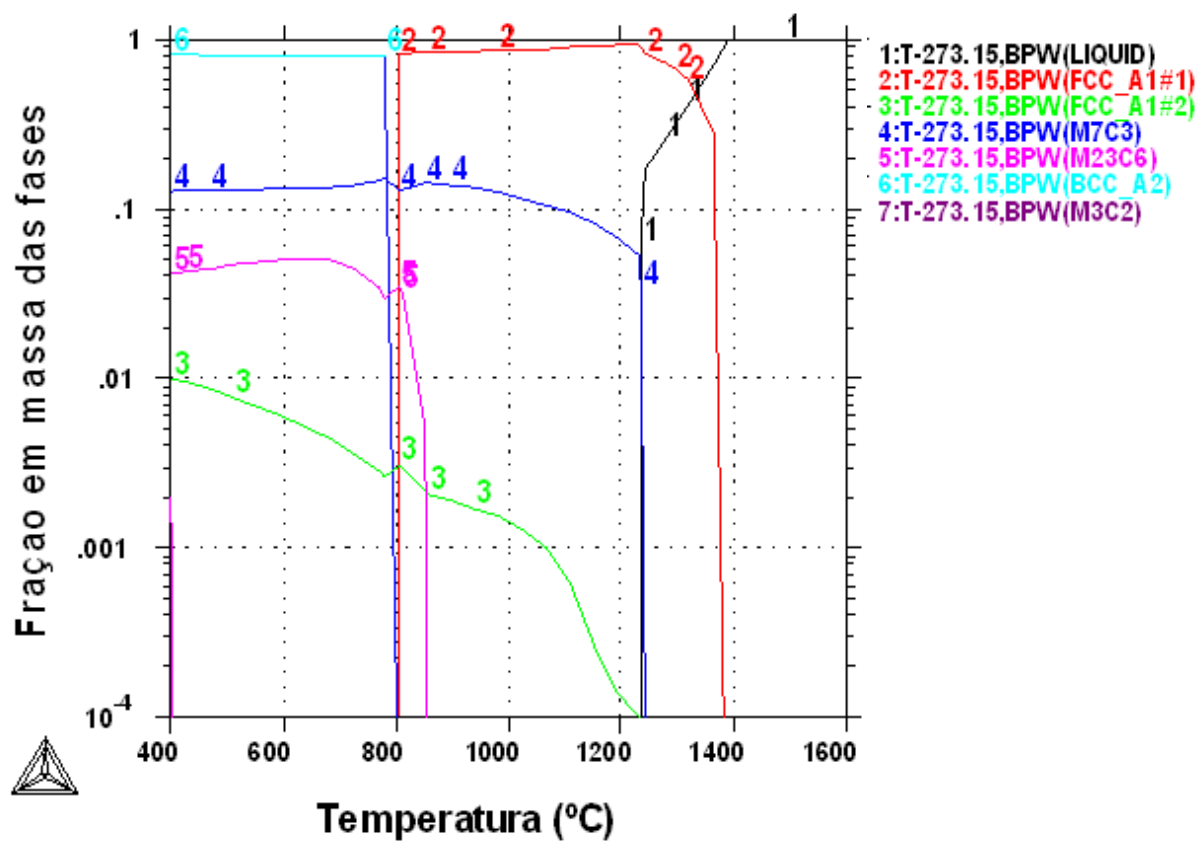

Figura 25 - Mapa de fases para o aço AISI D2 calculado pelo programa Thermo-Calc® aliado ao banco de dados TCFE. Nas ordenadas a escala é logarítmica (fração mássica das fases). 
Fe-Ni-C

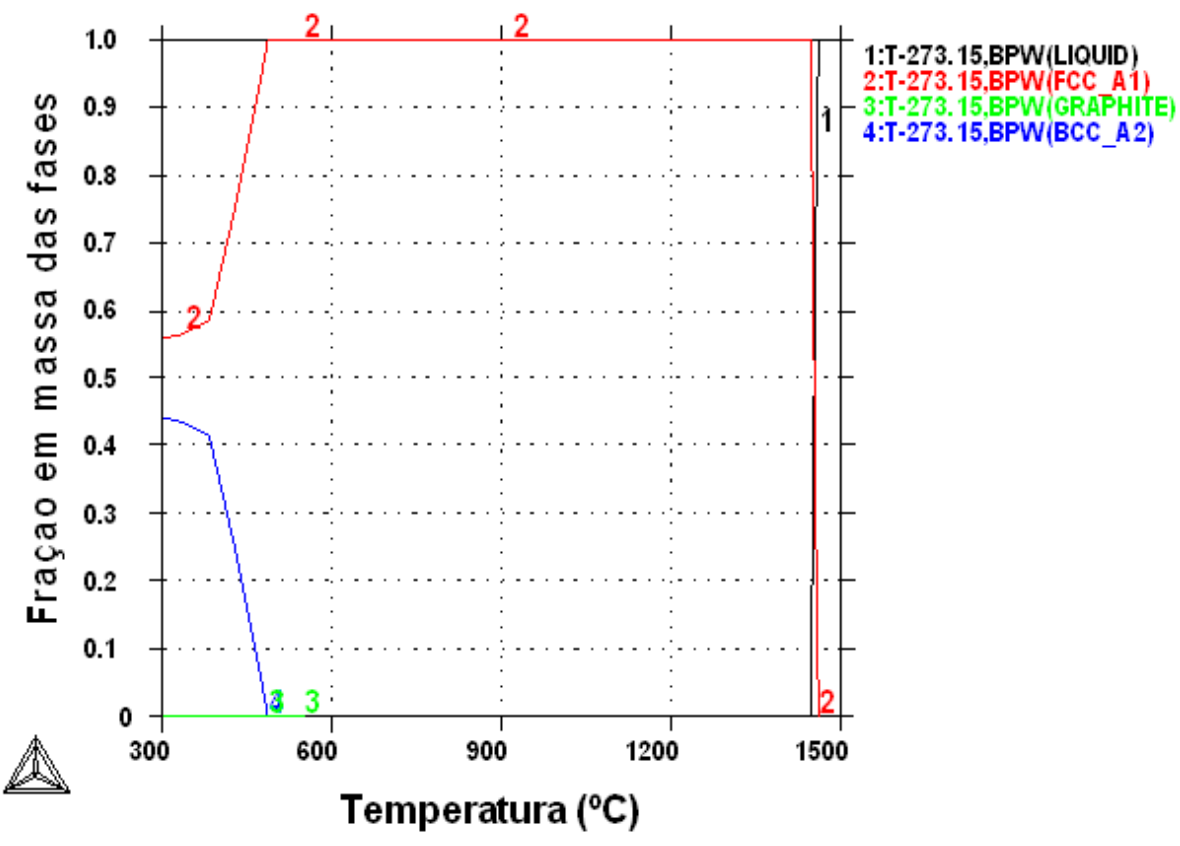

Figura 26 - Mapa de fases para a liga Fe-Ni-C calculado pelo programa Thermo-Calc $\circledast$ aliado ao banco de dados TCFE. Nas ordenadas a escala é linear (fração mássica das fases).

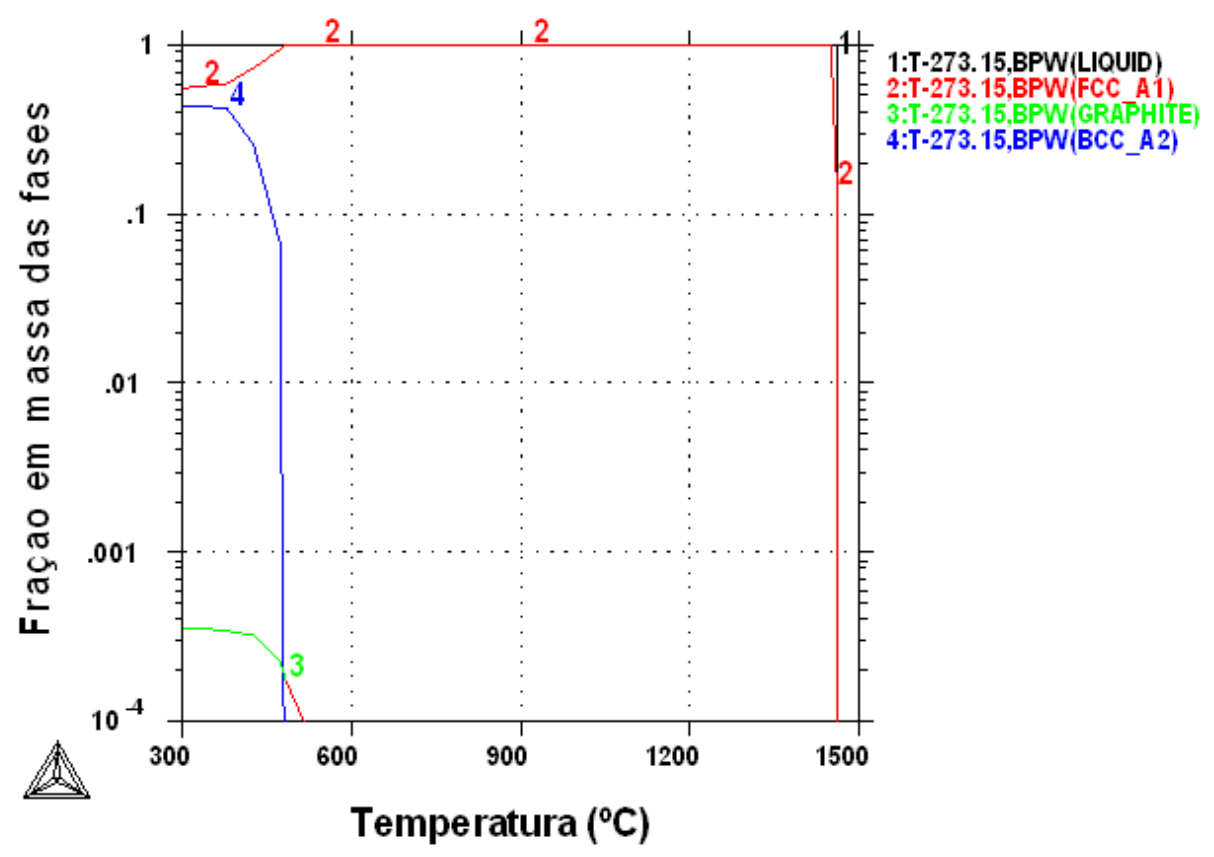

Figura 27 - Mapa de fases para a liga Fe-Ni-C calculado pelo programa Thermo-Calc $\circledast$ aliado ao banco de dados TCFE. Nas ordenadas a escala é logarítmica (fração mássica das fases). 
Optou-se por austenitizar o aço AISI D2 a uma temperatura de austenitização de $1200^{\circ} \mathrm{C}$ e a liga Fe-Ni-C a uma temperatura de $750^{\circ} \mathrm{C}$.

\subsection{Estimativa da temperatura Ms}

Para ter uma estimativa da temperatura Ms, obtivemos dados do software ThermoCalc®, nas respectivas temperaturas de austenitização.

\subsubsection{Para o aço AISI D2}

Tabela 6 - Composição química de equilíbrio (fração mássica dos componentes) da fase austenítica (FCC_A1\#1) presentes a $1200^{\circ} \mathrm{C}$, calculadas pelo Thermo-Calc® aliado ao banco de dados TCFE.

\begin{tabular}{lc}
\hline Fase Austenítica & $\begin{array}{c}\text { Fração mássica dos } \\
\text { componentes }\end{array}$ \\
\hline W(FCC_A1\#1,AL) & $0,03 \%$ \\
W(FCC_A1\#1,C) & $1,02 \%$ \\
W(FCC_A1\#1,CO) & $0,03 \%$ \\
W(FCC_A1\#1,CU) & $0,04 \%$ \\
W(FCC_A1\#1,MN) & $0,40 \%$ \\
W(FCC_A1\#1,N) & $0,02 \%$ \\
W(FCC_A1\#1,NI) & $0,42 \%$ \\
W(FCC_A1\#1,TI) & $0,00 \%$ \\
W(FCC_A1\#1,W) & $0,15 \%$ \\
W(FCC_A1\#1,CR) & $9,20 \%$ \\
W(FCC_A1\#1,FE) & $86,95 \%$ \\
W(FCC_A1\#1,MO) & $0,81 \%$ \\
W(FCC_A1\#1,NB) & $0,01 \%$ \\
W(FCC_A1\#1,SI) & $0,40 \%$ \\
W(FCC_A1\#1,V) & $0,52 \%$ \\
\hline
\end{tabular}


Tabela 7 - Ms empíricos para o aço AISI D2 a $1200^{\circ} \mathrm{C}$, calculados com diferentes equações empíricas e os resultados obtidos através do Thermo-Calc®.

\begin{tabular}{clrrll}
\hline & & $\mathbf{M s}\left({ }^{\circ} \mathbf{C}\right)$ & \multicolumn{1}{c}{ Ms $(\mathbf{K})$} & \\
\hline 1 & Payson and Savage & 1944 & $-96,91$ & 176,09 & \\
2 & Carapella & 1944 & 60,05 & 333,05 & \\
3 & Rowland and Lyle & 1946 & $-113,17$ & 159,83 & \\
4 & Grange and Stewart & 1946 & $-209,48$ & 63,52 & \\
5 & Nehrenberg & 1946 & $-33,01$ & 239,99 & \\
6 & Steven and Haynes & 1956 & $-114,58$ & 158,42 & \\
7 a & Andrew (linear) & 1965 & $-27,97$ & 245,03 & \\
$7 b$ & Andrew (nonlinear) & 1965 & $-262,37$ & 10,63 & \\
8 & Liu & 1981 & $-46,03$ & 226,97 & \\
9 & Liu & 1981 & $-77,10$ & 195,90 & \\
10 & Zhao & 1992 & 188,72 & 461,72 & (for twinned martensite) \\
11 & Zhao & 1992 & 114,63 & 387,63 & (for lath martensite) \\
\hline
\end{tabular}

\subsubsection{Para a liga Fe-Ni-C}

Tabela 8 - Apresenta a composição química de equilíbrio (fração mássica dos componentes) da fase austenítica (FCC_A1\#1) presentes a $750^{\circ} \mathrm{C}$, calculadas pelo Thermo-Calc $\circledast$ aliado ao banco de dados TCFE.

\begin{tabular}{lc}
\hline \multicolumn{1}{c}{ Fase austenítica } & $\begin{array}{c}\text { Fração mássica dos } \\
\text { componentes }\end{array}$ \\
\hline W(FCC_A1,C) & $0,04 \%$ \\
W(FCC_A1,FE) & $67,70 \%$ \\
W(FCC_A1,NI) & $32,27 \%$ \\
\hline
\end{tabular}

Tabela 9 - Ms empíricos para o aço $\mathrm{Fe}-\mathrm{Ni}-\mathrm{C}$ a $750^{\circ} \mathrm{C}$, calculados com diferentes equações empíricas e os resultados obtidos através do Thermo-Calc®.

\begin{tabular}{|c|c|c|c|c|c|}
\hline & & & $\operatorname{Ms}\left({ }^{\circ} \mathrm{C}\right)$ & Ms (K) & \\
\hline 1 & Payson and Savage & 1944 & $-34,55$ & 238,45 & \\
\hline 2 & Carapella & 1944 & $-219,40$ & 53,60 & \\
\hline 3 & Rowland and Lyle & 1946 & $-35,11$ & 237,89 & \\
\hline 4 & Grange and Stewart & 1946 & $-84,15$ & 188,85 & \\
\hline 5 & Nehrenberg & 1946 & $-33,99$ & 239,01 & \\
\hline 6 & Steven and Haynes & 1956 & $-4,18$ & 268,82 & \\
\hline $7 a$ & Andrew (linear) & 1965 & $-46,98$ & 226,02 & \\
\hline $7 \mathrm{~b}$ & Andrew (nonlinear) & 1965 & $-48,95$ & 224,05 & \\
\hline 8 & Liu & 1981 & $-11,23$ & 261,78 & \\
\hline 9 & Liu & 1981 & $-21,69$ & 251,32 & \\
\hline 10 & Zhao & 1992 & $-120,18$ & 152,82 & (for twinned martensite) \\
\hline 11 & Zhao & 1992 & $-142,10$ & 130,90 & (for lath martensite) \\
\hline
\end{tabular}


Os resultados mais razoáveis e confiáveis são os obtidos com a equação de Andrews Linear.

\subsection{Metodologia}

Para todos os ensaios com o aço AISI D2 as amostras foram encapsuladas sob vácuo, seladas em capsulas de vidro de sílica, e solubilizadas a $1200^{\circ} \mathrm{C}$ (por um tempo de 1 hora), seguido por tempera rápida em óleo; esta temperatura foi escolhida depois de executar cálculos no Thermo-Calc $\circledast$, como a mais alta temperatura segura de austenitização da amostra, sem risco de liquação. A $1200^{\circ} \mathrm{C}$ as fases de equilíbrio são: austenita, carboneto $\mathrm{M}_{7} \mathrm{C}_{3}$ e $\mathrm{M}(\mathrm{C}, \mathrm{N})$.

A liga $\mathrm{Fe}-\mathrm{Ni}-\mathrm{C}$ foi solubilizada a $750^{\circ} \mathrm{C}$ (por um tempo de $45 \mathrm{~min}$.), seguido por tempera rápida em água, temperatura esta escolhida depois de executar cálculos no Thermo-Calc®, onde só apresenta austenita.

Para a mudança do grão do Fe-Ni-C, foi solubilizada a tempos de $800^{\circ} \mathrm{C}, 1000^{\circ} \mathrm{C}$, $1200^{\circ} \mathrm{C}$ e $1350^{\circ} \mathrm{C}$, por tempos variáveis, conseguindo o aumento do tamanho de grão.

As amostras para a resistividade elétrica, emissões magnéticas de Barkhausen e emissão magnética espontânea SME, foram cortadas na forma de barra (Figura 28), com $60 \mathrm{~mm}$ de comprimento, larguras das espessuras de $7 \mathrm{~mm}$ e $5 \mathrm{~mm}$.

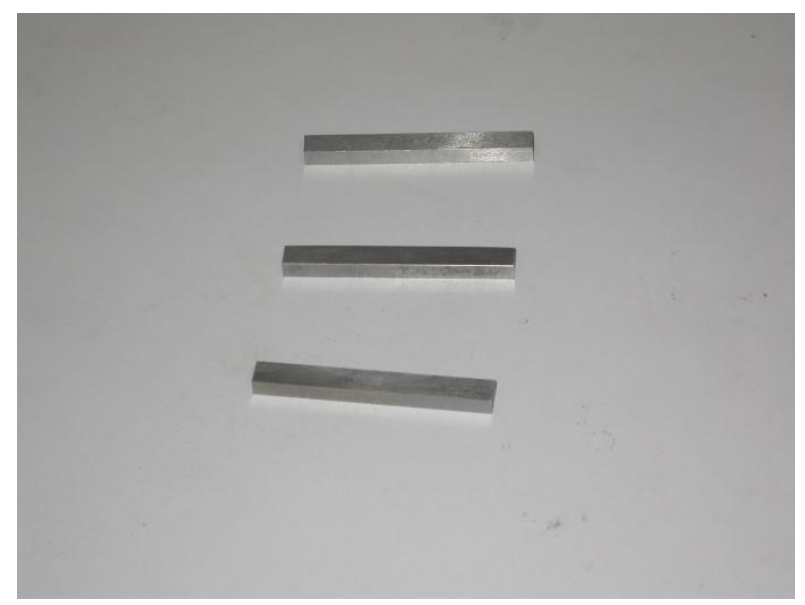

Figura 28 - Dimensões das amostras de Fe-Ni-C e AISI D2. 


\subsubsection{Difração de raios - $X$.}

Foram testadas no LNLS em Campinas amostras previamente preparadas metalograficamente com espessuras de 1-2mm sem ataque prévio, em ambos os lados.

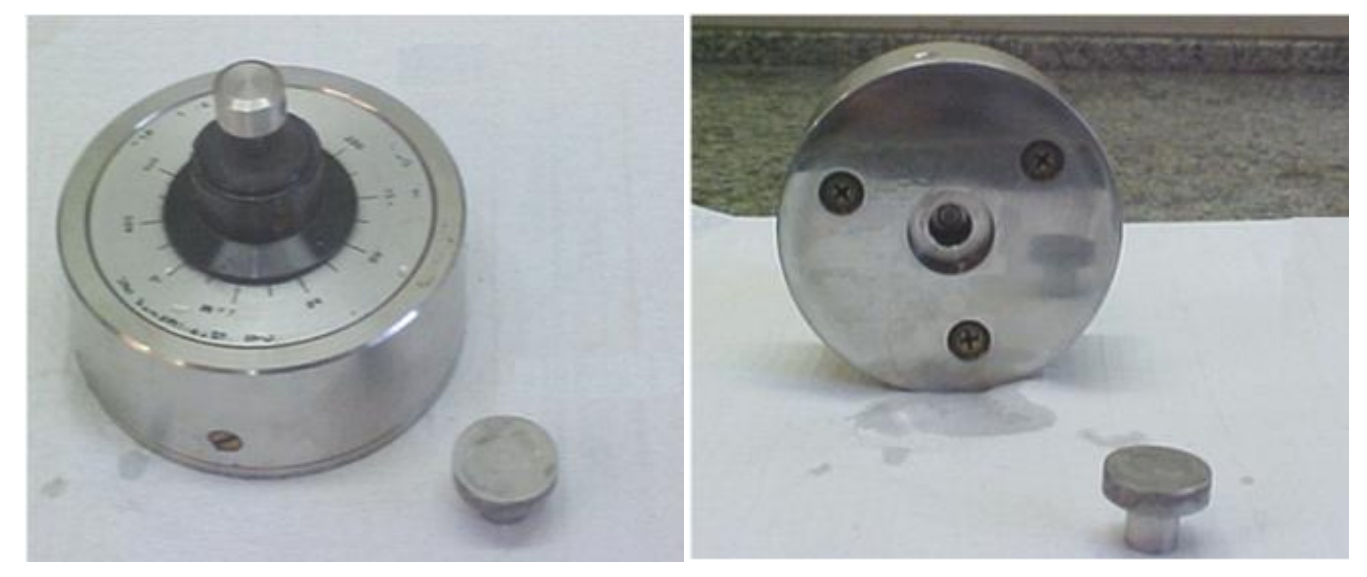

Figura 29 - Equipamento de lixamento "Disk-Grinder" as amostras foram colados com adesivo de poliacrilato e soltos com Acetona.

\subsubsection{Medição da resistividade elétrica}

Foi usado o método de quatro pontas para medições da resistividade e temperatura $(\rho-T)$; direção da corrente foi paralela ao sentido do comprimento das amostras. Foram registrados ciclos de aquecimento e resfriamento. Geralmente para as medições de $\rho-T$, as amostras foram primeiro resfriados até $77 \mathrm{~K}$, aproximadamente a $5 \%$ min e uma corrente (DC) de $2 \mathrm{~A}$ e posteriormente aquecido a $280 \mathrm{~K}$ à mesma taxa. A temperatura foi medida usando um dispositivo de resistência Pt 100.

Para "resultados mais redundantes na resistividade elétrica utilizou-se o equipamento Dedo Frio", onde se tem controle do vácuo e velocidade de resfriamento e aquecimento. 


\subsubsection{Medições magnéticas de Barkhausen}

A medição de sinais MBN foi realizada com um equipamento portátil "BarkTech" desenvolvido no Laboratório de Dinâmica (LADIN). As medições utilizaram uma excitação de onda senoidal magnética de $10 \mathrm{~Hz}$, e um campo magnético de \pm $1.2 \times 10^{4} \mathrm{~A} / \mathrm{m}$. Uma bobina de captação, colocada perpendicularmente ao modelo, detectando o sinal MBN a saída de sinal foi amplificado e a banda passante filtrada (1-100 kHz) para o aço AISI D2 e para a liga Fe-Ni-C (1-150kHz). A freqüência de amostragem aplicada foi de $200 \mathrm{kHz}$ para o aço AISI D2 e 300kHz para a liga Fe-NiC. O cartão National Instruments USB-6251 foi usado para medir o ruído de Barkhausen e um software especial foi desenvolvido para processar e armazenar o tempo de sinal de MBN. Neste trabalho, a resposta de MBN é sempre o valor médio quadrático (RMS) do ruído e é referida como voltagem RMS.

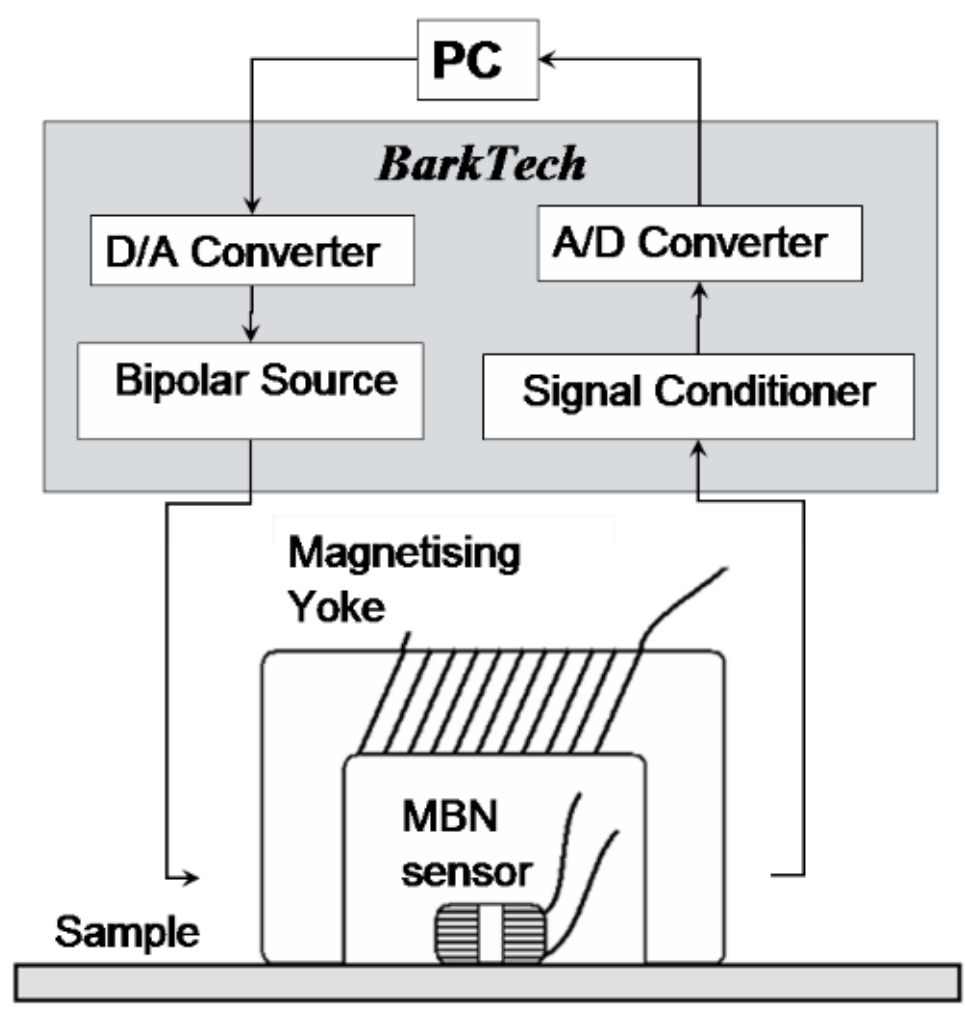

Figura 30 - Diagrama do esquema da medição de ruído magnético de Barkhausen. 
Para o aço AISI D2, MBN e resistência elétrica foram medidos, a temperaturas prédefinidas, durante o resfriamento da amostra. Para estas medições, o processo de resfriamento foi feito numa camara com temperatura controlada, com nitrogênio liquido.

Para as amostras da liga Fe-Ni-C o MBN, foi feita sem controle da velocidade de resfriamento, só próprio do material submergido em um Dewar com nitrogênio liquido. 


\section{RESULTADOS E DISCUSSÕES}

\subsection{Caracterização das amostras como temperadas}

AISI D2 - Solubilizado a $1200^{\circ} \mathrm{C}$, temperado em óleo apresenta uma estrutura austenítica com carbonetos esferoidizados distribuídos, com pequeno volume de carbonetos (Figura 31).

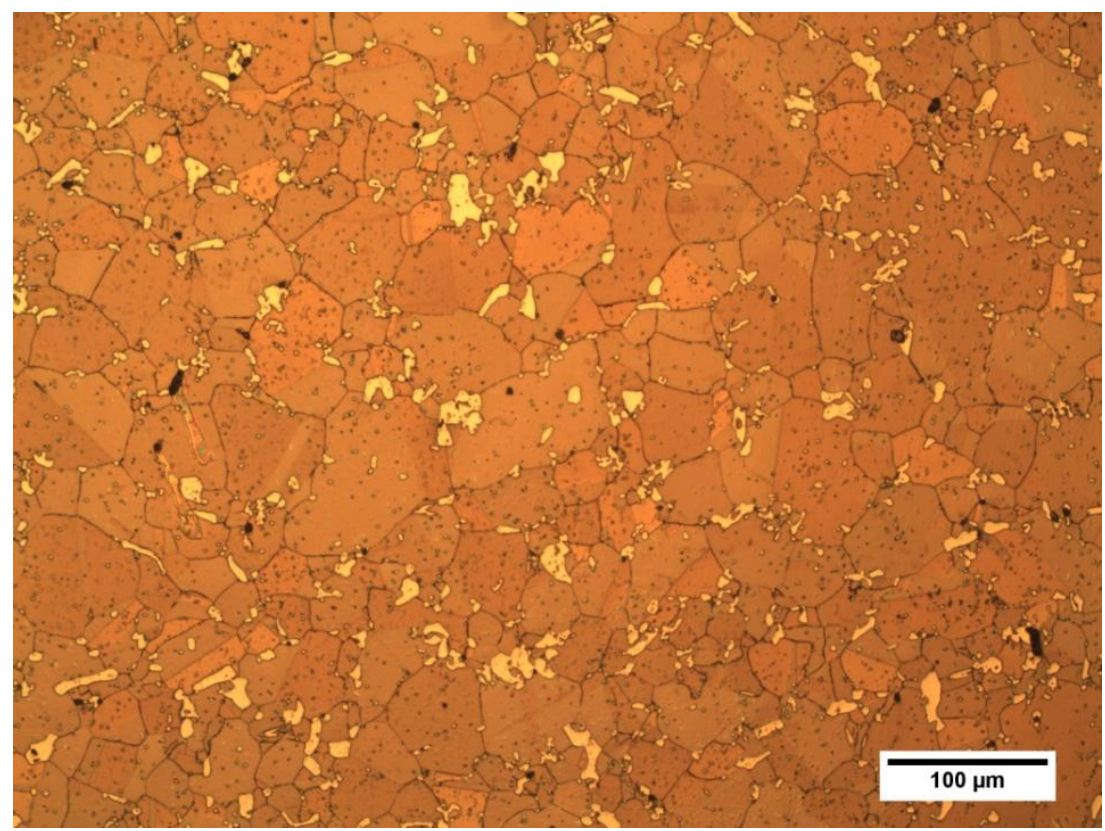




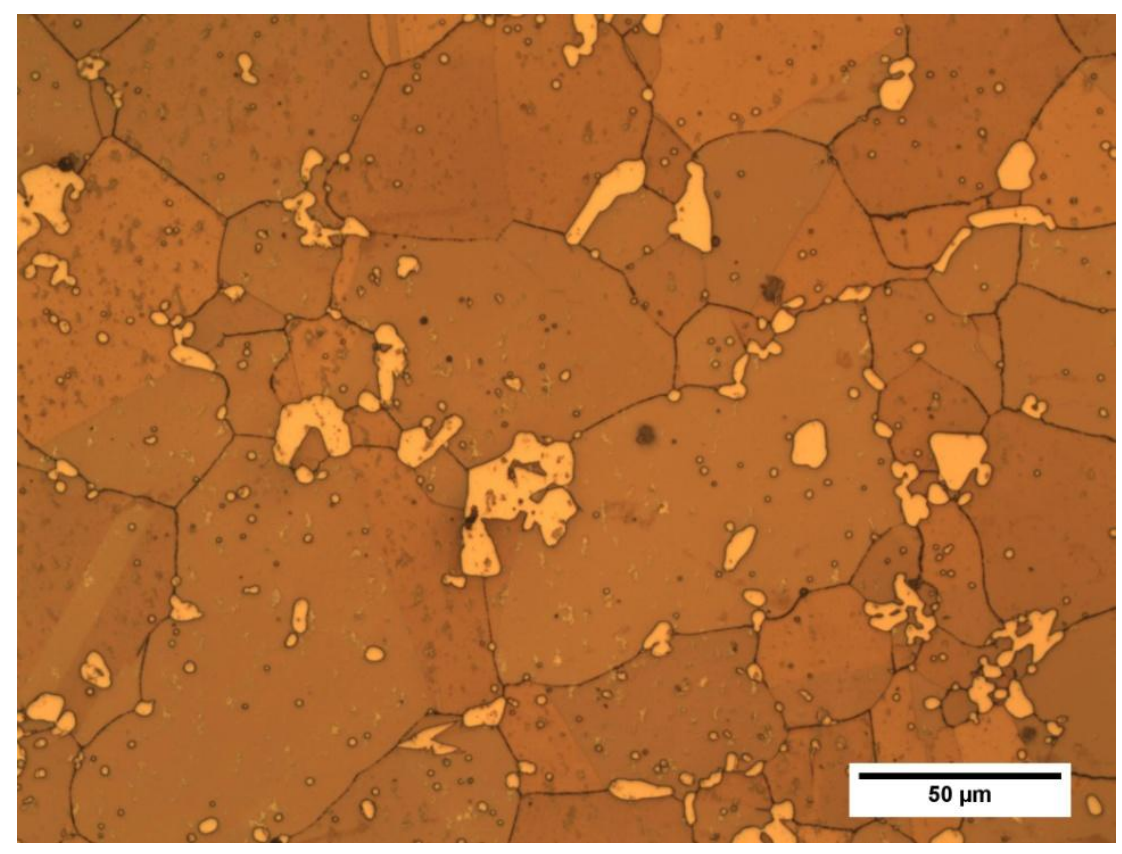

Figura 31 - Amostras AISI D2 temperadas em óleo e atacadas com Villela.

Tabela 10 - Dureza Vickers do aço AISI D2.

\begin{tabular}{cccccc}
\hline $\begin{array}{c}\text { Pré-carrega } \\
\text { (Kg.) }\end{array}$ & $\mathbf{D}^{1}$ & $\mathbf{D}^{2}$ & $\mathbf{H}_{\mathbf{V}}$ & Média & Desv. Pad. \\
\hline & 0,161 & 0,164 & 316,02 & & \\
0,5 & 0,154 & 0,150 & 361,18 & 351 & 23,7 \\
& 0,152 & 0,149 & 368,42 & & \\
\hline
\end{tabular}

Fe-Ni-C - Solubilizado a $750^{\circ} \mathrm{C}$, temperado em água, apresenta uma estrutura só austenítica. 

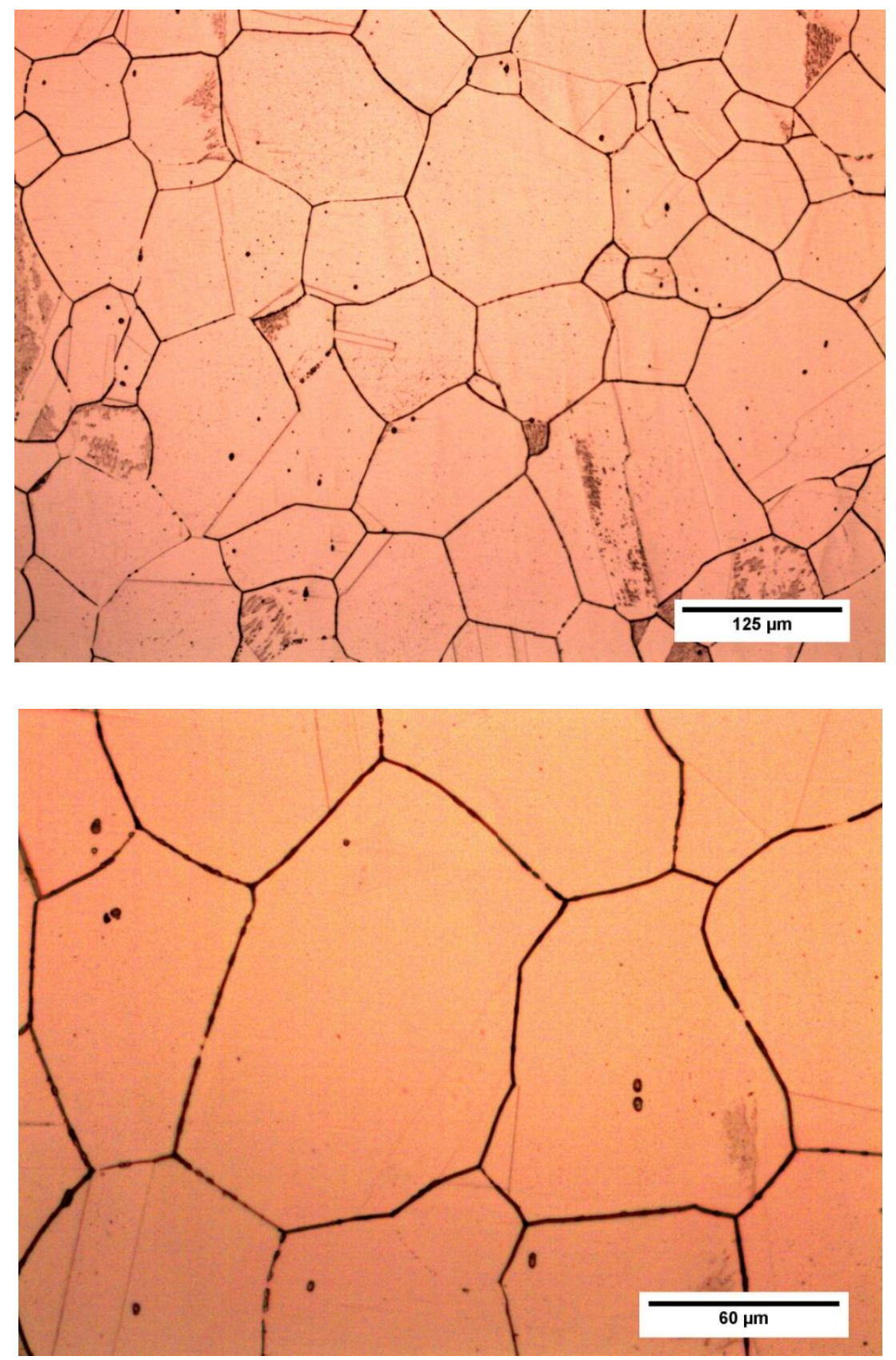

Figura 32 - Amostras Fe-Ni-C temperadas em água e atacadas com nital 2\%.

Tabela 11 - Dureza Vickers do Fe-Ni-C.

\begin{tabular}{cccccc}
\hline $\begin{array}{c}\text { Pré-carrega } \\
\text { (Kg.) }\end{array}$ & $\mathbf{D}^{\mathbf{1}}$ & $\mathbf{D}^{\mathbf{2}}$ & $\mathbf{H}_{\mathbf{v}}$ & Média & Desv. Pad. \\
\hline & 0,109 & 0,130 & 584,36 & & \\
0,5 & 0,110 & 0,150 & 493,78 & 547 & 39,9 \\
& 0,108 & 0,140 & 542,72 & & \\
& 0,112 & 0,130 & 569,96 & & \\
\hline
\end{tabular}




\subsection{Porcentagens do carboneto do aço AISI D2}

\subsubsection{Porcentagem por metalografia quantitativa}

A determinação da porcentagem de carbonetos foi realizada com ajuda do software ImageJ. A Figura 33 mostra as micrografias das amostras polidas e atacadas com Villela como testadas com ImageJ. As porcentagens obtidas através deste método são apresentadas na tabela 12.

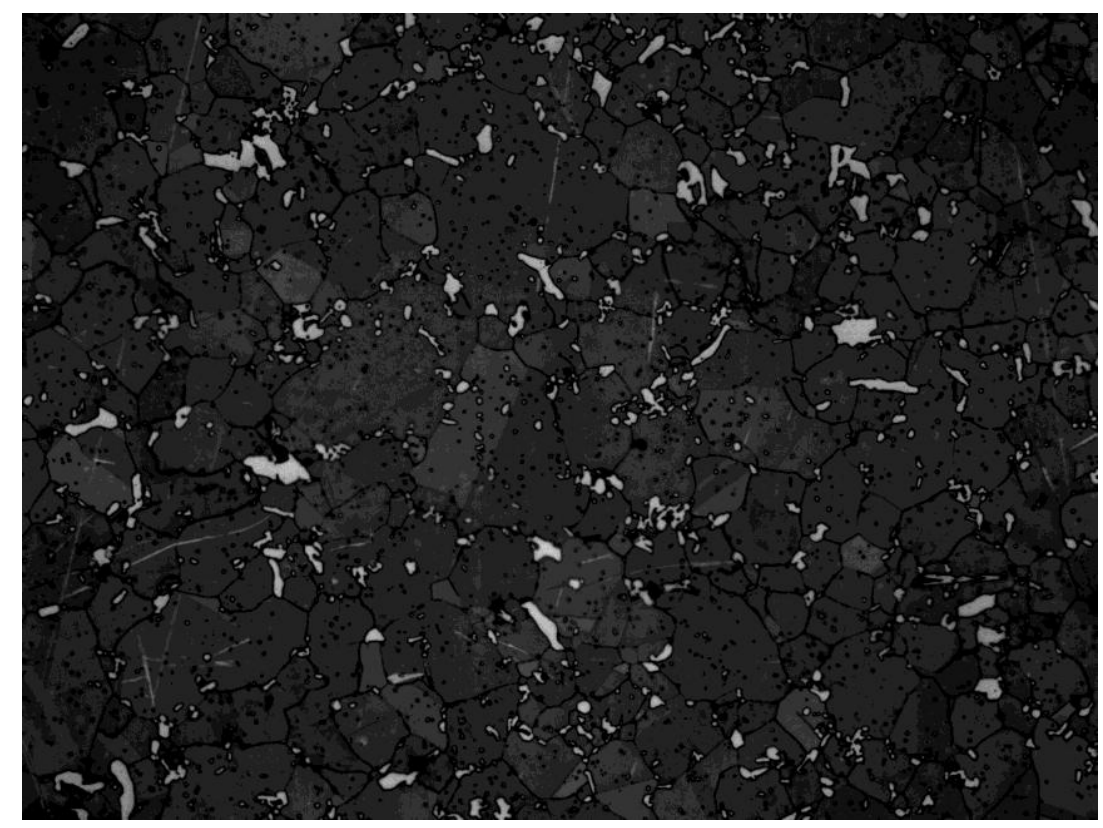




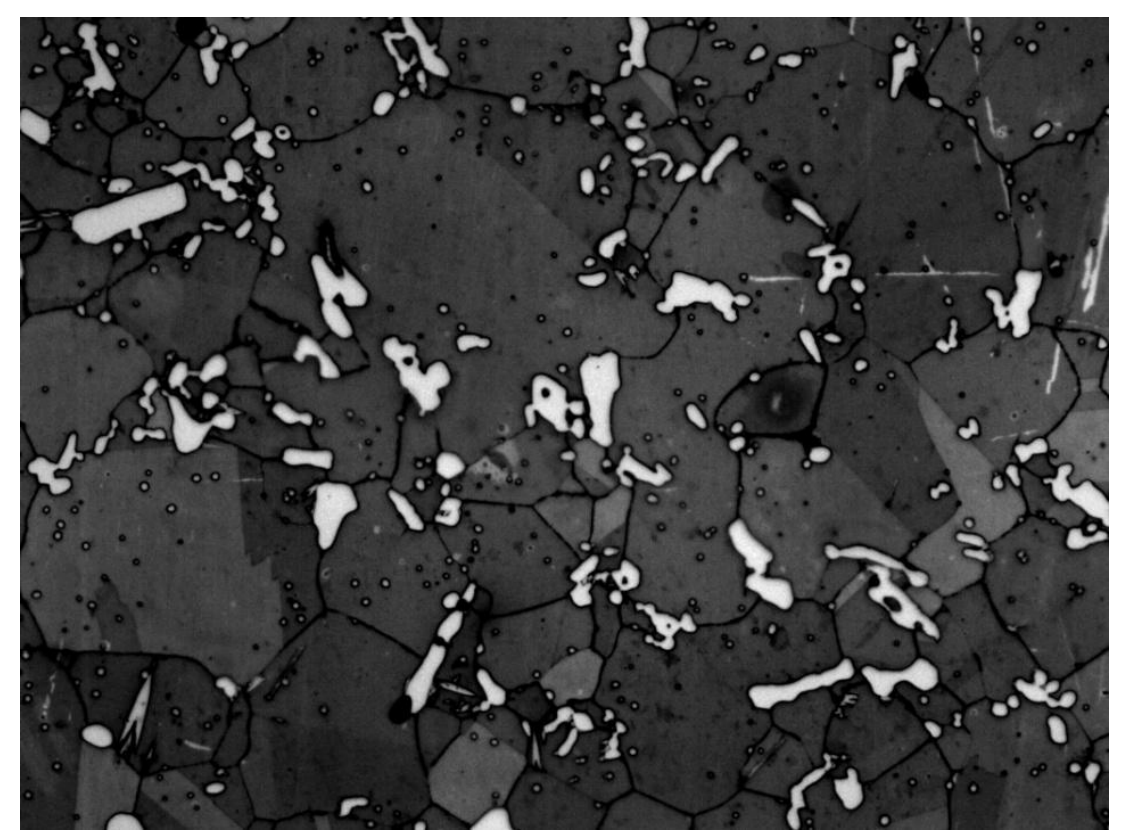

Figura 33 - Amostras de ampliação de 200x e 500x respectivamente para ser testadas no ImageJ.

Tabela 12 - Porcentagem de carbonetos:

\begin{tabular}{ccccc}
\hline Amostra & Área(um2) & \%Área & Média & $\begin{array}{c}\text { Desv. } \\
\text { Pad. }\end{array}$ \\
\hline $\begin{array}{c}\text { Ampliação } \\
\text { 200X1 }\end{array}$ & 344911,19 & 4,60 & & \\
$\begin{array}{c}\text { Ampliação } \\
\text { 200X2 }\end{array}$ & 344911,19 & 4,13 & & \\
$\begin{array}{c}\text { Ampliação } \\
\text { 500X1 }\end{array}$ & 55039,89 & 5,52 & 5,27 & 1,18 \\
$\begin{array}{c}\text { Ampliação } \\
\mathbf{5 0 0 X 2}\end{array}$ & 55039,89 & 6,82 & & \\
\hline
\end{tabular}




\subsubsection{Porcentagem de carbonetos obtida a partir de cálculos no Thermo-Calc $\circledast$}

A porcentagem de carbonetos foi calculada através do Thermo-Calc®.
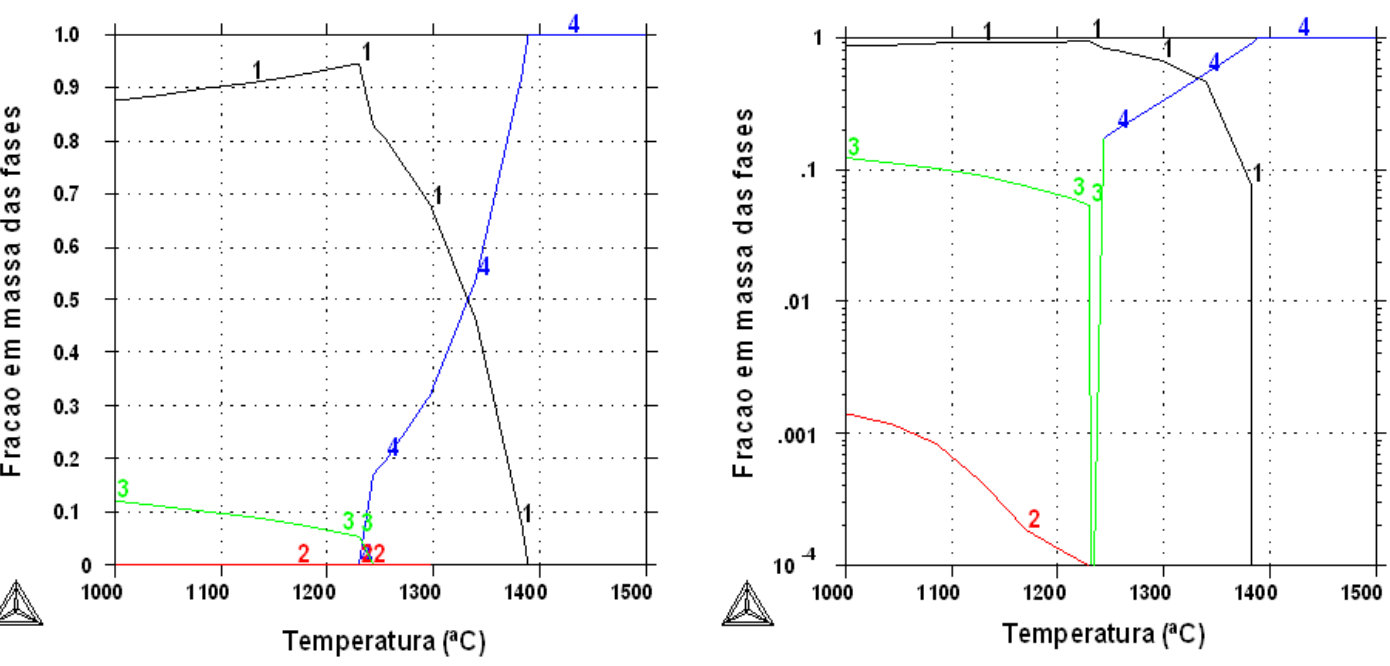

Figura 34 - Mapa de fases para o aço AISI D2 calculado pelo programa Thermo-Calc® aliado ao banco de dados TCFE. Nas ordenadas a escala é linear e logarítmica respectivamente (fração mássica das fases).

Pelo Thermo-Calc $\AA$ :

Tabela 13 - Porcentagem em massa das fases calculadas para o aço AISI D2 a $1200^{\circ} \mathrm{C}$, pelo Thermo-Calc $®$ aliado ao banco de dados TCFE.

\begin{tabular}{lc}
\hline \multicolumn{1}{c}{ Fases } & Porcentagem \\
\hline BPW(LIQUID) & 0,00 \\
BPW(BCC_A2) & 0,00 \\
BPW (FCC_A1\#1) & 93,46 \\
BPW (FCC_A1\#2) & 0,01 \\
BPW(M23C6) & 0,00 \\
BPW(M3C2) & 0,00 \\
BPW(M7C3) & 6,53 \\
\hline
\end{tabular}




\subsection{EDS do carboneto}

A identificação do carboneto $\mathrm{M}_{7} \mathrm{C}_{3}$. Através de microanálise por MEV-EDS, mostrou que ele é basicamente composto de $\mathrm{Cr}$ e $\mathrm{C}$.

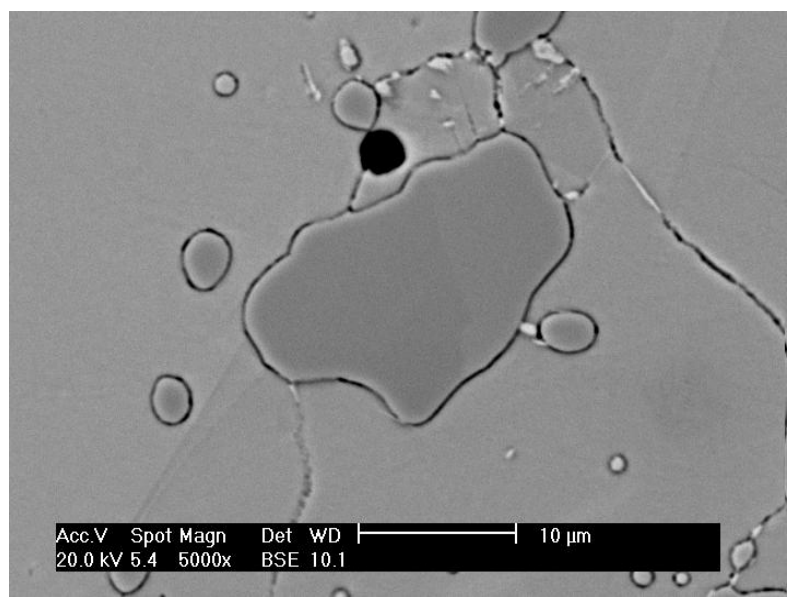

C:AAlunos1\}EdgarA EDS105-05-101gra02.spc
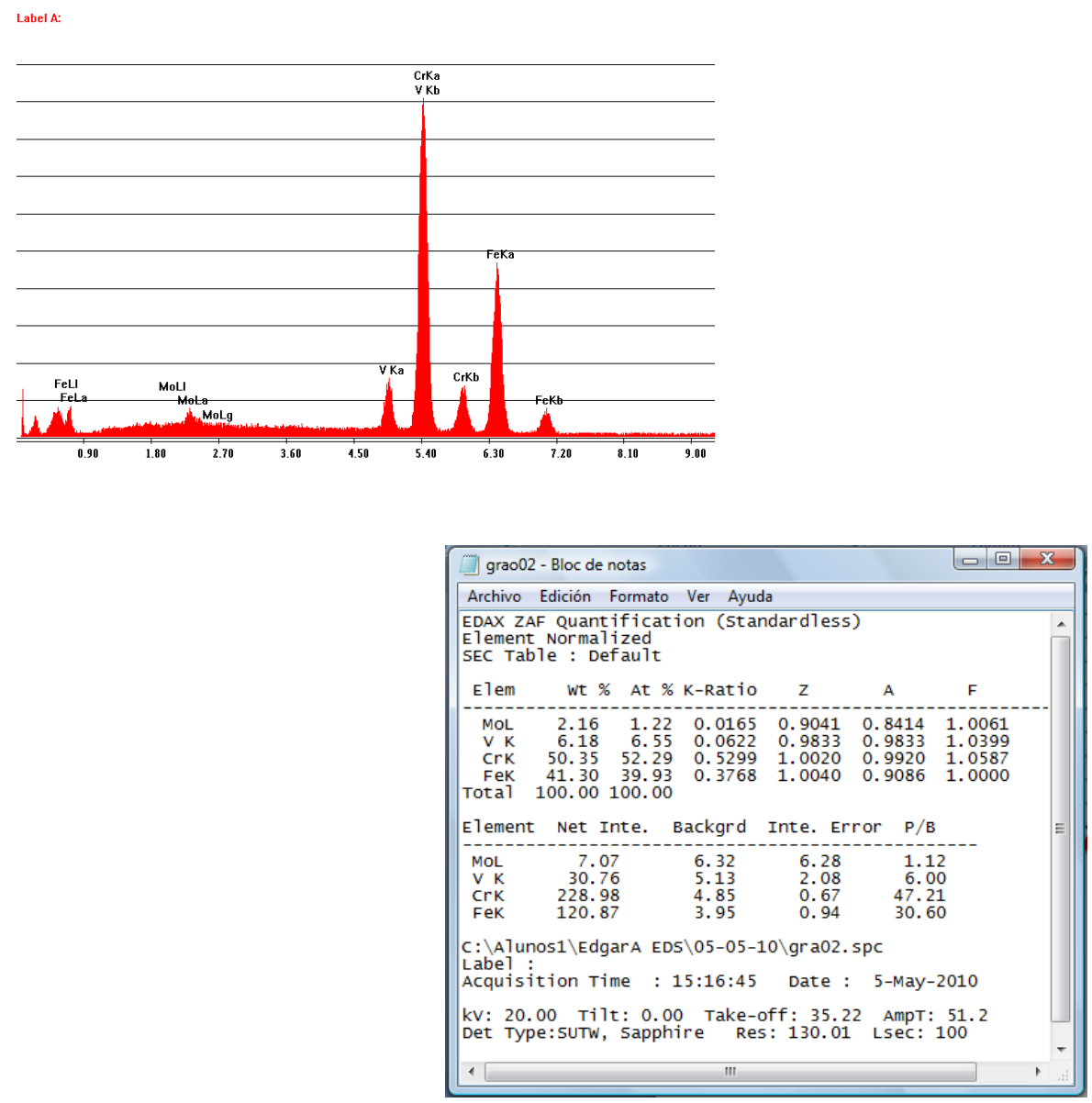

Figura 35 - EDS do carboneto AISI D2. 


\subsection{Difração de raios $X$.}

Os dados foram obtidos no LNLS - Campinas, usando radiação com comprimento de onda do Co Ka1, onde se obteve os resultados descritos na Tabela 14.

As amostras foram temperadas (Figura 36A) e submersas no nitrogênio liquido por 3, 10 e 30 horas (Figura 36B, C e D respectivamente), onde os resultados mostram que o material como recebido tem quase $100 \%$ de ferrita mais carboneto. Foi confirmado que o carboneto $\mathrm{M}_{7} \mathrm{C}_{3}$ é $\mathrm{Cr}_{7} \mathrm{C}_{3}$, pelos parâmetros de rede de $\mathrm{Cr}_{7} \mathrm{C}_{3}$ $\left(a=7,0149 A^{\circ}, b=12,153 A^{\circ}, c=4,532 A^{\circ}\right)$.

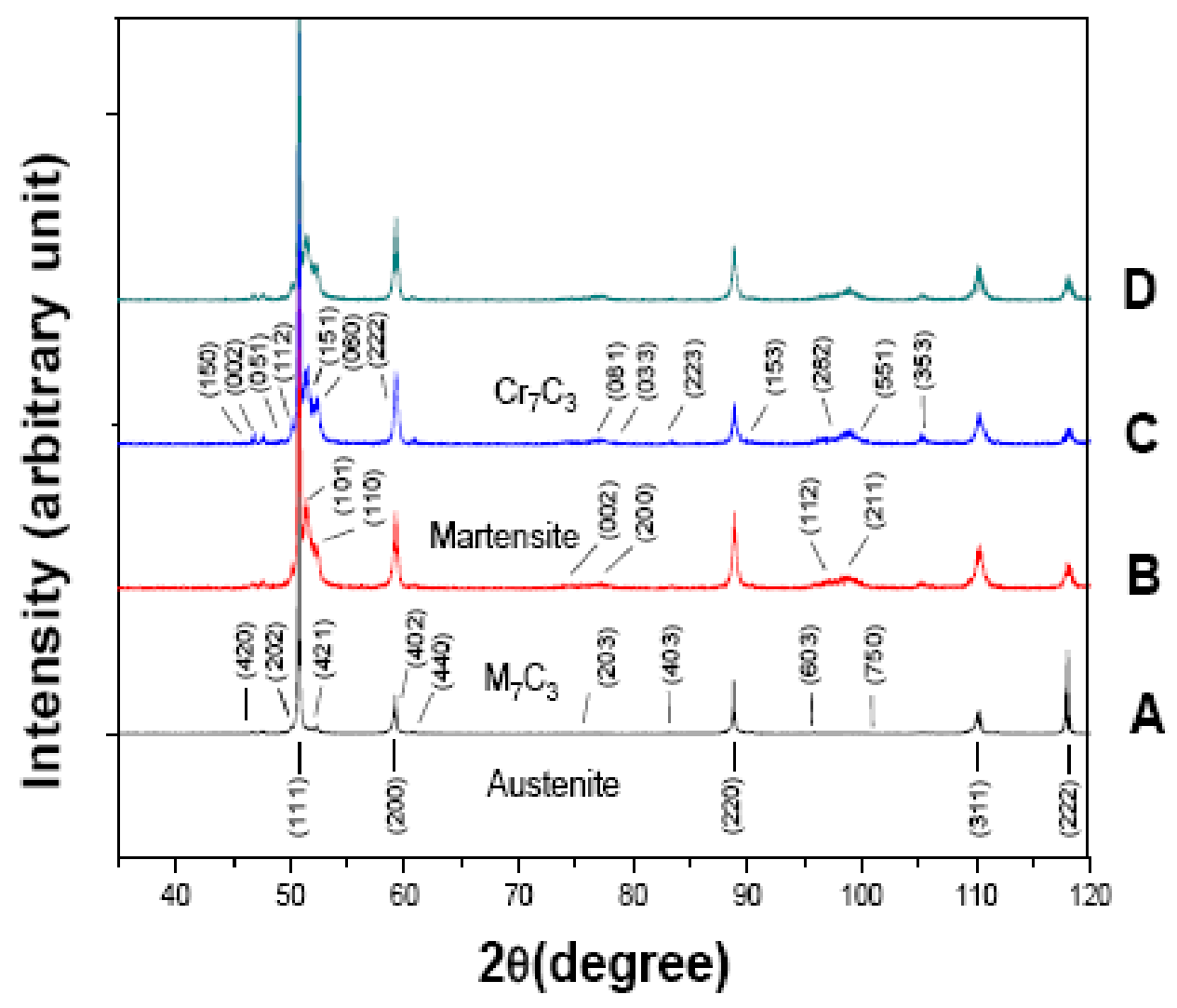

Figura 36 - Difração de Raios-X no aço AISI D2. 
Tabela 14 - Resultados de difração de raios-X no LNLS do aço AISI D2

\begin{tabular}{|c|c|c|c|c|c|c|c|c|c|c|}
\hline \multirow{2}{*}{ Amostra } & \multicolumn{4}{|c|}{ Martensita } & \multicolumn{2}{|c|}{ Austenita } & \multicolumn{4}{|c|}{ M7C3 } \\
\hline & a & c & $\mathbf{c} / \mathbf{a}$ & $\%$ & a & $\%$ & $\mathbf{a}$ & b & c & $\%$ \\
\hline Recozida & 2,872 & 2,869 & 0,9992 & 90,64 & 3,612 & 0,01 & 4,503 & 7,013 & 12,115 & 9,35 \\
\hline Temperada & 2,876 & 2,994 & 1,0411 & 14,50 & 3,620 & 83,73 & 4,514 & 7,042 & 12,126 & 1,75 \\
\hline$-196^{\circ} \mathrm{C} / 3 \mathrm{~h}$ & 2,875 & 2,956 & 1,0282 & 43,00 & 3,617 & 55,07 & 4,511 & 7,037 & 12,127 & 1,93 \\
\hline$-196^{\circ} \mathrm{C} / 10 \mathrm{~h}$ & 2,871 & 2,960 & 1,0312 & 45,87 & 3,616 & 52,23 & 4,507 & 7,054 & 12,110 & 1,91 \\
\hline$-196^{\circ} \mathrm{C} / 30 \mathrm{~h}$ & 2,873 & 2,956 & 1,0288 & 40,20 & 3,617 & 57,86 & 4,513 & 7,029 & 12,110 & 1,93 \\
\hline
\end{tabular}

\subsection{Resistividade elétrica}

Mudanças substanciais de resistividade elétrica ocorrem na transformação de austenita em martensita. A Figura 37 mostra a resistividade elétrica em função da temperatura medida para curvas de resfriamento e aquecimento do aço AISI D2 na faixa de temperaturas ( $77 \leq \mathrm{T} \leq 280 \mathrm{~K})$.

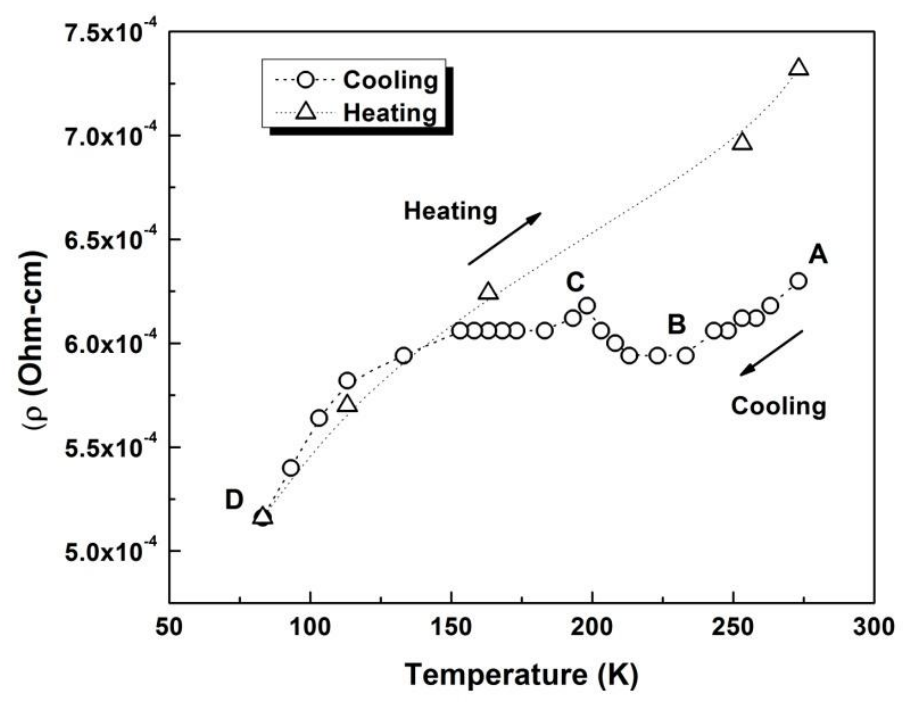

Figura 37 - Resistividade elétrica em função da temperatura. 
Este comportamento de resistividade observada pode ser divido em três regiões, como ilustrado na Figura 37. Região $A B$, uma queda inicial, pequeno e rápido na resistividade; Região $B C$, um aumento de um pico e subseqüente diminuição; e Região $C D$ uma continuação da diminuição, a uma taxa progressivamente mais lenta, a uma queda rápida total a $77 \mathrm{~K}$. Na Região $A B$ a resistividade diminui bem abaixo da inicial à temperatura ambiente e o fim desta etapa é associado com o início da transformação da austenita em martensita para esta liga. A região BC, caracterizada por aumento da resistividade do material, atingindo um pico nas proximidades de $200 \mathrm{~K}$ é onde está acontecendo a maior parte da transformação. De acordo a Taylor e Cohen (1992), podem estar ocorrendo ainda alterações relacionadas à segregação de átomos de carbono para os defeitos da rede (discordâncias e sub-contornos), bem como a formação de clusters em $\mathrm{C}$, o que aumenta a resistividade. $O$ aumento da resistividade para atingir o ponto máximo ocorre aproximadamente entre a faixa de temperatura de 190 até $230 \mathrm{~K}$; finalmente a região $C D$ corresponde a uma diminuição totalmente reversível da resistividade com a temperatura. A Figura 37 mostra também que a dependência da resistividade térmica com a temperatura foi uniforme, atingindo ao final do ciclo uma maior resistividade à temperatura ambiente do que no início. A variação de resistividade a temperatura ambiente foi de aproximadamente de $16 \%$.

Estes resultados pareceram um pouco diferente do relatado na literatura para outras martensitas; para verificar se este efeito não era produto do artefato, foram feitos também medidas de resistividade com controle de parâmetros de temperatura e vácuo das amostras do aço AISI D2 e da liga Fe-Ni-C, utilizando um criostato de tipo "dedo frio", com velocidade de resfriamento de $5 \mathrm{~K} / \mathrm{min}$, no laboratório do grupo de transições de fase e supercondutividade do IF-USP. Os resultados estão nas Figura 38 a Figura 40 para o aço AISI D2 e Figura 41 para a liga Fe-Ni-C. 
AISI D2:

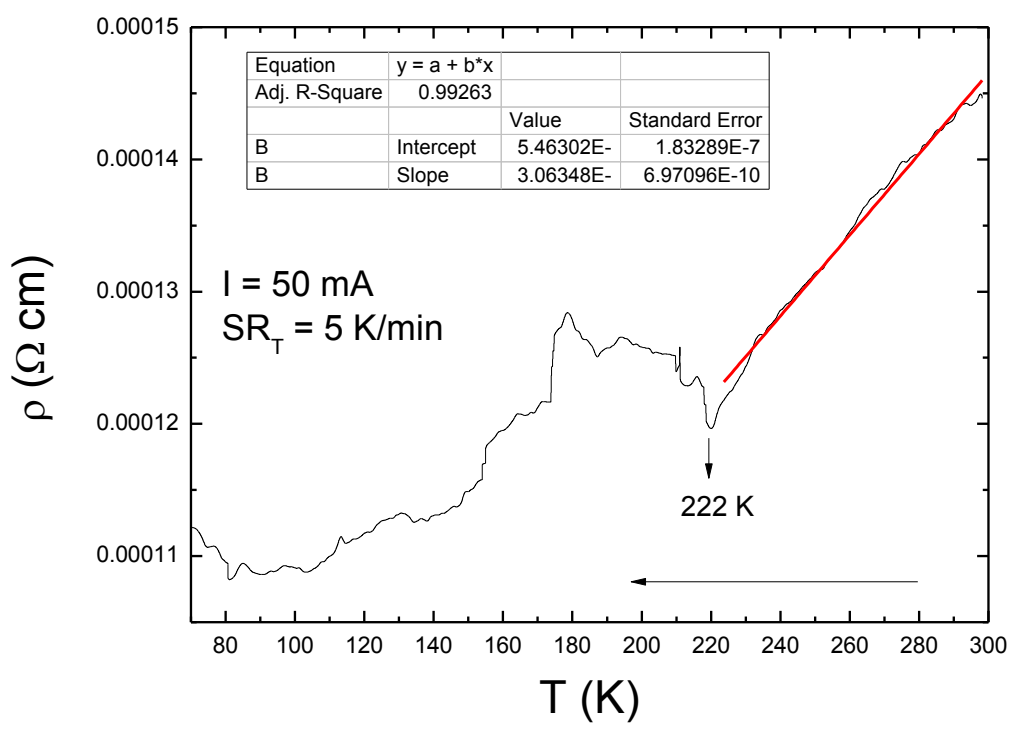

Figura 38 - Resistividade elétrica no dedo frio no ciclo de resfriamento.

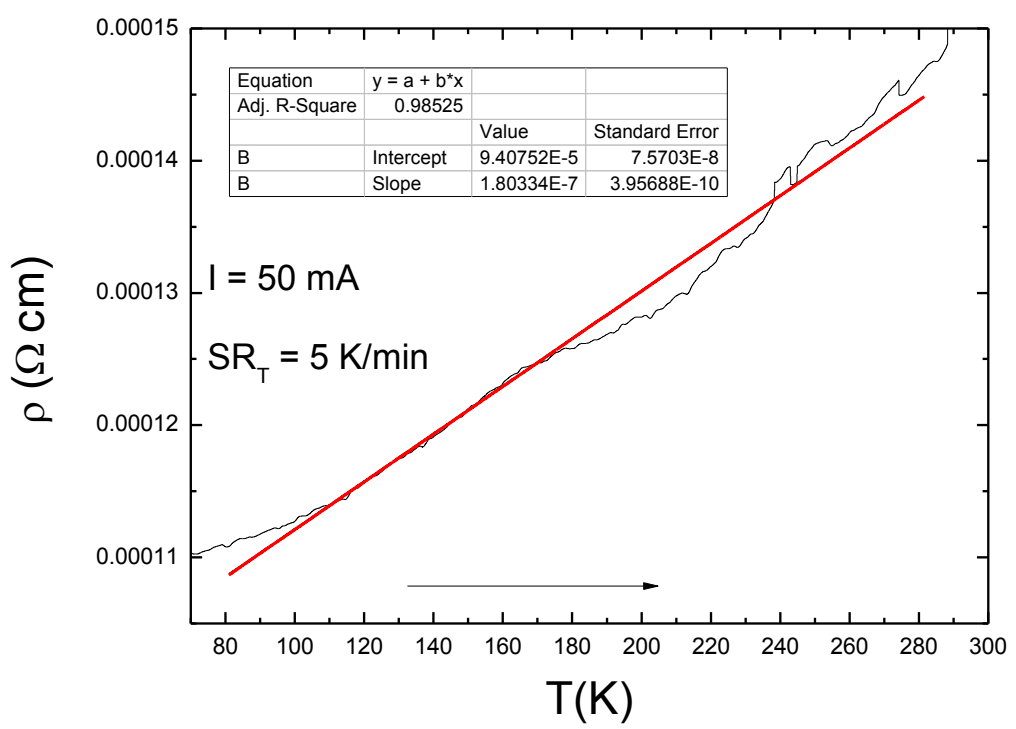

Figura 39 - Resistividade elétrica no dedo frio no ciclo de aquecimento. 

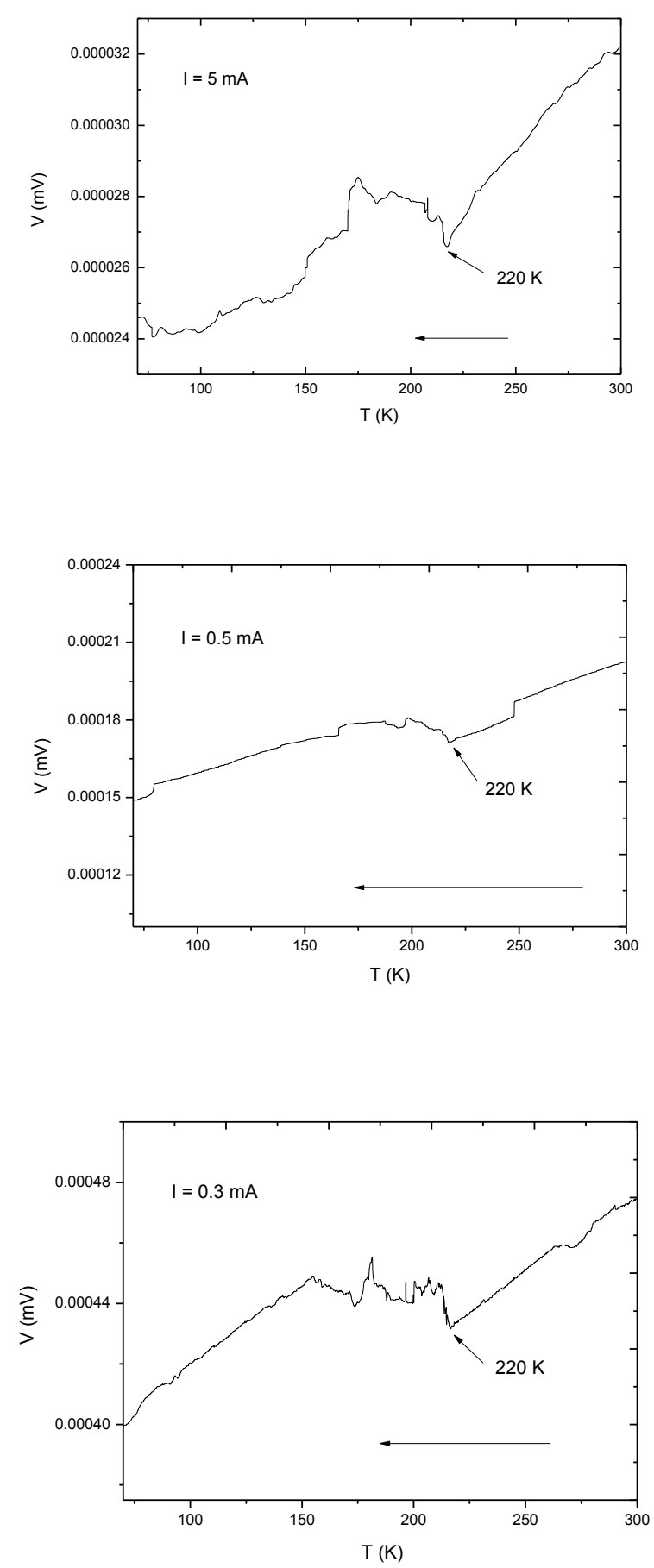

Figura 40 - Resistividade elétrica com variação de corrente.

Onde é confirmado que o aço AISI D2 apresenta a anomalia da resistividade elétrica na transformação martensítica, que apresenta um aquecimento que é pouco comum na transformação. 
Fe-Ni-C

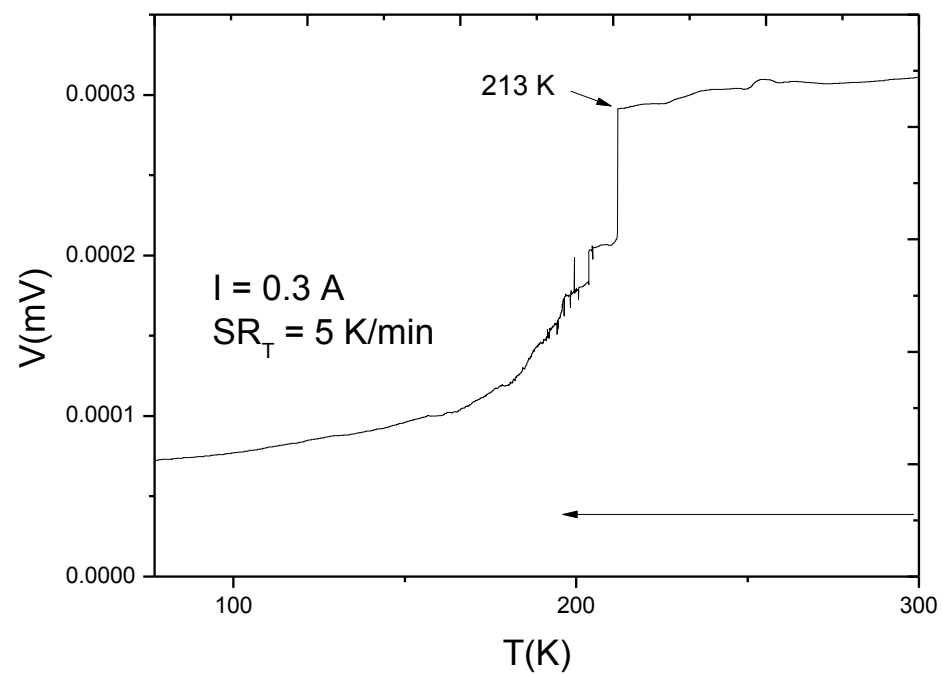

Figura 41 - Resistividade elétrica na liga Fe-Ni-C no ciclo de resfriamento.

A resistividade na liga $\mathrm{Fe}-\mathrm{Ni}-\mathrm{C}$ apresenta um comportamento típico da transformação martensítica, com queda considerável da resistividade, associada à transformação. 


\subsection{Ruído de Barkhausen}

\subsubsection{Ruído de Barkhausen no decorrer da temperatura}

As medidas de ruído de Barkhausen MBN foram feitas com o seguinte arranjo experimental (como também para a resistividade elétrica), onde foi controlado a temperatura de resfriamento e aquecimento (no forno / câmara criogênica GRION).

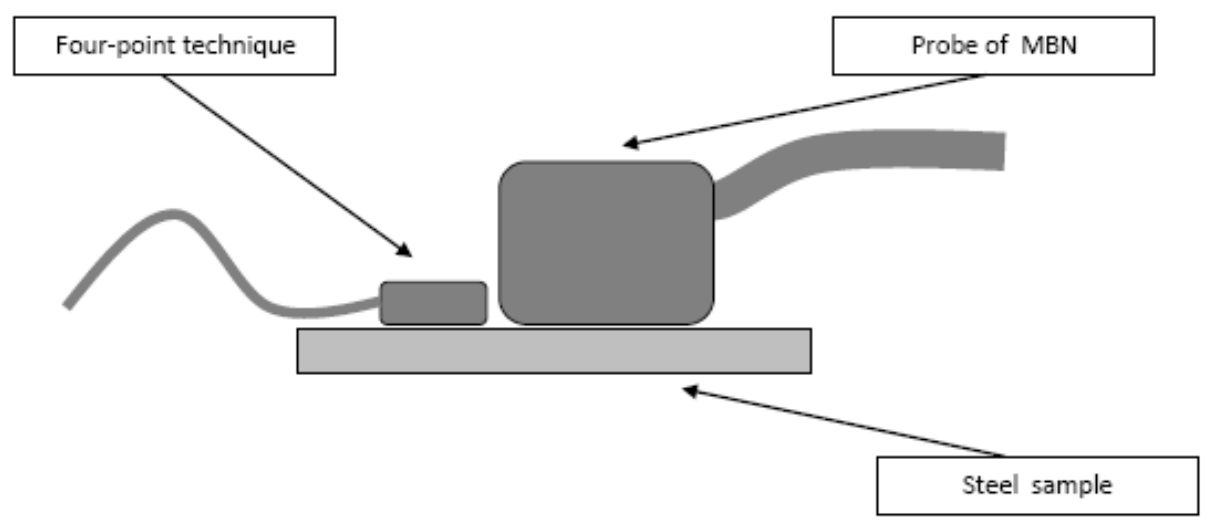

Figura 42 - Arranjo experimental para o Barkhausen e resistividade em função da temperatura.

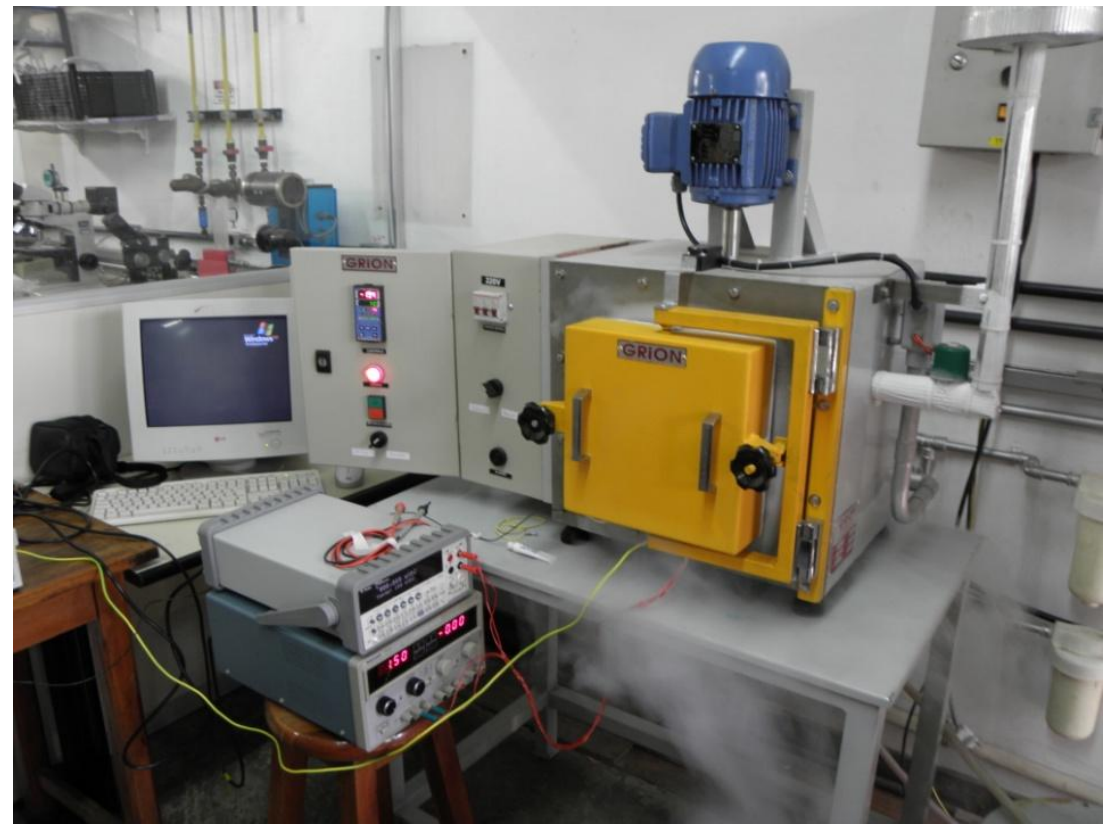

Figura 43 - Forno / câmara criogênica GRION. 
Mostrando os seguintes sinais típicos de Barkhausen medidos em quatro temperaturas diferentes durante o resfriamento (280K, $220 \mathrm{~K}, 200 \mathrm{~K}$ e $77 \mathrm{~K})$.
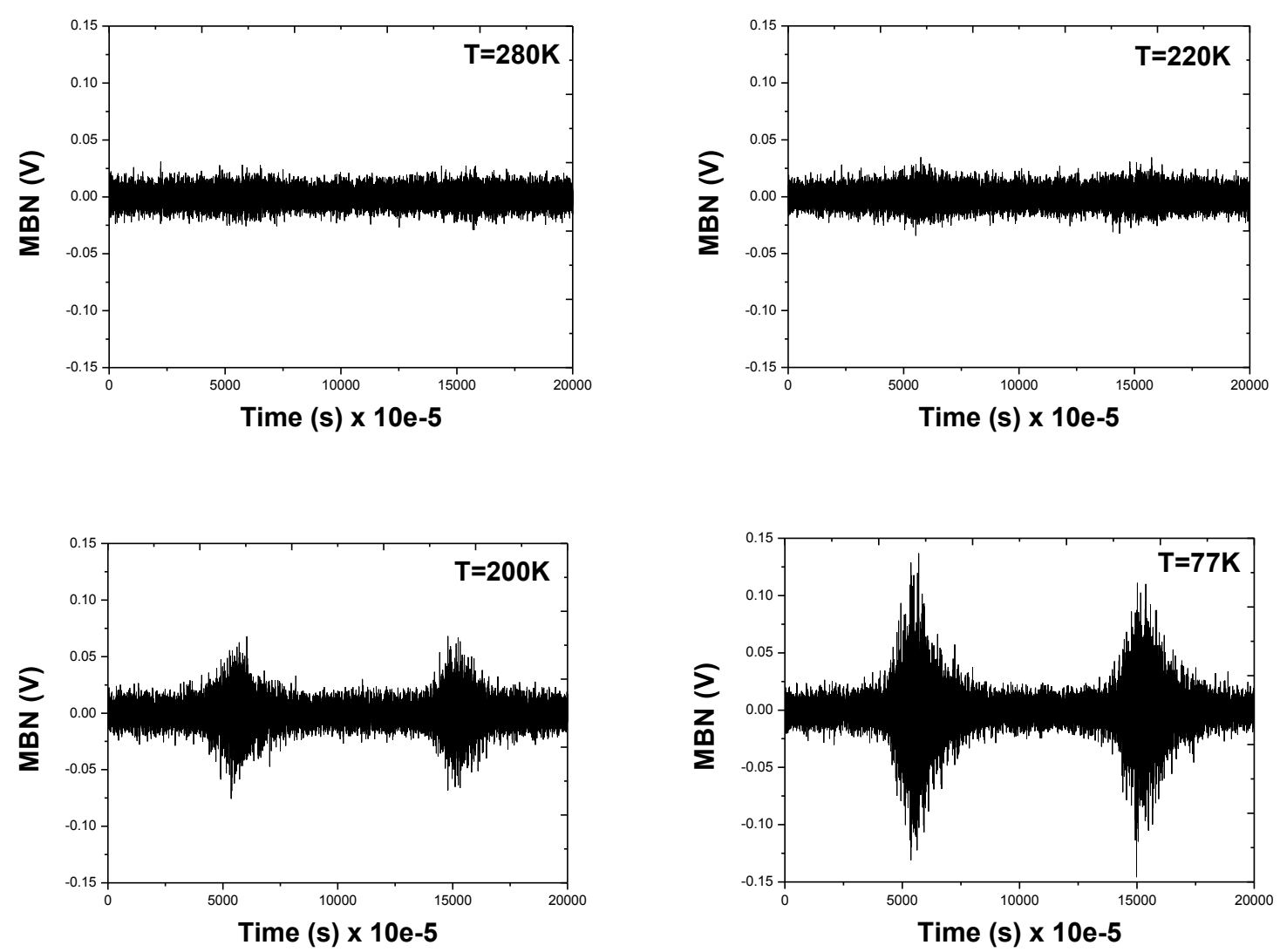

Figura 44 - Ruído de Barkhausen medido em quatro temperaturas durante o resfriamento da amostra.

Distribuição de probabilidades nas 4 temperaturas (280K, 220K, 200K e 77K).
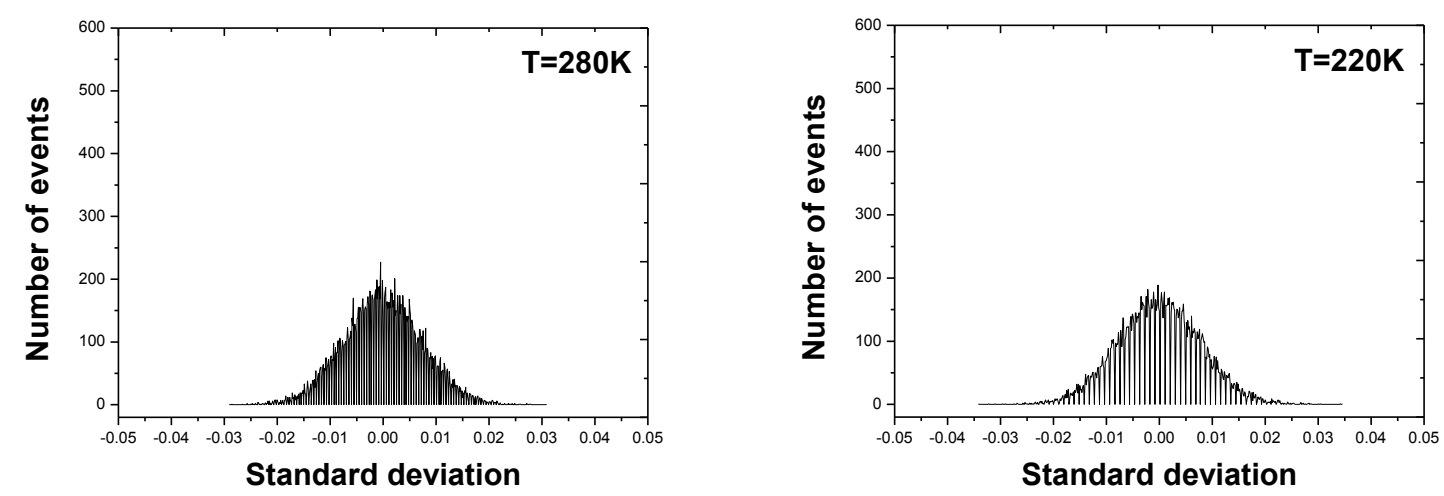

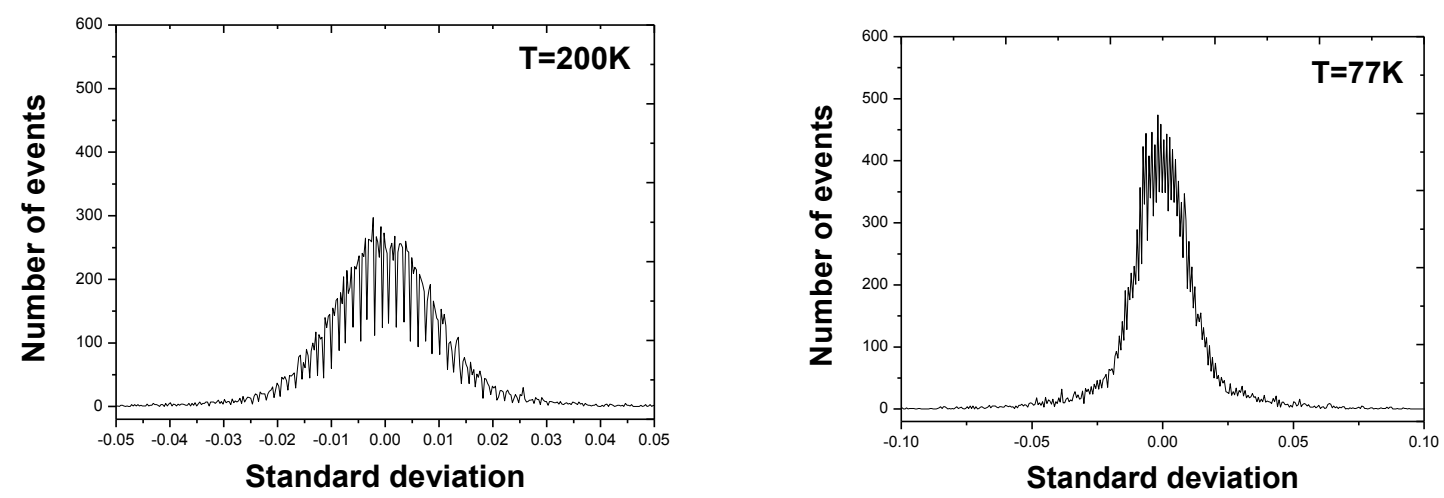

Figura 45 - Distribuição de probabilidades de MBN em 4 temperaturas durante o resfriamento do AISI D2.

As Figura $45 \mathrm{a} \mathrm{e} \mathrm{b}$ apresentam aproximadamente a mesma distribuição de eventos ocasionados pela modulação do campo magnético aplicado na medição do MBN. A partir da Figura $45 \mathrm{c}$ é observado um aumento notável da magnitude dos eventos associado à transformação martensítica. Finalmente a Figura 45d, obtida para uma temperatura de $77 \mathrm{~K}$, mostra a transformação estrutural praticamente completa em correspondência com o máximo do RMS de MBN.

Esta geração de ruído magnético devido à transformação não seria somente devida ao campo magnético externo aplicado, mas também aos efeitos do resfriamento provocando transformação da austenita em martensita. Esta hipótese foi subseqüentemente testada usando inicialmente a técnica de Okamura (com campo magnético $\mathrm{CC}$ ) e sem nenhum campo externo aplicado.

A voltagem RMS de MBN em função da temperatura para o aço AISI D2 temperado a $1200^{\circ} \mathrm{C}$ é mostrado na Figura 46 na faixa de temperatura ( $77 \leq \mathrm{T} \leq 280 \mathrm{~K}$ ). Primeiro a amostra foi lentamente resfriada até $77 \mathrm{~K}$ e depois foi lentamente aquecida até $280 \mathrm{~K}$. A curva de resfriamento apresenta um grande salto, indicando a transformação de austenita para martensita (Ms) na temperatura aproximada de transformação $\mathrm{Ms} \approx 230 \mathrm{~K}$. Após a transformação, o sinal de MBN aumenta perto de $11 \%$. O aumento no sinal de MBN é causado pelo surgimento da fase martensita magnética. Na restante da curva não há outra transformação até $77 \mathrm{~K}$. Na curva de aquecimento observou-se dependência uniforme de temperatura. A variação total de 
MBN após o ciclo de resfriamento e aquecimento de volta até temperatura ambiente foi de aproximadamente $100 \%$.

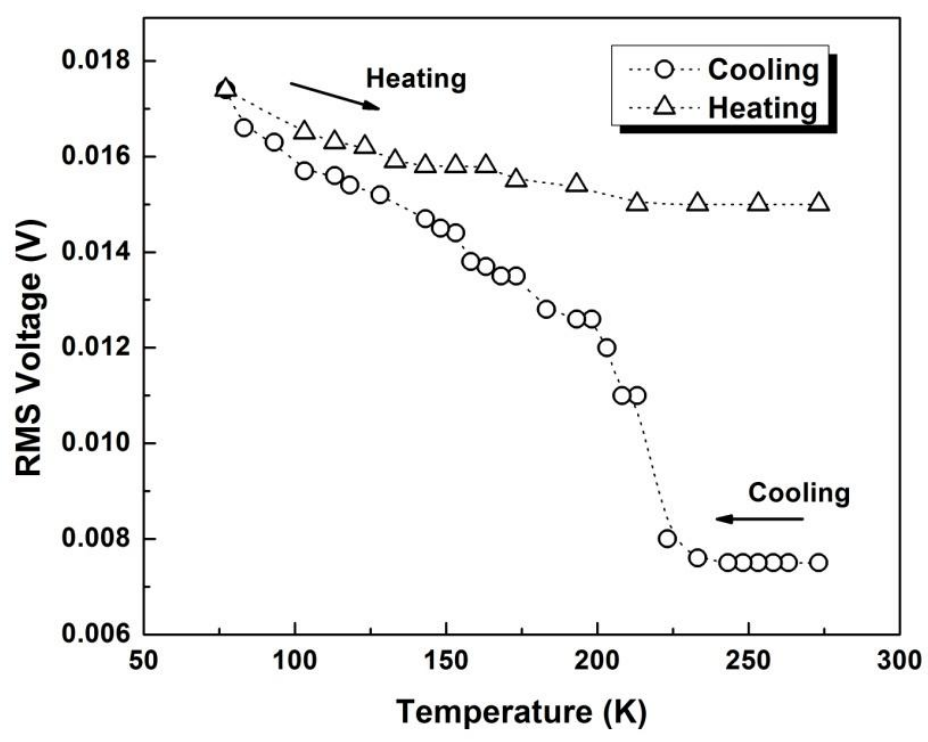

Figura 46 - RMS do ruído de Barkhausen medido em diferentes temperaturas durante o resfriamento da amostra.

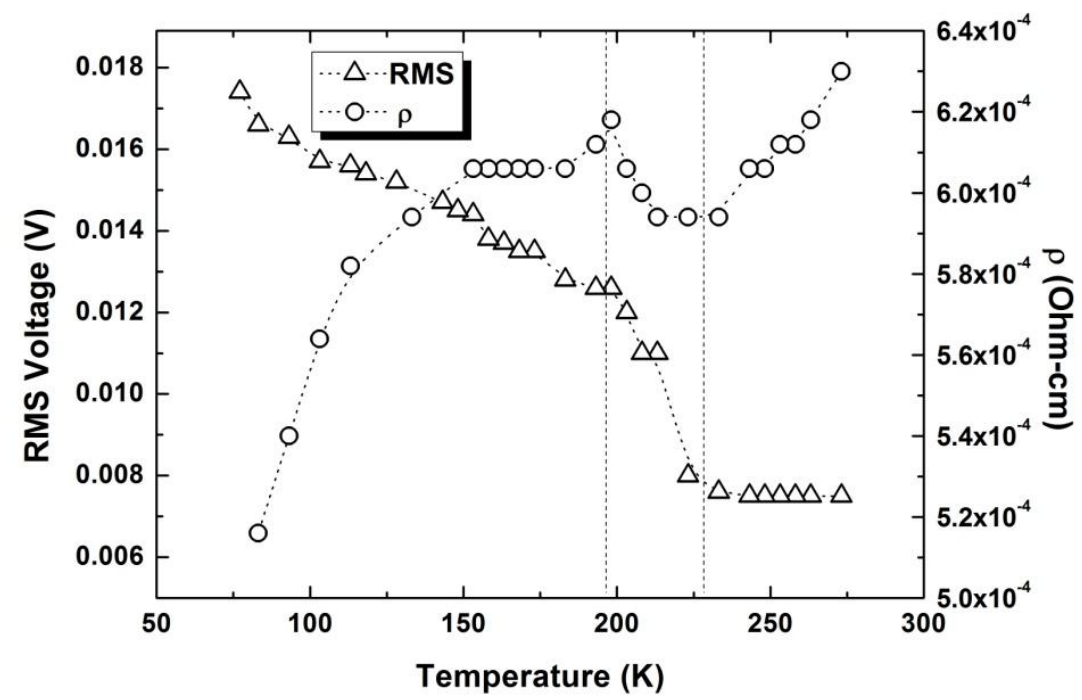

Figura 47 - Resistividade elétrica e emissão de sinal magnético medido em diferentes temperaturas durante o resfriamento da amostra. 
As mudanças de resistividade elétrica e MBN da amostra durante o resfriamento são resumidas na Figura 47, mostrando coincidência da faixa de temperatura em que ocorrem comportamentos descontínuos em ambos sinais: resistividade elétrica e voltagem de RMS, fornecendo uma estimativa da temperatura Ms em torno de 230K, e um intervalo de máxima atividade de MBN entre $230 \mathrm{~K}$ e $180 \mathrm{~K}$.

\subsubsection{Ruído de Barkhausen no decorrer do tempo}

Utilizou-se o seguinte arranjo experimental para o Barkhausen, submergido no Dewar com nitrogênio liquido por aproximadamente 40 minutos:

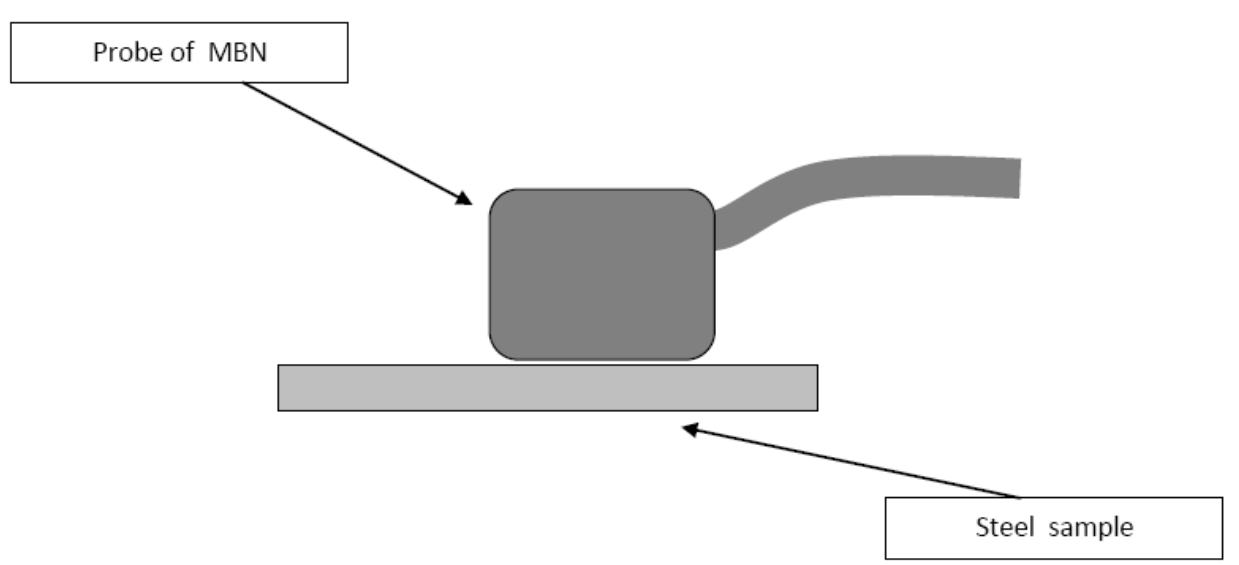

Figura 48 - Arranjo experimental para o Barkhausen no decorrer do tempo. 
Mostrando os seguintes resultados:

Sinais típicos de Barkhausen testados a 6 tempos (2s, 20s, 60s, 80s, 180s e 360s)
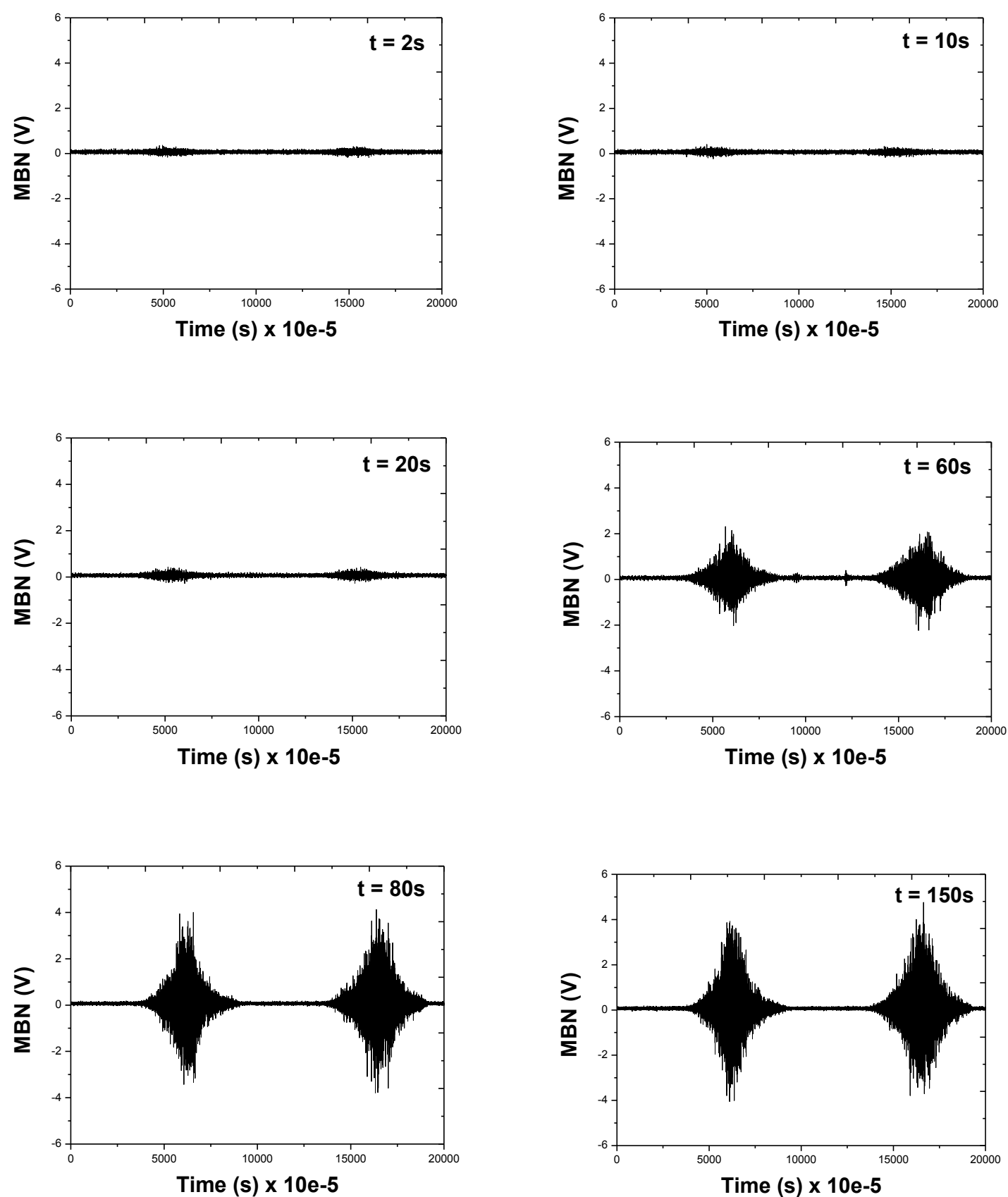

Figura 49 - Sinais típicos de Barkhausen com decorrer do tempo. 
Distribuição de probabilidades nos 6 tempos durante o resfriamento.
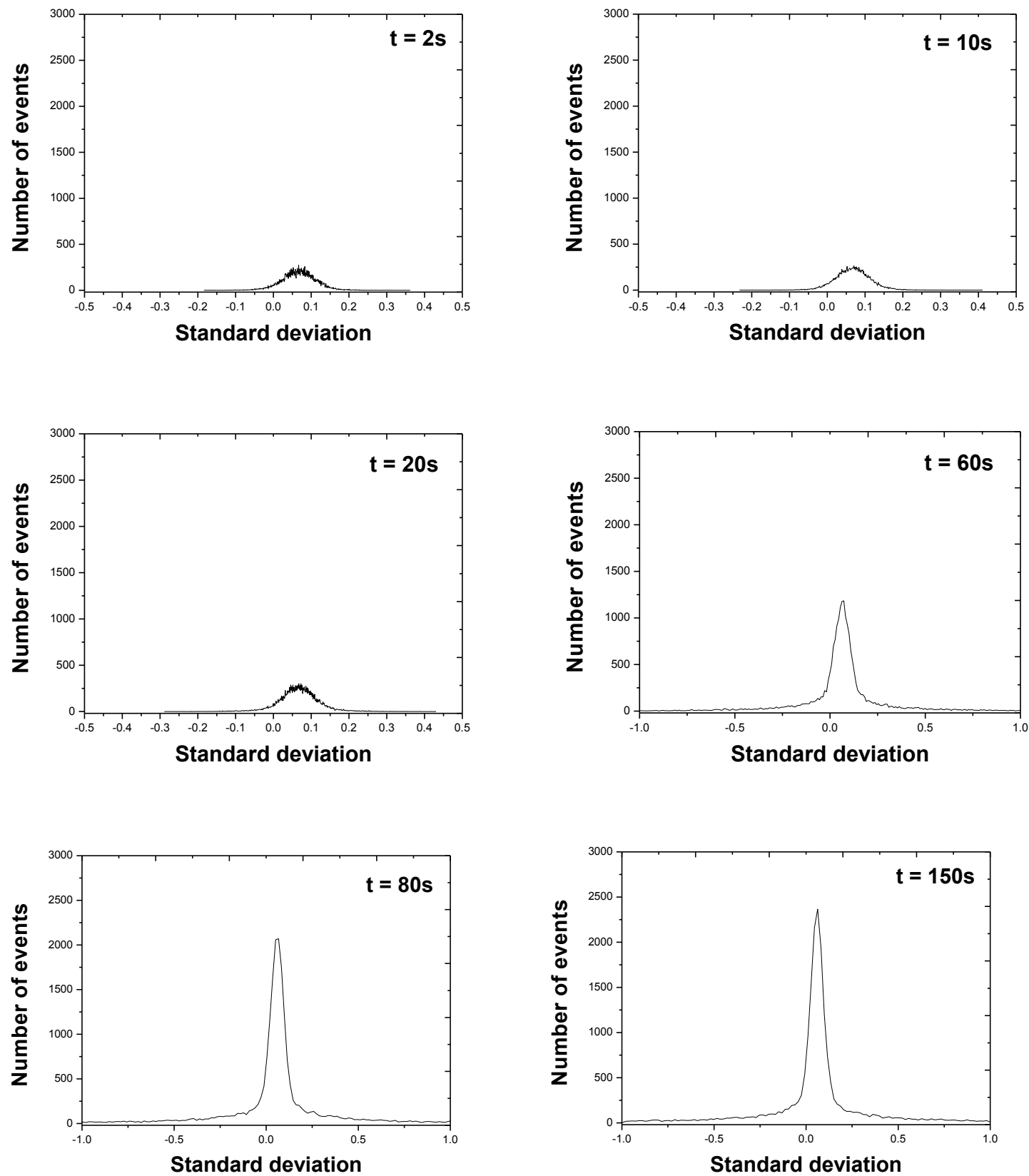

Figura 50 - Distribuição de probabilidades com o tempo. 
Para uma melhor percepção do que acontece na transformação se fez uma ampliação para ver detalhes da variação do MBN com respeito ao tempo (Figura 51), observando-se uma mudança abrupta aproximadamente aos 60 segundos. Os eventos predominantes foram na faixa de 40 até 80 segundos, após o que ocorreu pouca variação até atingir a estabilização do MBN. Na ampliação é observado claramente uma região de picos magnéticos provavelmente devido à transformação martensítica. No AISI D2, temos que ter presente que o sensor de bobina capta ao mesmo tempo a MBN induzida assim como qualquer outra variação de fluxo magnético presente no material. Motivo que ao inicio das medições a magnitude de MBN é pequena correspondente da fase austenítica, e depois é muito maior, evidenciando a presença de uma forte fase magnética correspondente à martensita.
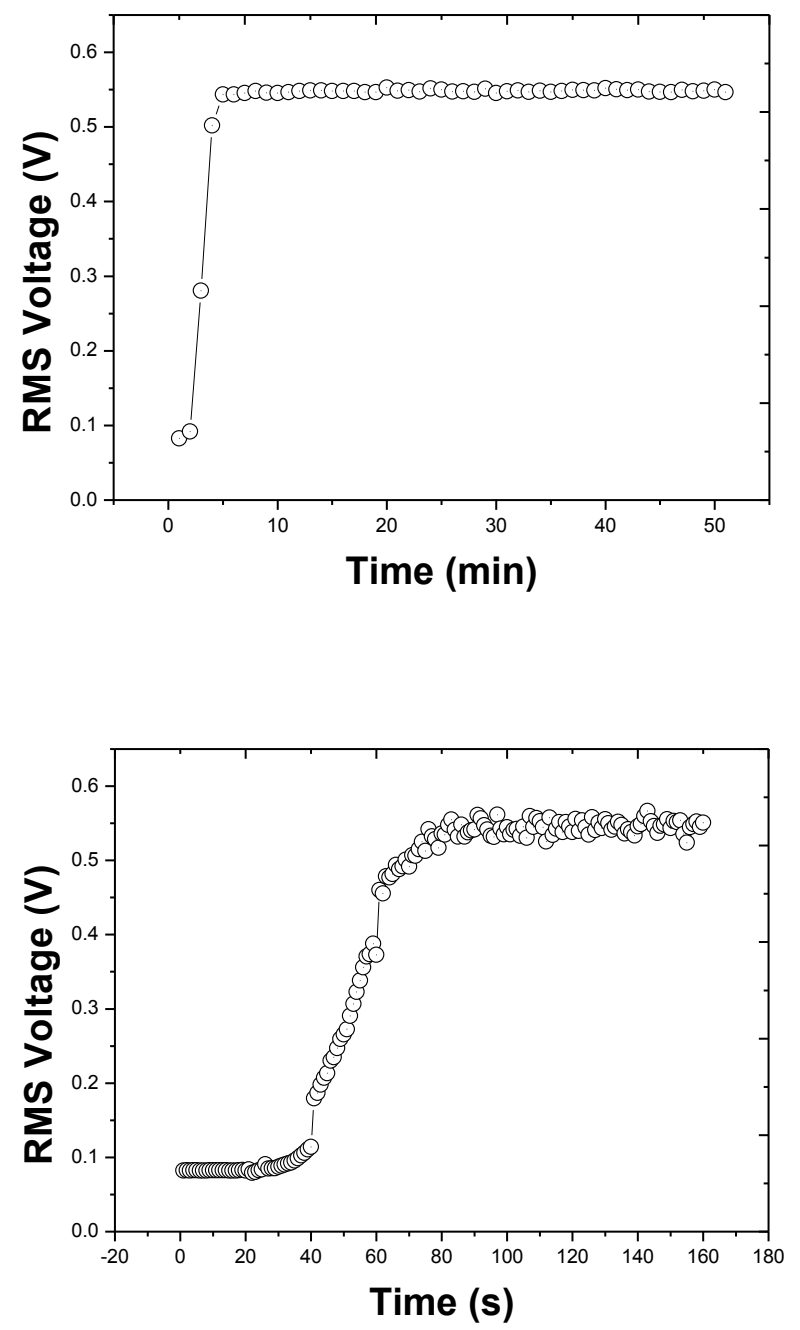

Figura 51 - Dependência do MBN (RMS Voltagem) em função do tempo. 
O mesmo procedimento foi feito na liga invar $\mathrm{Fe}-\mathrm{Ni}-\mathrm{C}$, com as medições iniciadas no mesmo instante em que a amostra foi introduzida no nitrogênio liquido, realizando-se continuamente medições até os 80 segundos.

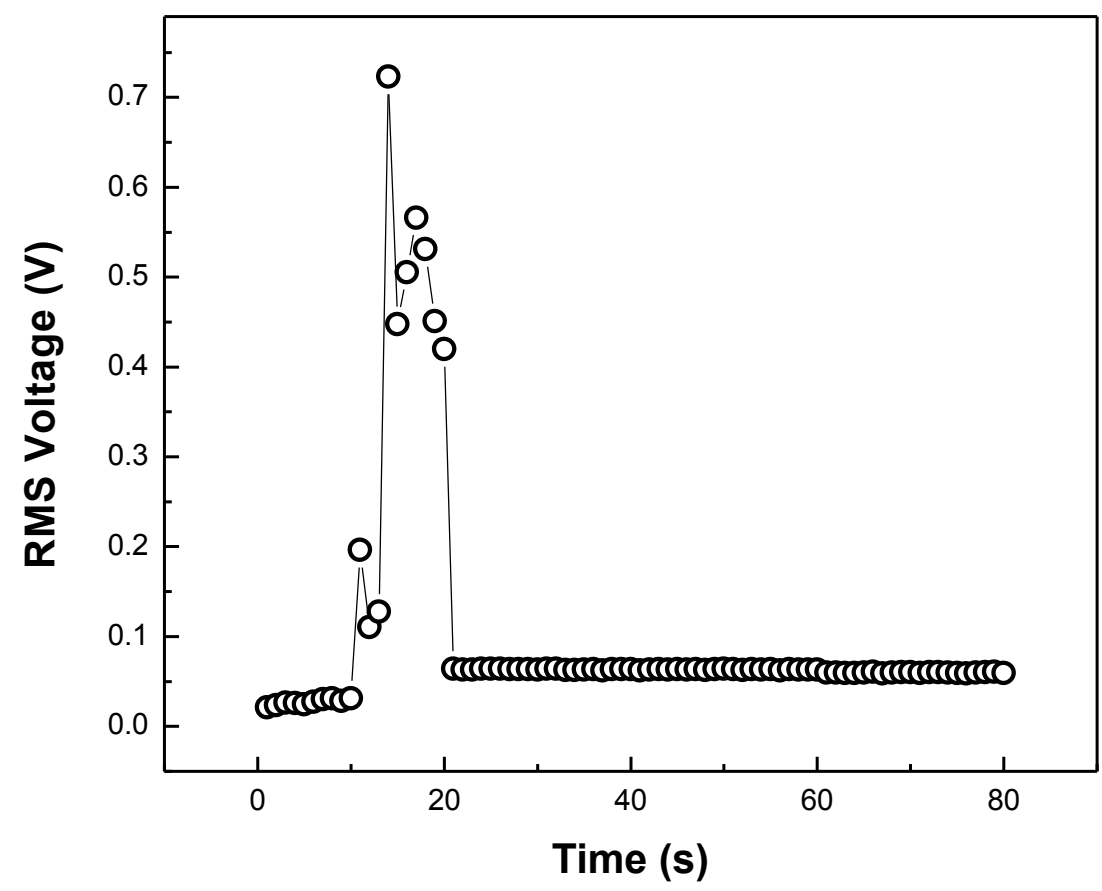

Figura 52 - Dependência do MBN (RMS Voltagem) em função do tempo, mostrando os picos magnéticos devido à transformação martensítica na liga Fe-Ni-C.

O resultado mostra claramente um forte sinal presente durante o resfriamento, que deixa de ser medido quando a transformação atinge uma estabilidade final. Note-se que a austenita do Fe-Ni-C também é ferromagnética, o que faz com que seja pequena a diferença do sinal RMS no início (perto da temperatura ambiente) e ao fim (perto da temperatura do nitrogênio liquido), e realça a diferença do sinal durante o resfriamento, correspondente a uma emissão espontânea. 
A Figura 53 mostra sinais típicos de MBN para a Liga Fe-Ni-C, medidos em quatro diferentes temperaturas durante o resfriamento, segundo os resultados anteriores.
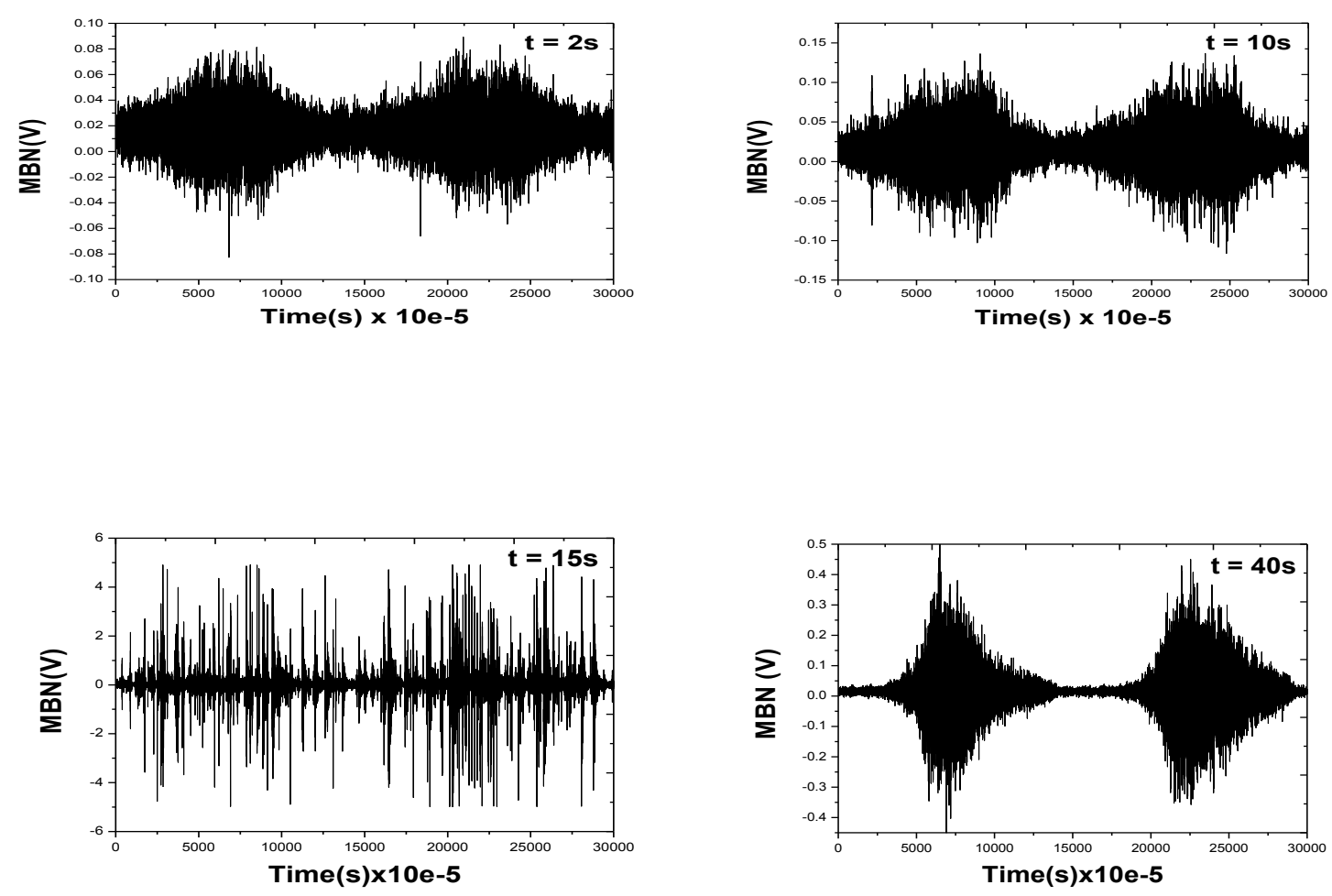

Figura 53 - Ruído de Barkhausen medido durante a transformação martensítica.

São mostrados os histogramas durante o transcurso da medição do ensaio, mostrando a distribuição de probabilidades de picos de MBN calculadas para diversos tempos acompanhando a transformação martensítica, segundo os resultados anteriores: 


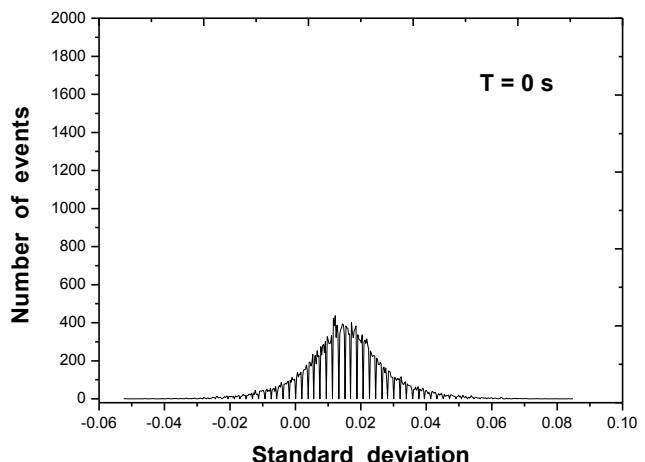

a

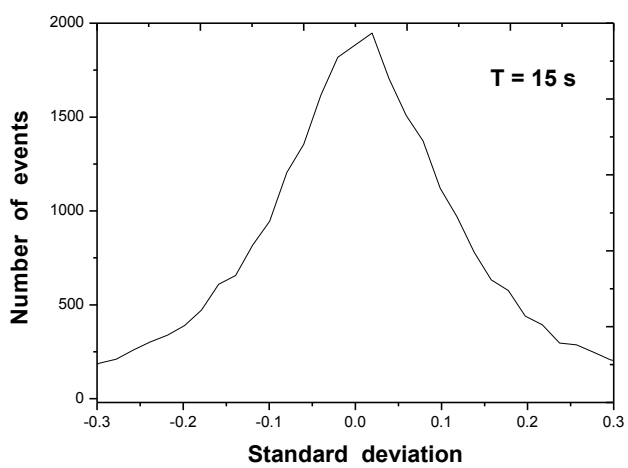

C

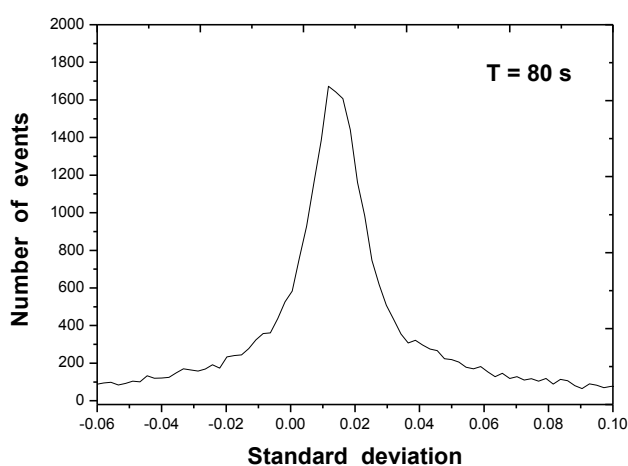

e

Figura 54 - Distribuição de probabilidades da quantidade de eventos MBN no tempo.

A Figura 54a apresenta uma distribuição antes de que o material seja submergido em nitrogênio liquido, a Figura 54b apresenta um aumento de eventos ocasionado 
pela transformação assim como também produto do resfriamento do material em todo o intervalo do tempo, a partir da Figura 54c é observada um aumento notável da magnitude dos eventos associados à transformação martensítica. Finalmente a partir das Figura $54 \mathrm{~d}$ - e é mostrado à transformação estrutural praticamente completa em correspondência com o máximo do RMS de MBN.

\subsection{Emissão magnética espontânea (SME) por transformação de fase}

Em 1942, Okamura et al. (apud NISHIYAMA, 1978) acompanharam a transformação da austenita para a martensita, registrando a intensidade dos picos de magnetização usando a técnica de efeito de Barkhausen durante o resfriamento de uma liga austenítica sob um campo magnético fixo e constante de 550 Oe. A Figura 55 mostra o dispositivo experimental usado para reproduzir o experimento de Okamura et al. e registra avalanches magnéticas causadas pelo movimento magnético das paredes de domínio durante a transformação martensítica. Foram utilizados ímãs permanentes Nd2Fe14B, com dimensões de $3.75 \mathrm{~mm} \times 5.75 \mathrm{~mm} \times 12 \mathrm{~mm}$ que foram dispostos em dois blocos, cada um composto de três ímãs empilhados, o que corresponde a uma indução magnética de $0.44 \mathrm{~T}$. O circuito magnético foi fechada usando uma barra de FeSi. O sinal de MBN foi detectado por uma bobina de captação (1000 voltas de fio de Cu 44AGW), colocado perpendicularmente sob amostra.

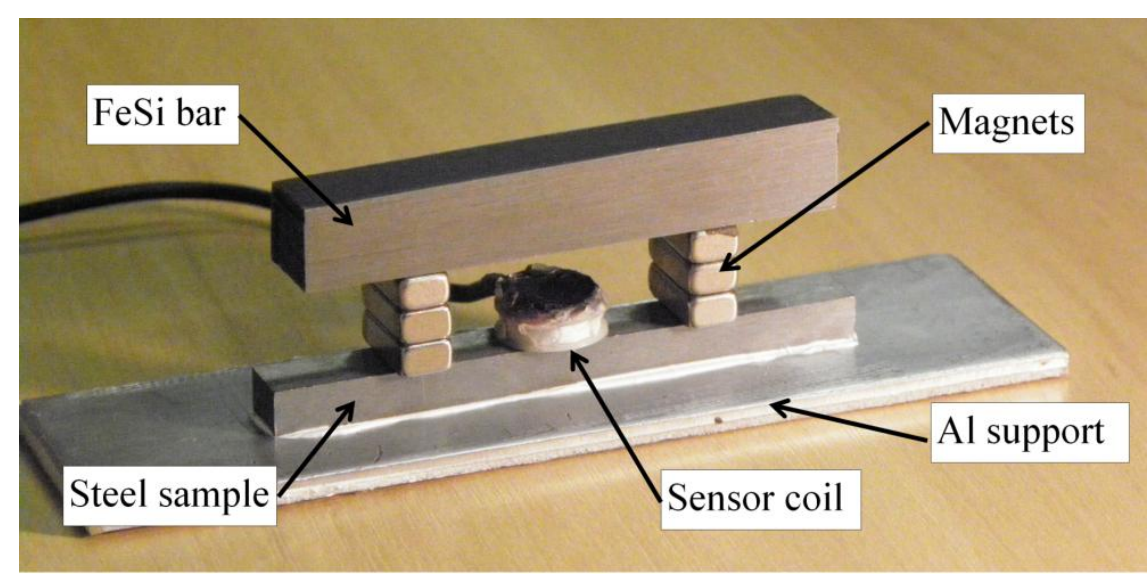

Figura 55 - Fotografia do arranjo experimental usado para reproduzir o experimento de Okamura apud Nishiyama (1978). 
sinal magnética de saída foi amplificado por o dispositivo BarkTech e enviados para uma laptop. A câmara fotográfica registrou a tela do PC, mostrando avalanches magnéticas que ocorreram no material, enquanto toda a instalação foi resfriada num Dewar contendo nitrogênio liquido.
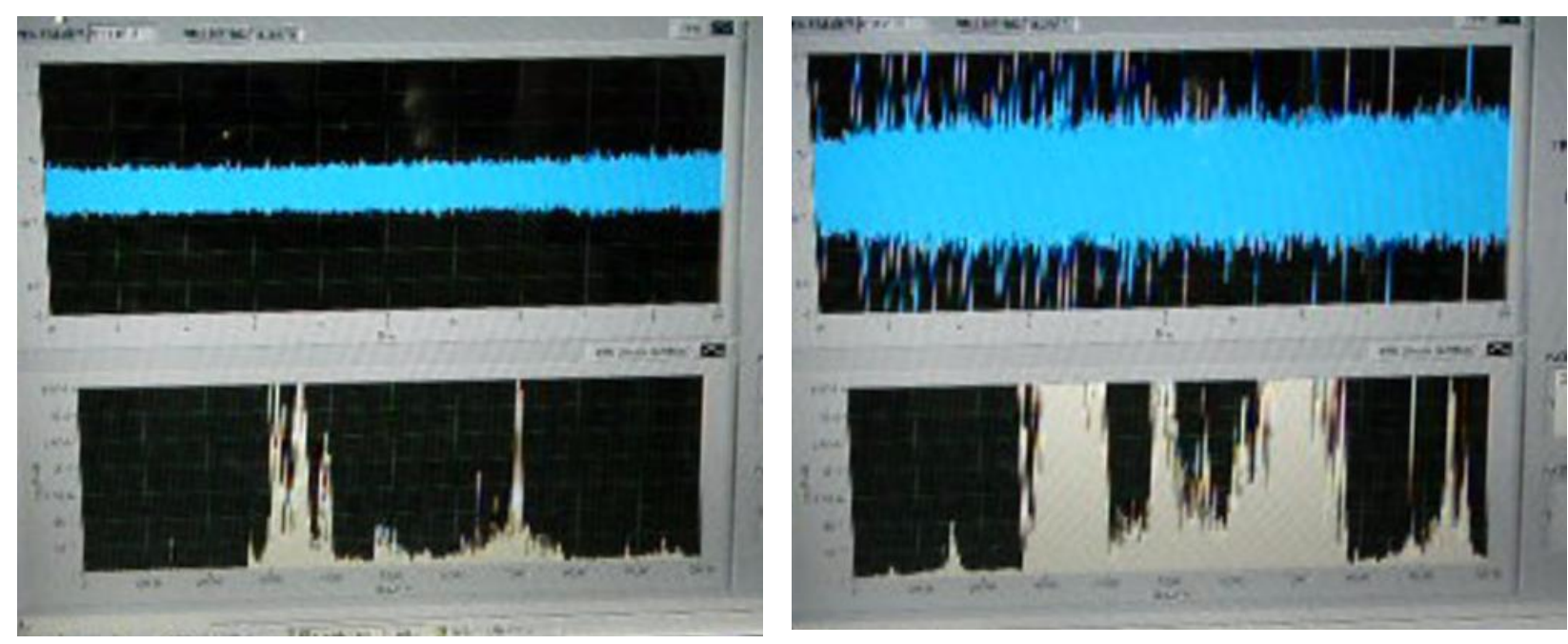

Figura 56 - (a) registro fotográfico do ruído captado pelo pick-up antes do resfriamento da amostra. Fig. 8 (b) sinal de ruído durante o resfriamento, os picos correspondem a avalanches magnéticas, devido ao movimento de paredes de Bloch. A variação do espectro do ruído pode ser observado na parte inferior da figura.

Reproduzindo o experimento de Okamura especulou-se que poderia haver emissão de ruído magnético espontâneo durante a migração da interface de martensita/austenita, sem nenhum campo magnético externo aplicado. A idéia era que o movimento das paredes de Bloch, poderia desencadear sinais magnéticos espontaneamente durante a nucleação e crescimento de domínios de Weiss, acompanhando o crescimento das placas de martensita. De mesma forma, esta hipótese poderia explicar o resultado inesperado encontrado ao medir MBN em $\mathrm{Fe}$ $\mathrm{Ni}-\mathrm{C}$ durante o resfriamento, Figura 52 mostrando alta intensidade de ruído durante o resfriamento. Para testar esta hipótese, foi utilizado um arranjo experimental similar ao utilizado para medir MBN convencional, sem nenhum campo magnético externo aplicado, conforme descrito no diagrama da Figura 57. 


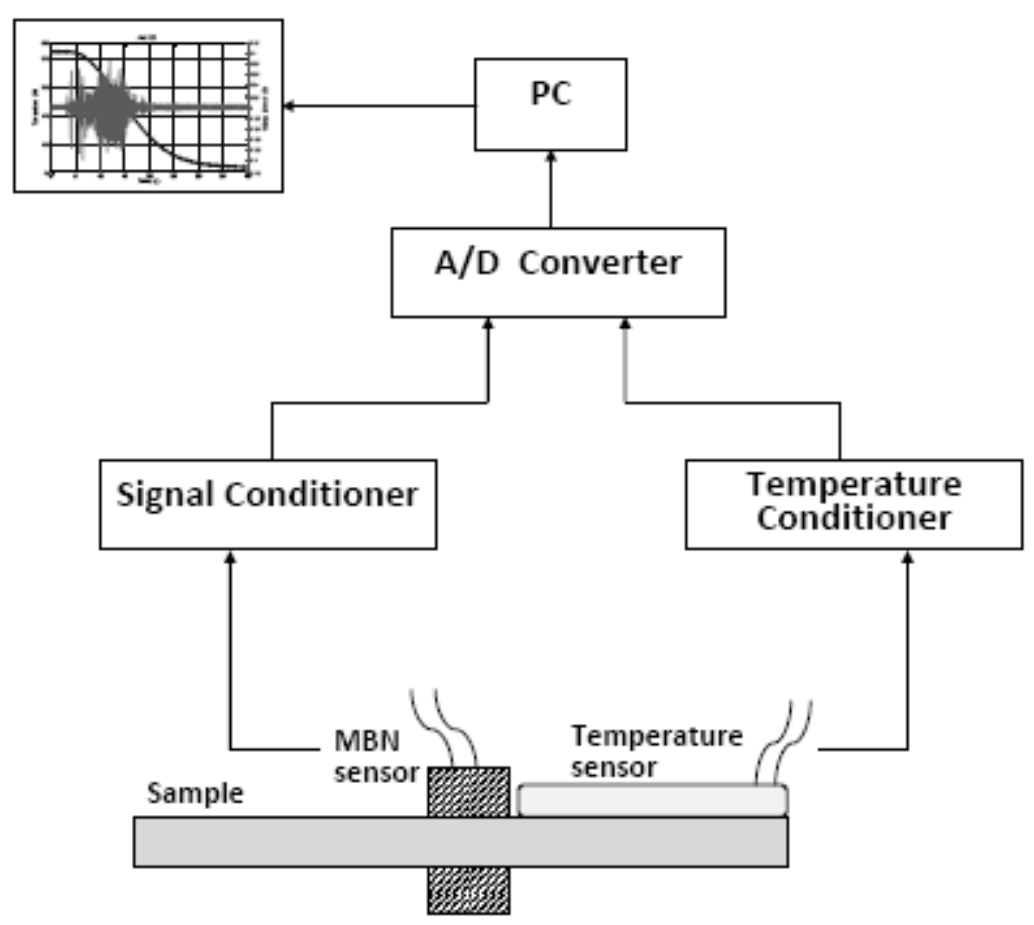

Figura 57 - Diagrama do esquema de medição da Emissão Magnética Espontânea (SME).

O sistema de medição consistiu apenas em uma bobina de captação colocado na superfície da amostra, e seu condicionamento eletrônico (composto de uma bobina feita de um fio fino AWG 44 e 1000 voltas, que tem uma alta sensibilidade, permitindo registrar pequenas variações de voltagem, na Figura 58 é apresentado o arranjo experimental SME). A diferença do experimento de Okamura foi usada sem excitação magnética. O sinal de saída foi medido continuamente através do equipamento Barktech e registrado num computador. Com a ajuda do sensor de termorresistência PT-100, a temperatura na superfície do material foi registrada simultaneamente. A amostra, sensor magnético e de temperatura foram imersos em um Dewar com nitrogênio liquido. 


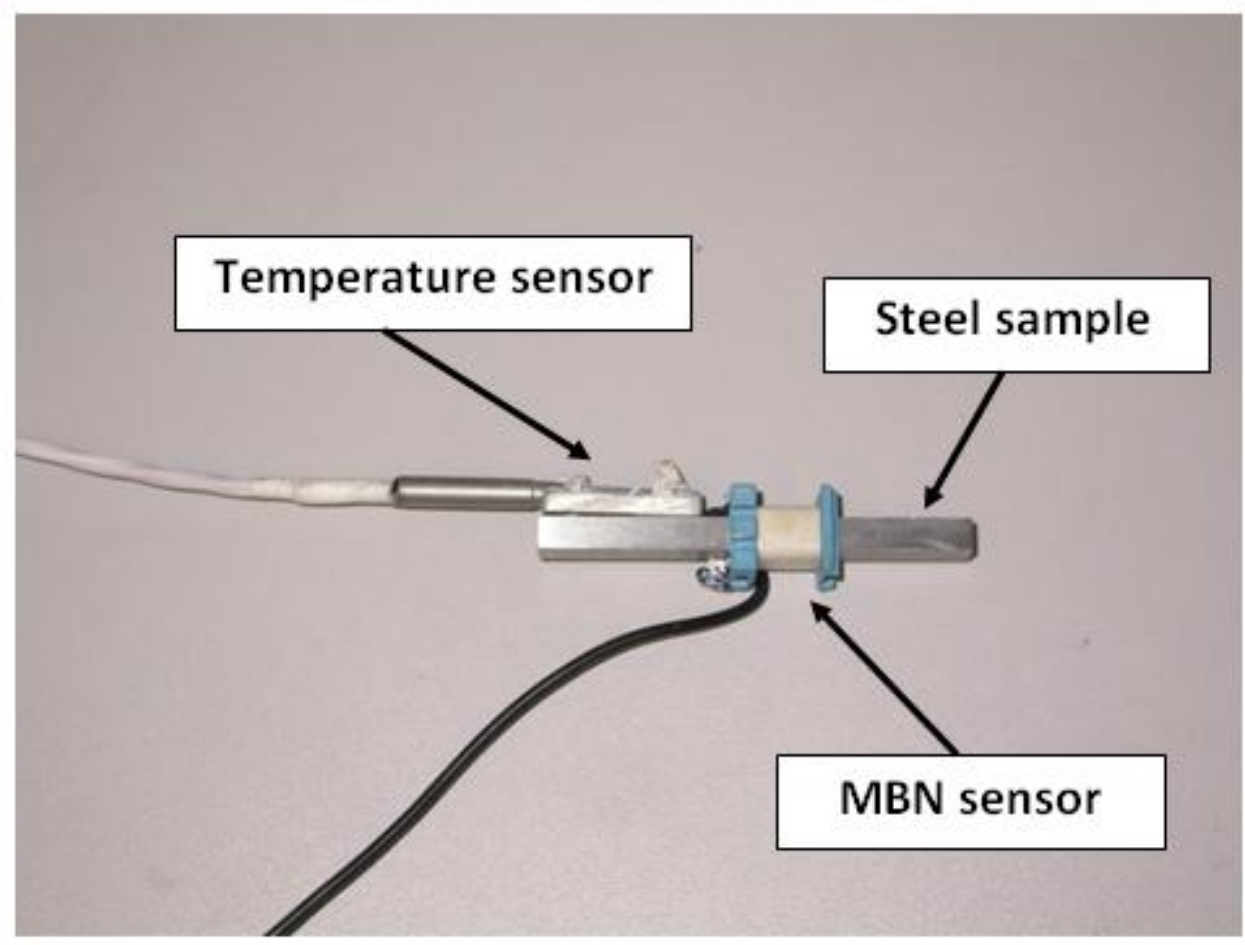

Figura 58 - Fotografia do arranjo experimental usado no SME.

A Figura 59 mostra picos da emissão magnética espontânea (SME), capturados durante o resfriamento da amostra de AISI D2. O SME corresponde às avalanches magnéticas provocadas pelo movimento das paredes de Bloch, cada evento relacionado ao crescimento de uma ou mais placas ou a um fenômeno de burst, uma avalanche de placas nucleadas por um fenômeno auto-catalitico. O início de atividade magnética com o resfriamento atinge um máximo de avalanches a $280 \mathrm{~K}$ e termina abaixo de $210 \mathrm{~K}$.

A fim de confirmar se este fenômeno não é um artefato produzido pela configuração particular do arranjo experimental, foram realizados dois experimentos: primeiro uma amostra que já havia sido resfriado à temperatura de $\mathrm{LN}_{2}$ e aquecida de novo à temperatura ambiente, foi resfriado novamente, não mostrando nenhum pico em todo o teste. Outro experimento foi realizado com amostras com elevado grau de pureza da liga ternaria Fe-Ni-C.

A liga, com $32,27 \% \mathrm{Ni}$ e $0,035 \% \mathrm{C}$, foi recozida a $750^{\circ} \mathrm{C}$ e temperada em água, apresentando-se 100\% austenítica mas uma austenita ferromagnética, como costuma ocorrer em ligas Invar. Os sinais SME obtidos a partir dessa amostra foram 
muito mais fortes que os obtidos com o aço AISI D2, e acompanhados por surpreendentemente alta emissão acústica (não registrada).
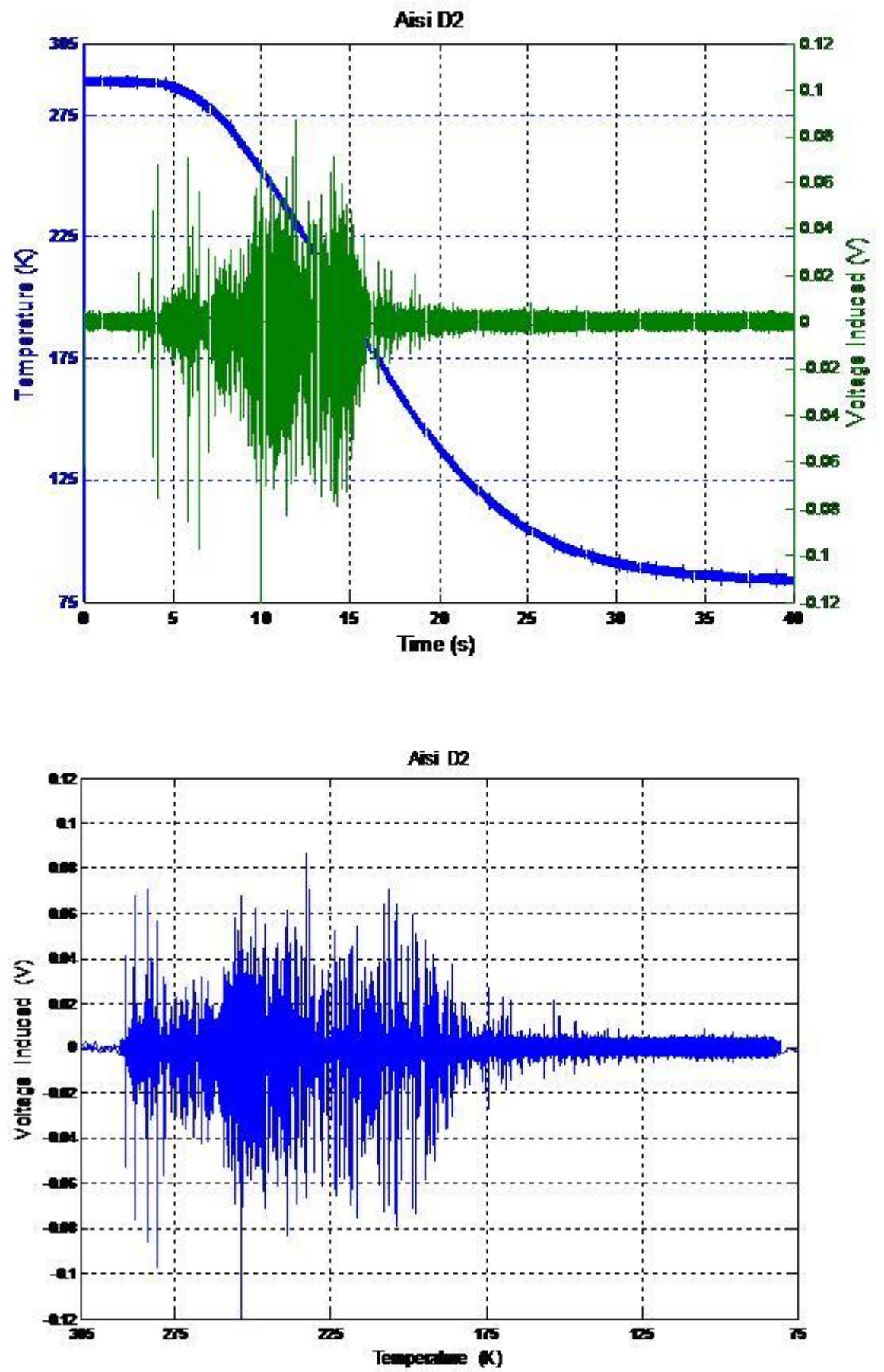


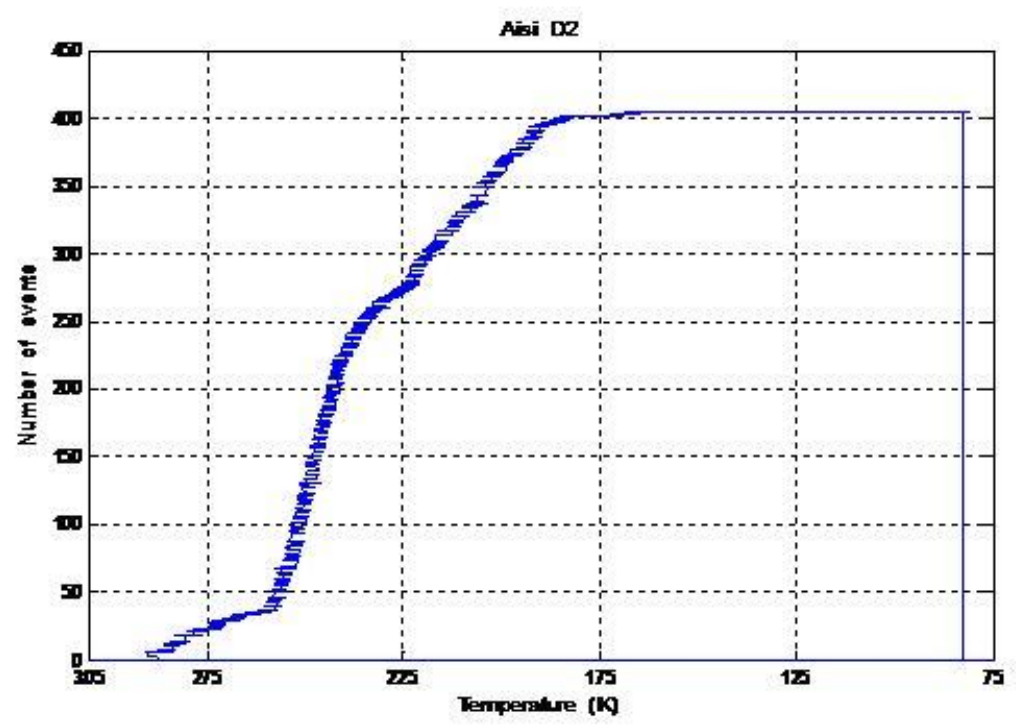

Figura 59 - a e b sinais da Emissão Magnética Espontânea (SME) capturados durante o resfriamento da amostra, do aço ferramenta AISI D2, previamente temperada de $1200^{\circ} \mathrm{C}$, e c contagem acumulativa das ocorrências de SME com intensidades acima de $0.02 \mathrm{~V}$, em um total de 405 ocorrências.

O sinal da SME do aço AISI D2 foi filtrado usando o Software Matlab, e obtiveram-se picos com a temperatura com amplitude de 0,01 Volts (Figura 60), ou seja, picos que aparecem para um limite superior a esta magnitude. Baseados nesta amplitude se podem caracterizar as primeiras emissões termicamente estimuladas.

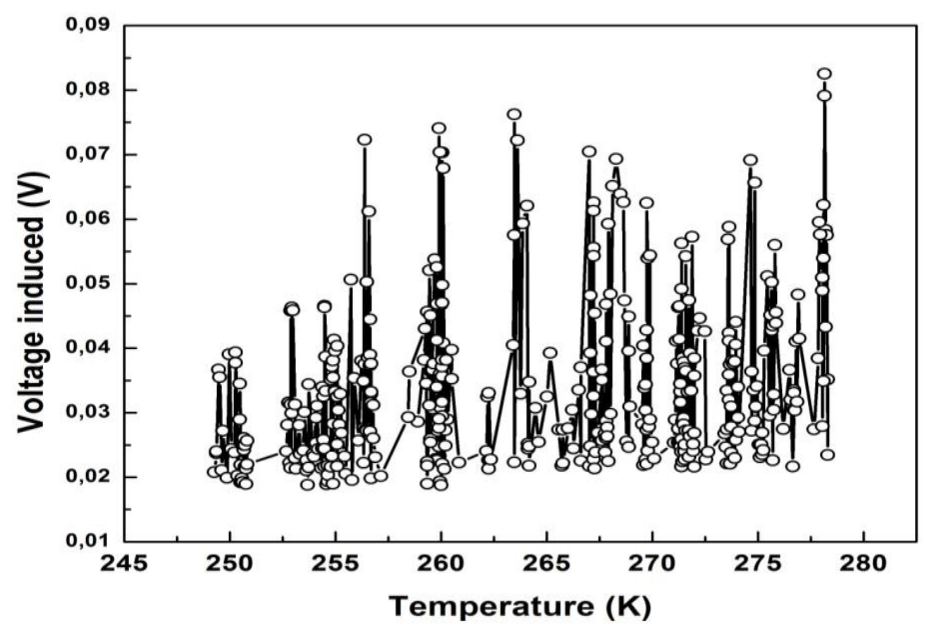

Figura 60 - Primeiras emissões termicamente ativadas. 
A Figura 61 mostra a emissão magnética espontânea da liga Fe-Ni-C.
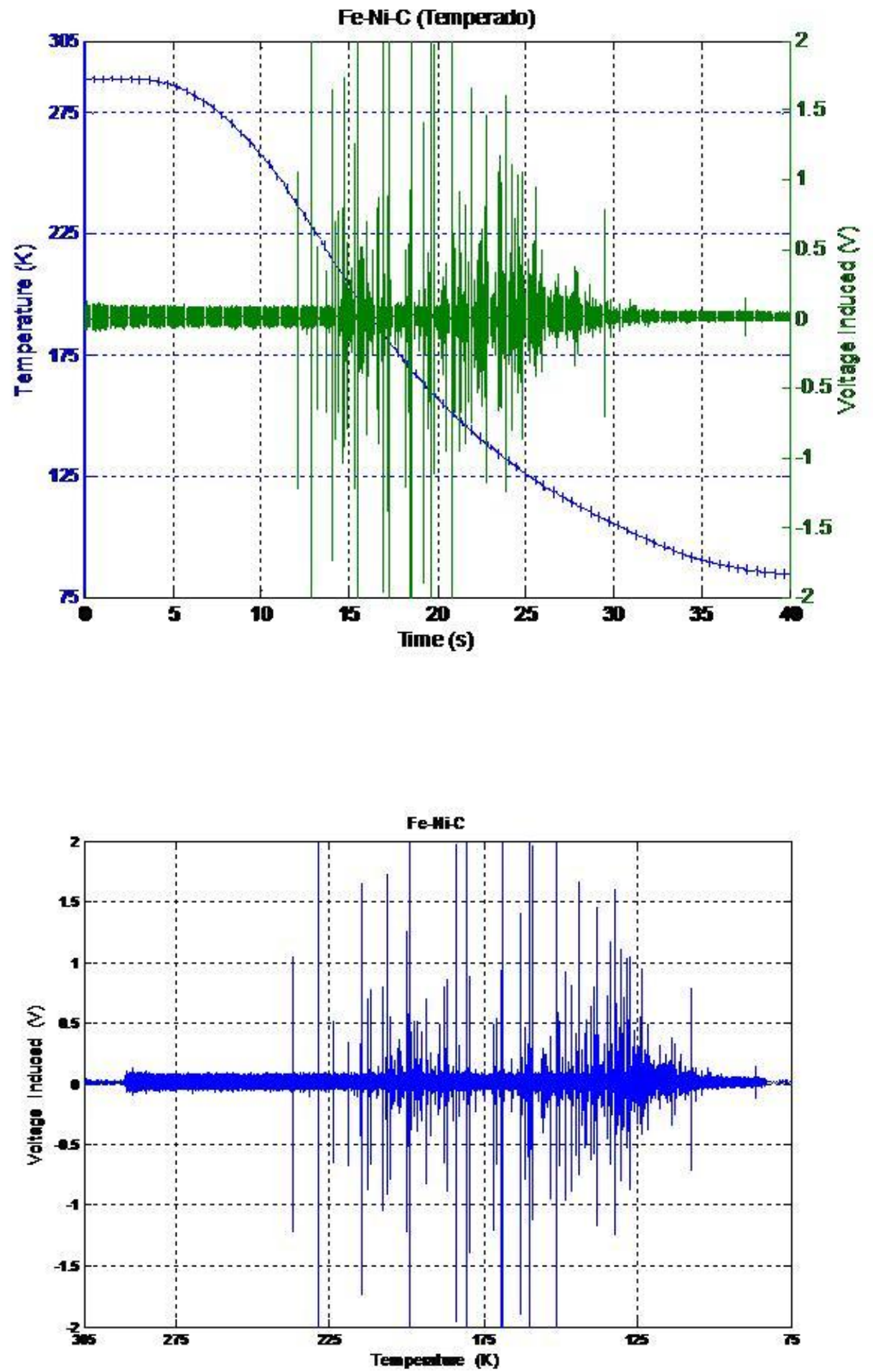


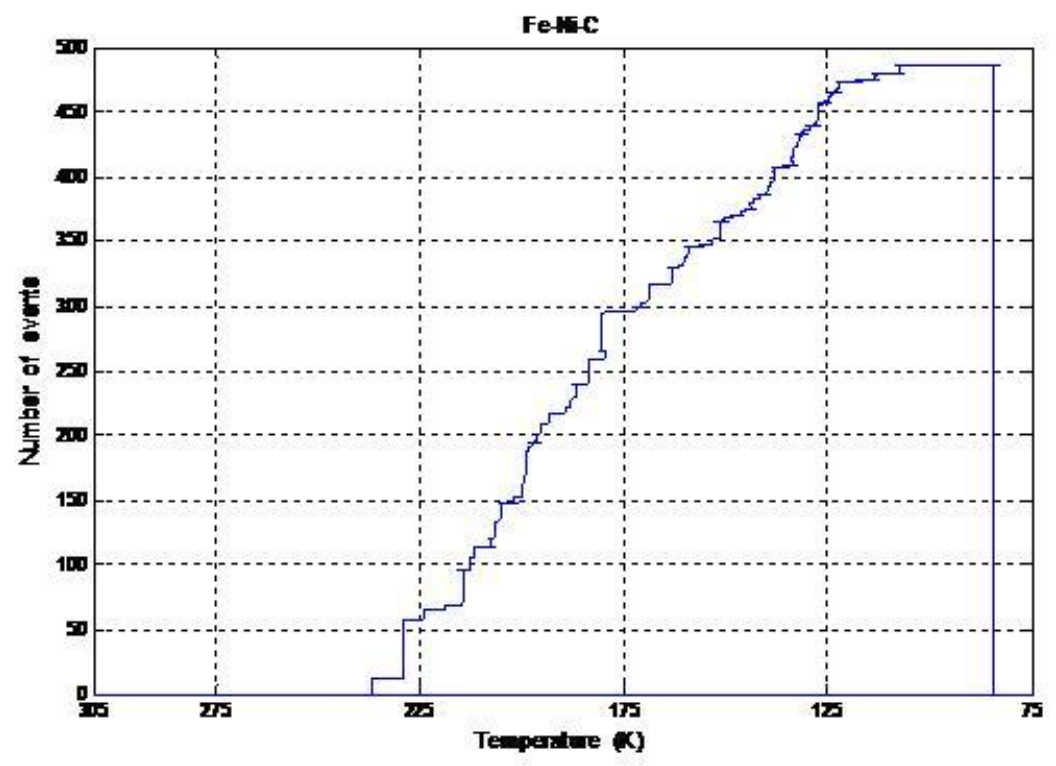

Figura 61 - Sinais da Emissão Magnética Espontânea (SME) capturado durante o resfriamento da amostra, para uma liga ternaria $\mathrm{Fe}-32,27 \% \mathrm{Ni}, 0,035 \% \mathrm{C}$, previa tempera de $750^{\circ} \mathrm{C}$, e o contagem de ocorrências de 486 acima de $0.25 \mathrm{~V}$, . 
Gráficos do SME, antes durante e depois da transformação Fe-Ni-C

Temperado

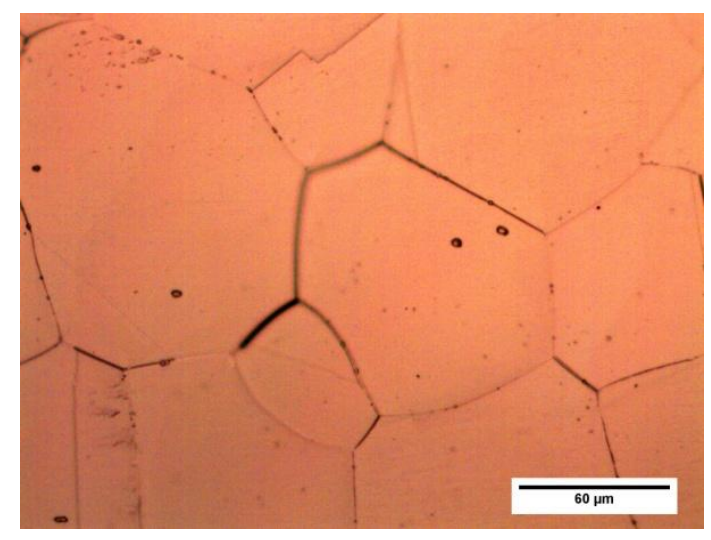

$-60^{\circ} \mathrm{C}(213 \mathrm{~K})$

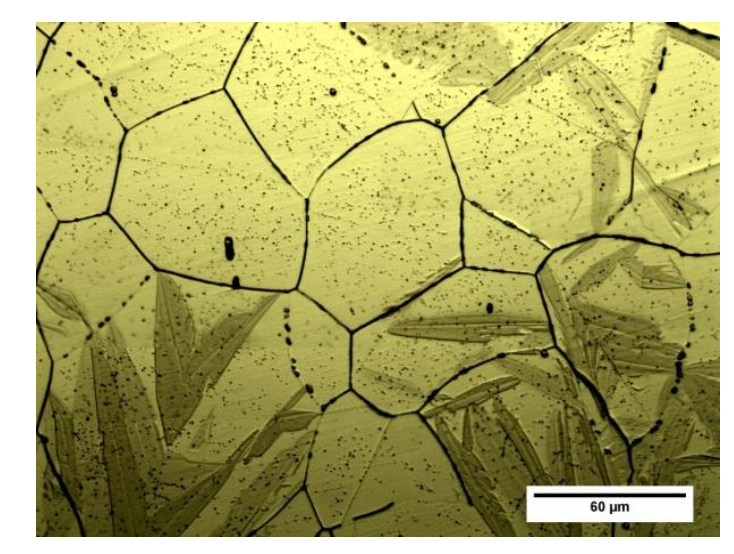

Depois da transformação

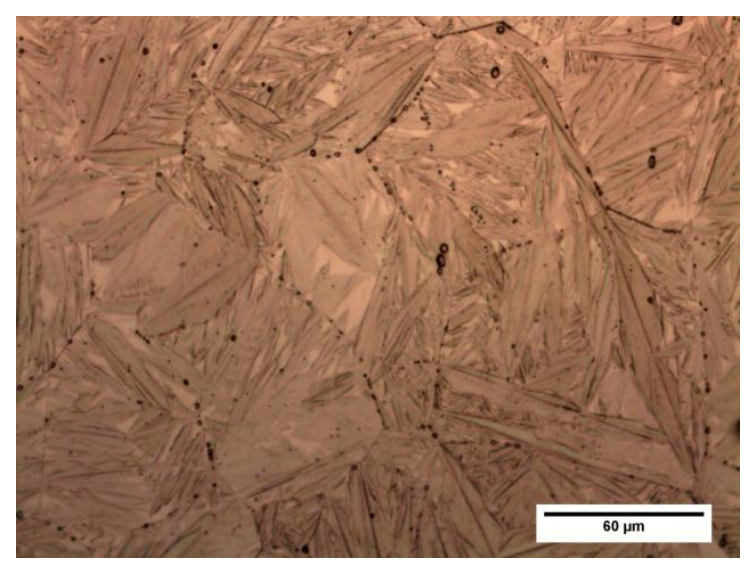

Figura 62 - Micrografias típicas do material Fe-Ni-C: a.após têmpera à temperatura ambiente,300K apenas austenita, b. Transformada parcialmente em temperatura de $-60^{\circ} \mathrm{C}$ (213K) usando uma mistura de LN2 e etanol pa, c. Transformada na temperatura de $-196^{\circ} \mathrm{C}(77 \mathrm{~K})$ 
Tabela 15 - Fração experimental da martensita transformada num aço AISI D2, obtido nos 3 procedimentos.

\begin{tabular}{|c|c|c|c|}
\hline & $\begin{array}{c}\text { Temperado a } 1200^{\circ} \mathrm{C}, \\
\text { com taxa de } \\
\text { resfriamento }-2,5^{\circ} \mathrm{C} / \mathrm{min} \\
\text { até }-196^{\circ} \mathrm{C}\end{array}$ & $\begin{array}{c}\text { Temperado a } 1200^{\circ} \mathrm{C}, \\
\text { taxa de }-4^{\circ} \mathrm{C} / \mathrm{min} \text { com } \\
\text { campo fixo até }-196^{\circ} \mathrm{C} \\
\text { (Okamura) }\end{array}$ & $\begin{array}{c}\text { SME } \\
\text { Diretamente em } \\
\text { dewar com LN2 }\end{array}$ \\
\hline Amostras & Martensita & Martensita & Martensita \\
\hline 1 & 17,50 & 17,00 & 14,00 \\
\hline 2 & 15,50 & 16,00 & 12,00 \\
\hline 3 & 16,50 & 17,50 & 18,00 \\
\hline 4 & 18,50 & 11,50 & 14,00 \\
\hline 5 & 11,50 & 11,50 & 18,50 \\
\hline 6 & 15,50 & 12,50 & 14,00 \\
\hline 7 & 17,50 & 11,00 & 11,00 \\
\hline 8 & 14,50 & 14,50 & 15,50 \\
\hline 9 & 14,50 & 15,00 & 14,00 \\
\hline 10 & 8,50 & 15,00 & 16,50 \\
\hline 11 & 15,00 & 16,00 & 16,00 \\
\hline 12 & 14,50 & 14,50 & 13,00 \\
\hline 13 & 13,00 & 11,00 & 11,00 \\
\hline 14 & 14,50 & 14,00 & 16,50 \\
\hline 15 & 9,00 & 11,00 & 19,00 \\
\hline 16 & 15,00 & 11,00 & 17,50 \\
\hline 17 & 11,50 & 11,50 & 17,00 \\
\hline 18 & 17,00 & 11,50 & 13,50 \\
\hline 19 & 13,50 & 16,50 & 15,50 \\
\hline 20 & 13,00 & 14,00 & 17,50 \\
\hline Media & 14,30 & 13,63 & 15,20 \\
\hline Porcentagem \% & 34,05 & 32,44 & 36,19 \\
\hline
\end{tabular}


A Figura 63 micrografias do aço AISI D2 obtidos nos 03 procedimentos.
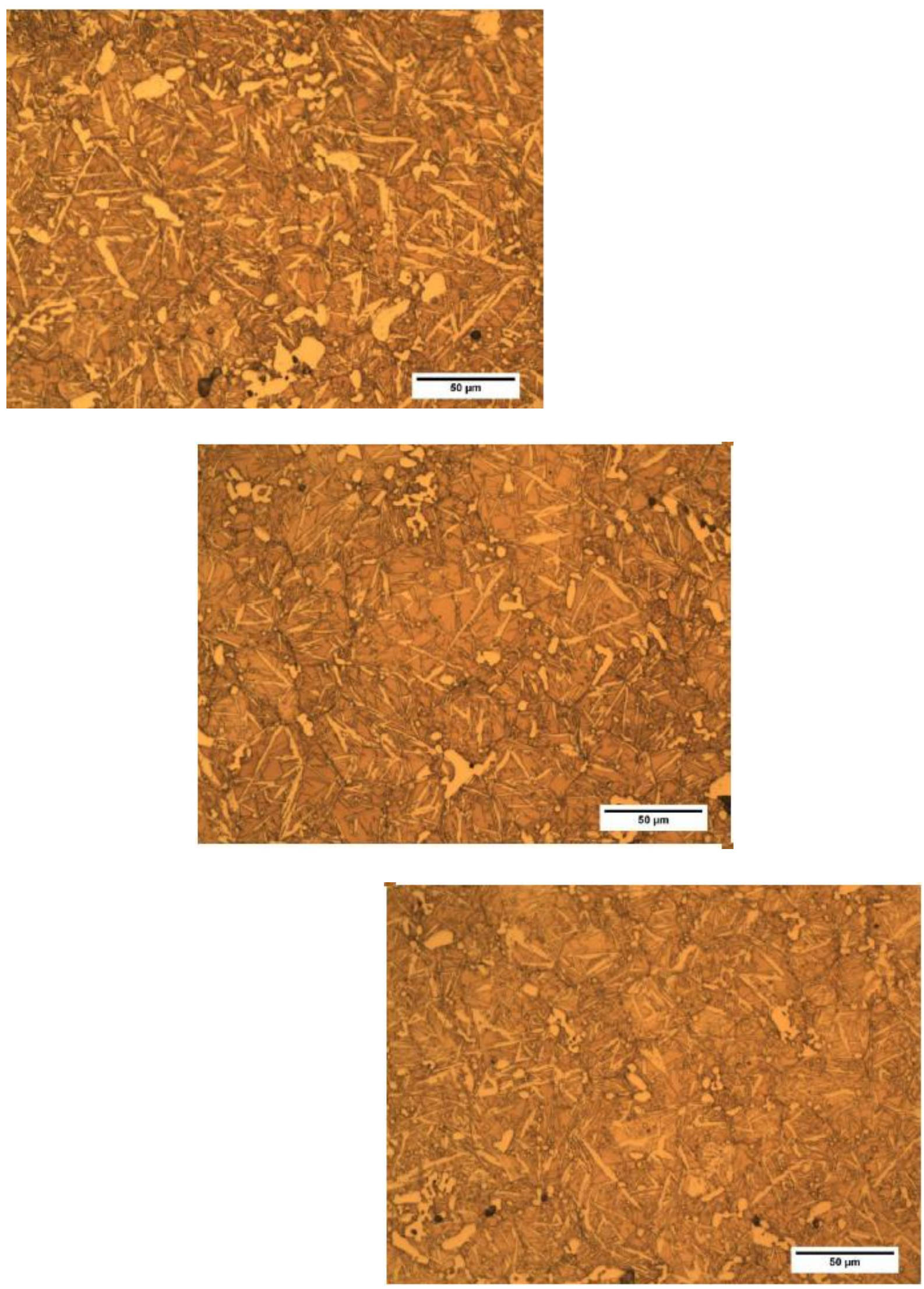

Figura 63 - Micrografias do aço AISI D2 obtidos nos 3 procedimentos e atacadas com vilela. 
Amostras do Fe-Ni-C, no SME.
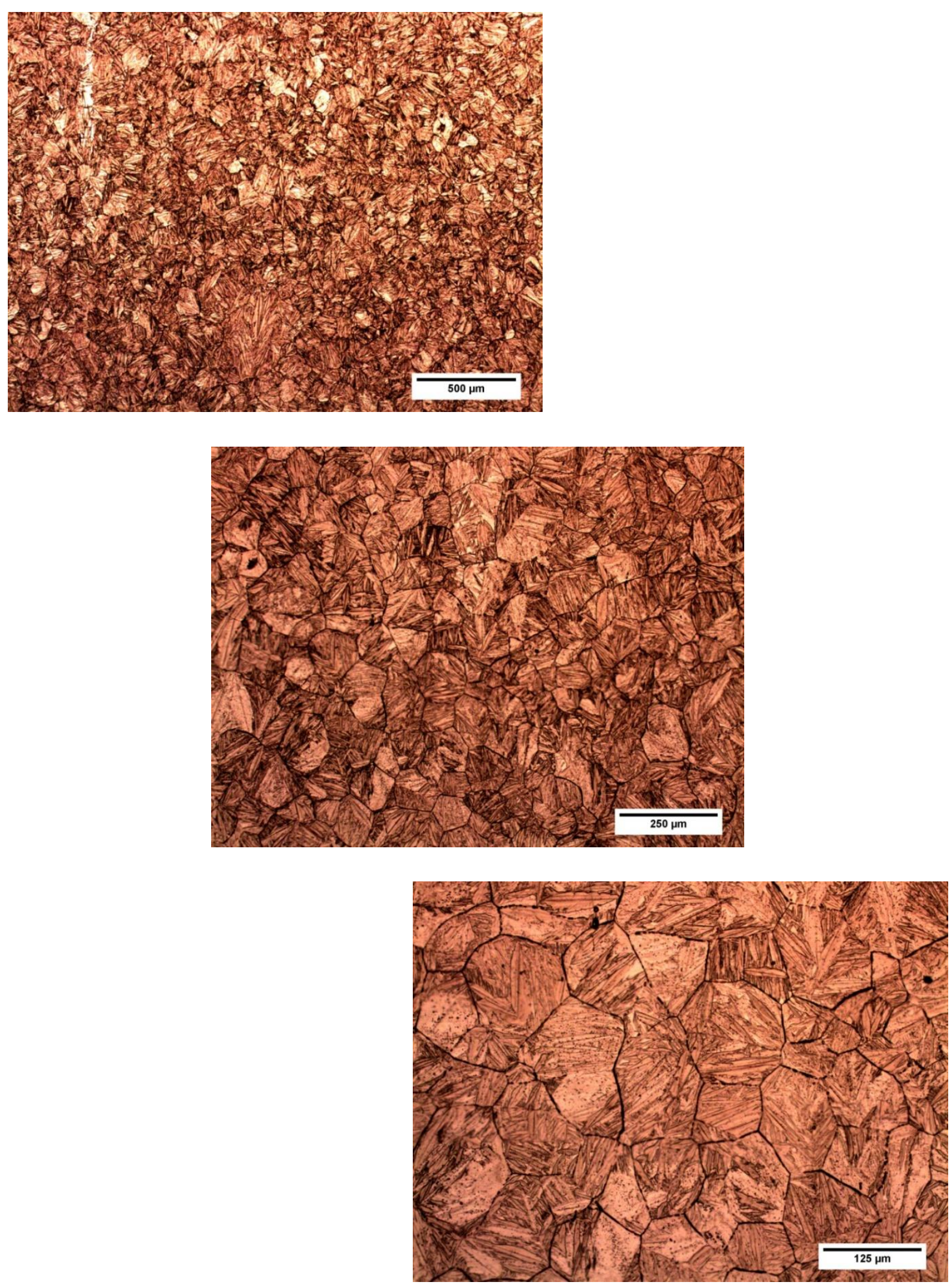

Figura 64 - Martensita em placas do Fe-Ni-C testadas no SME, atacadas com nital. 


\subsection{Variação do inicio da transformação martensítica em função do tamanho de grão por emissão magnética espontânea (SME).}

A literatura mostra que o inicio da transformação martensítica (Ms) muda com a variação do tamanho de grão da austenita (NISHIYAMA, 1978; GUIMARÃES; RIOS, 2010; YANG; BHADESHIA, 2009); em geral quanto maior o tamanho de grão, mais alto é o Ms; no entanto além de que a martensita nucleia nos contornos de grão da austenita e cresce rapidamente até interceptar outro limite de grão ou outra agulha de martensita, a mais resfriamento mais avança a transformação, se conseguiu 04 diferentes tamanhos de grão da liga Fe-Ni-C (Figura 65).
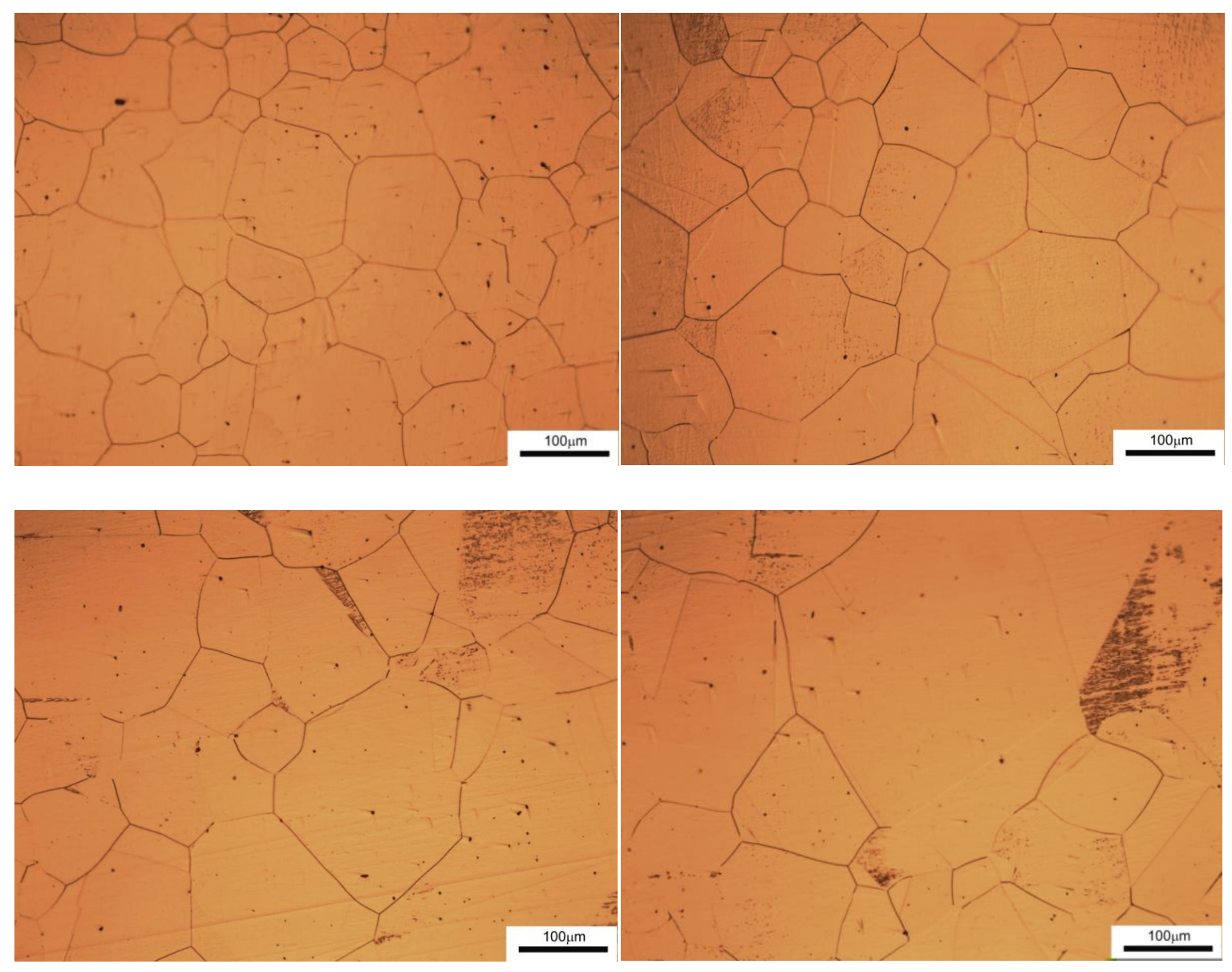

Figura 65 - Mudança no tamanho de grão na fase da austenita onde Grao $01<$ Grao $02<$ Grao $03<$ Grao 04. 
Foi testado no método de SME, nos 04 tamanhos de grãos de austenita para ver a mudança do inicio da transformação martensítica (Figura 66 - Figura 68).

Grão 01
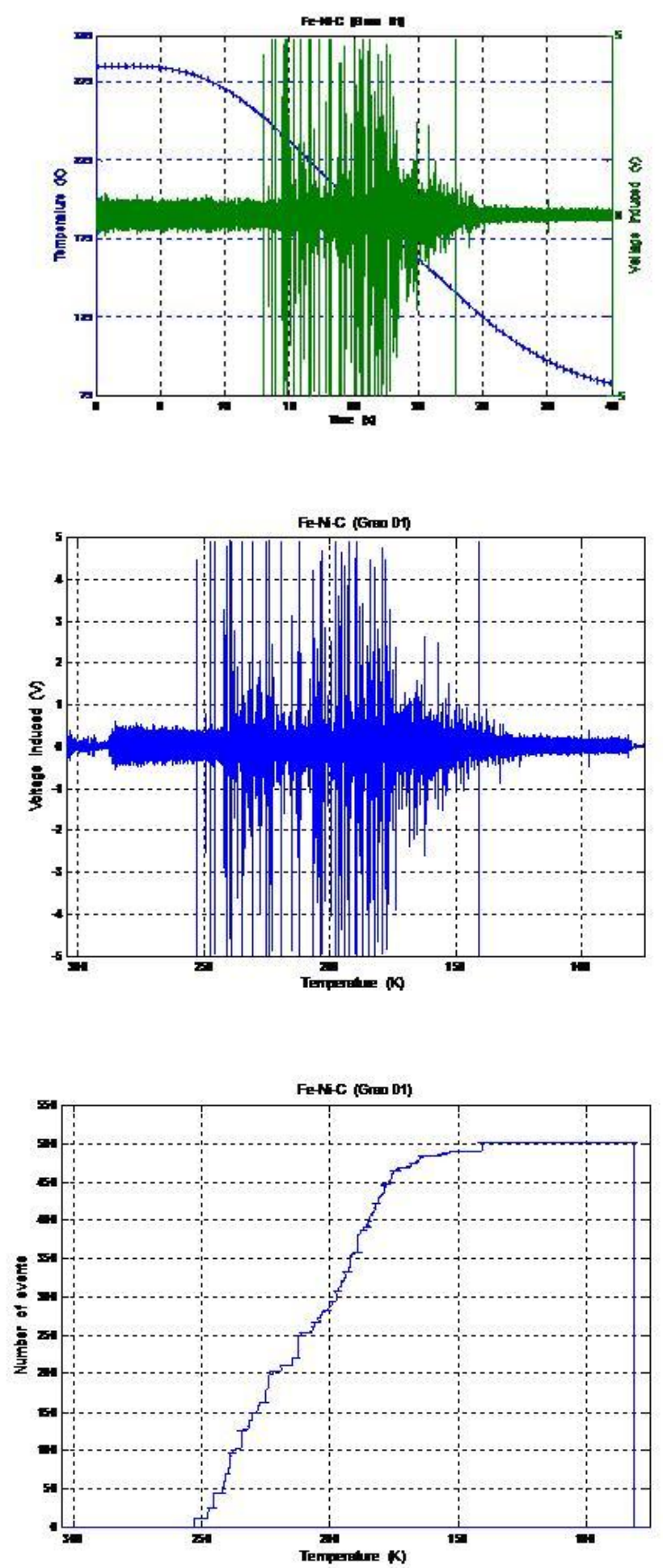

Figura 66 - SME para o Grão 01, e 501 ocorrências acima de 1V. 
Grão 02
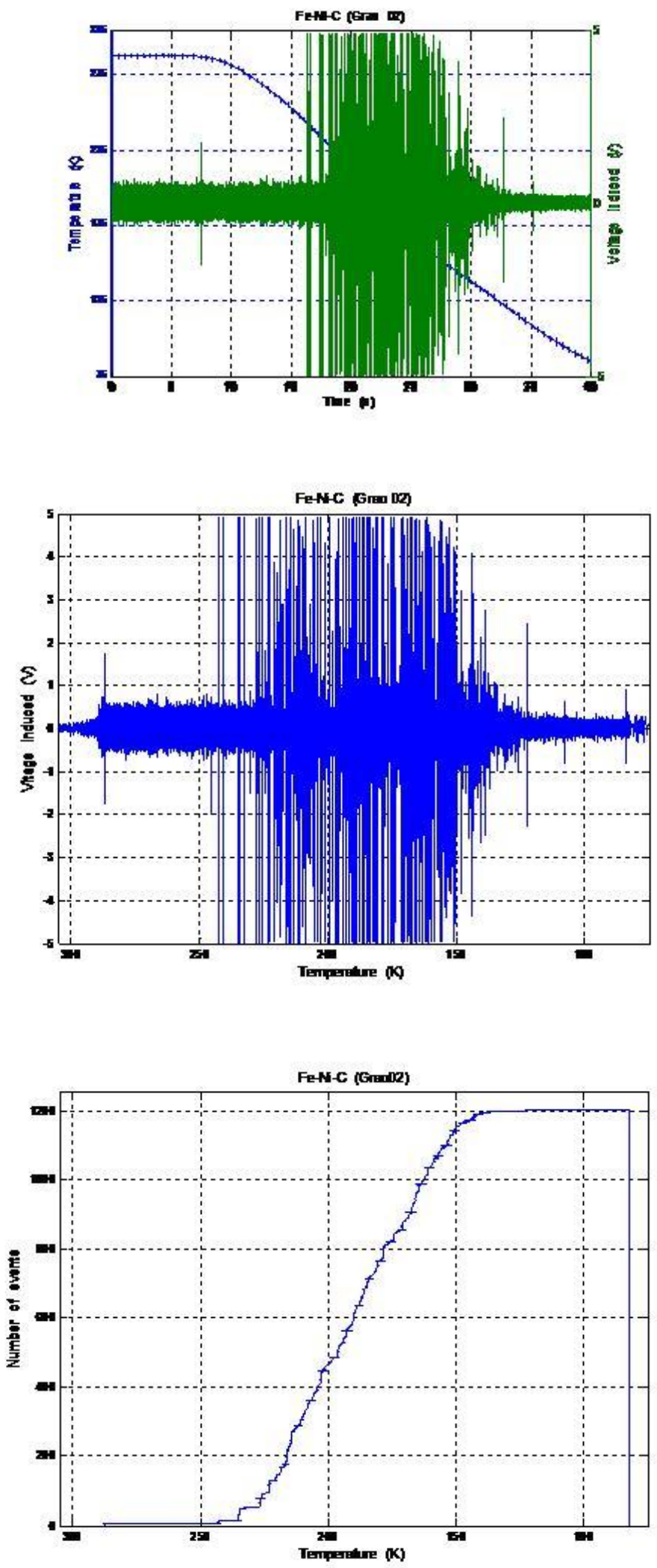

Figura 67 - SME para o Grão 02, e 1201 ocorrências acima de 1V. 
Grão 03
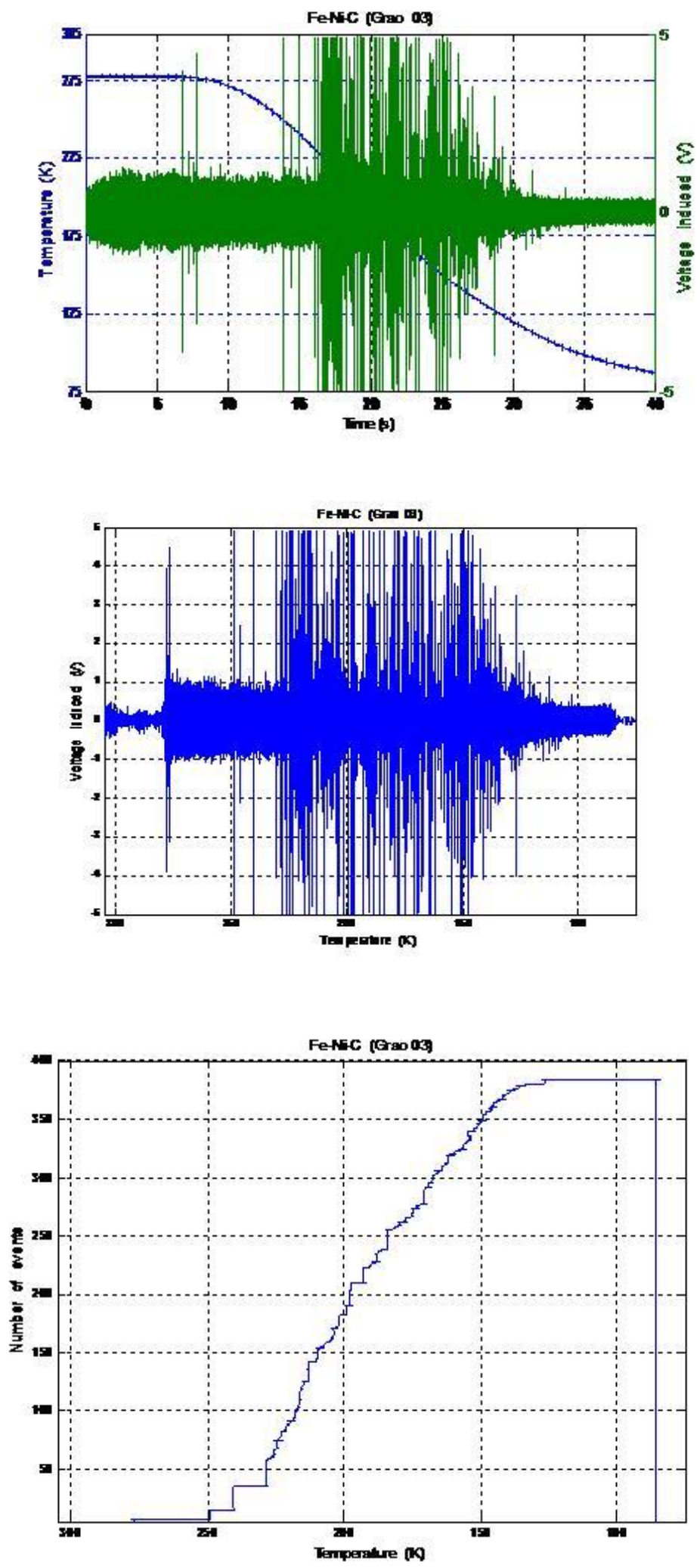

Figura 68 - SME para o Grão 03 e 384 ocorrências acima de 2V. 
Grão 04
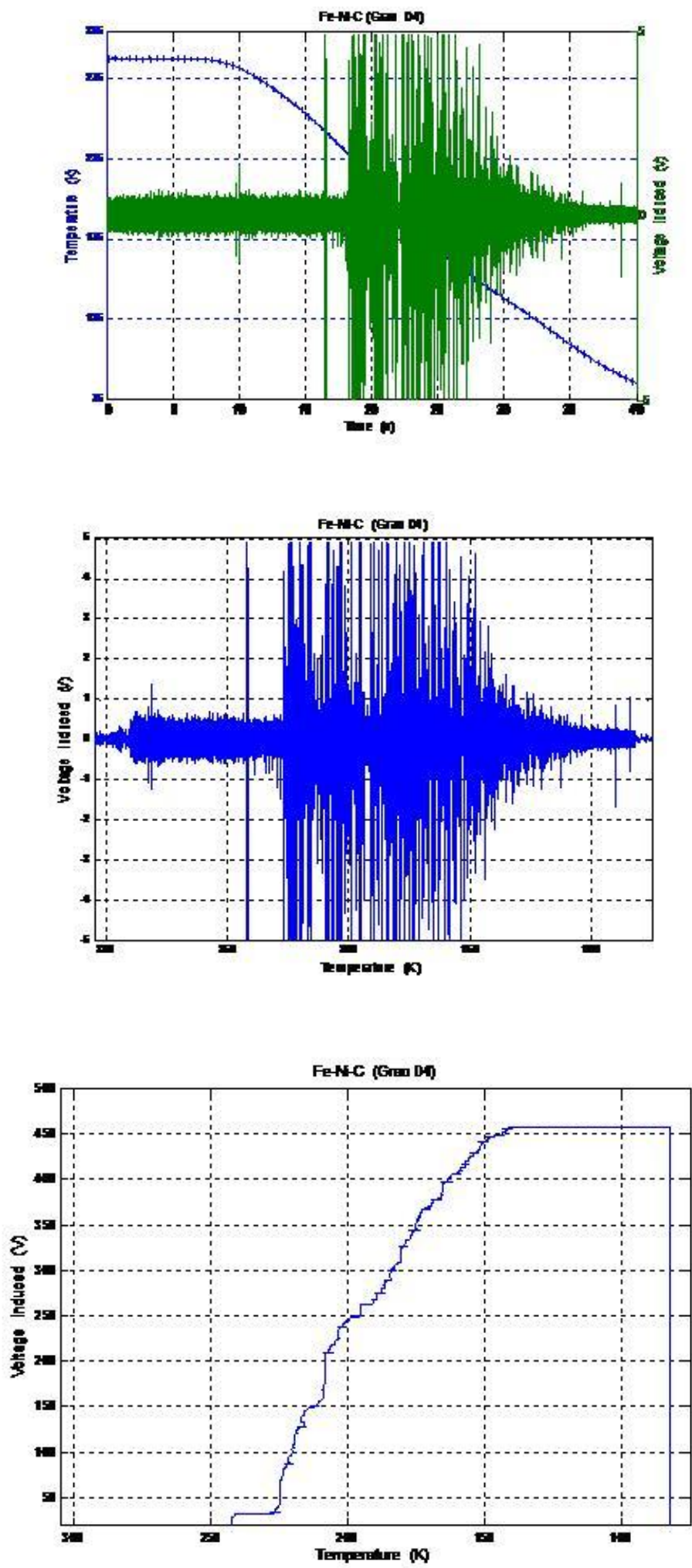

Figura 69 - SME para o Grão 04 e 457 ocorrências acima de 1,5V. 
Na Figura 70 é mostrado o inicio da transformação em função do tamanho de grão.

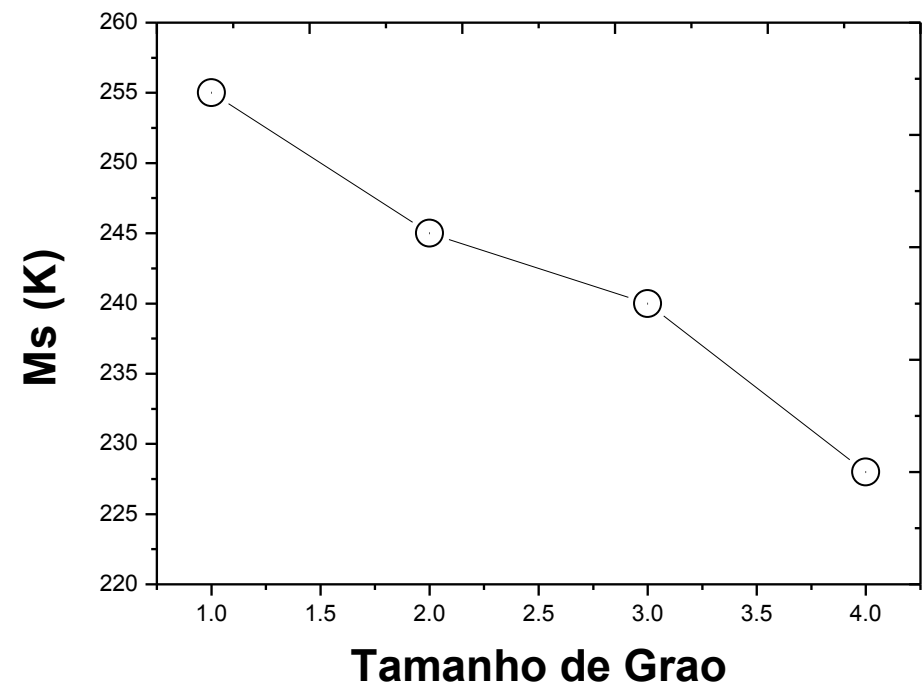

Figura 70 - Inicio da transformação em função do tamaño de grão da austenita na liga Fe-Ni-C.

Onde é mostrada a queda do inicio da transformação, devido a que contornos de grao da austenita se comportam como pontos favoráveis ao inicio da transformacao, fazendo de que nos grãos pequenos seja mais cedo o inicio das agulhas de martensita.

Também foram submetidas só com a bobina de sensor em função do tempo tendo os seguintes resultados:

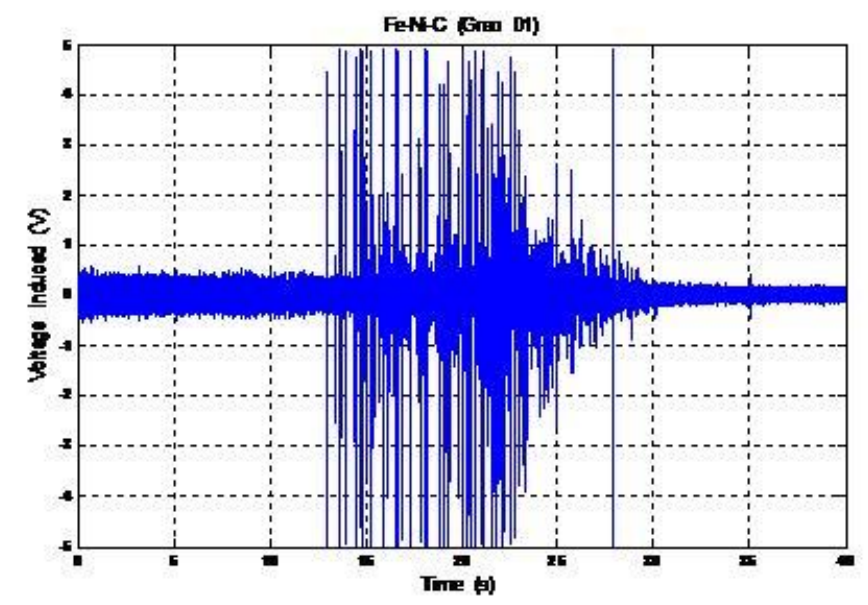



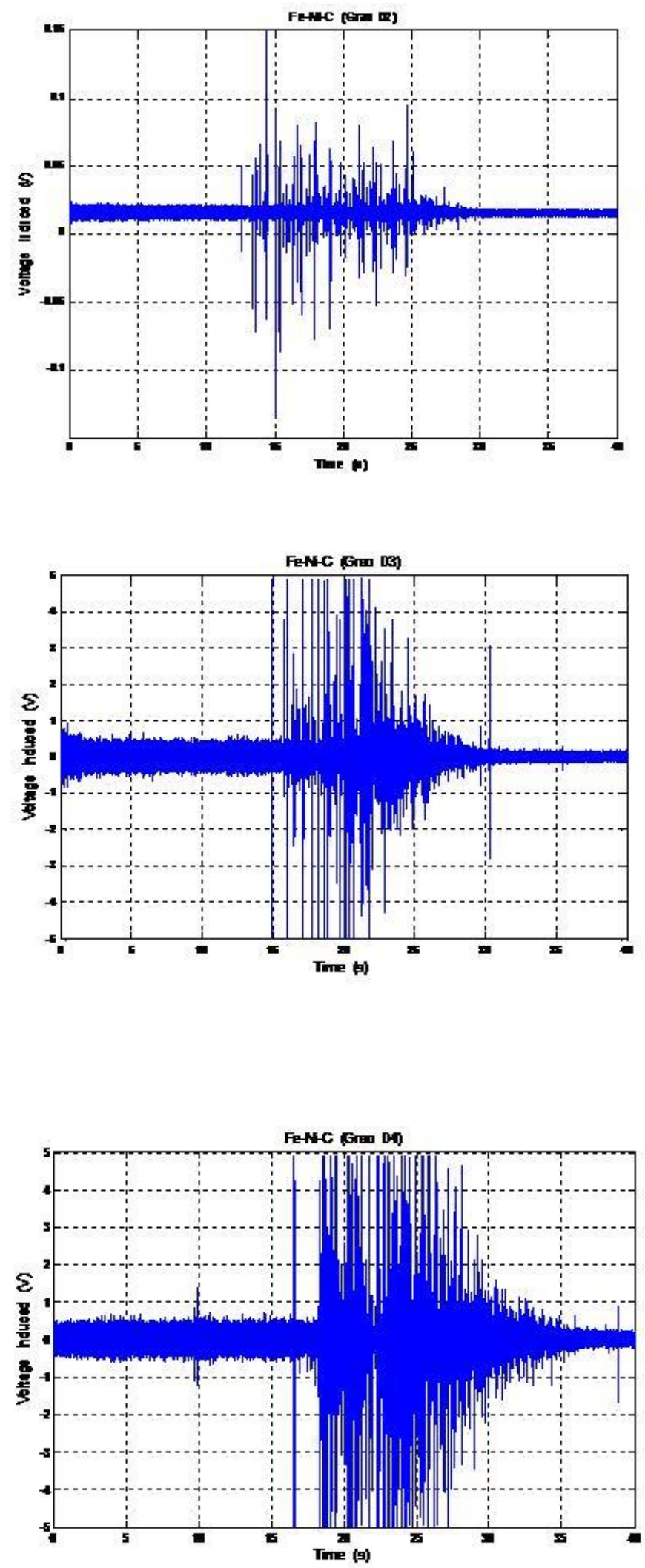

Figura 71 - SME sem o sensor de temperatura para as ligas Fe-Ni-C. 
Na Figura 72 é mostrado SME sem sensor da temperatura em função do tempo.

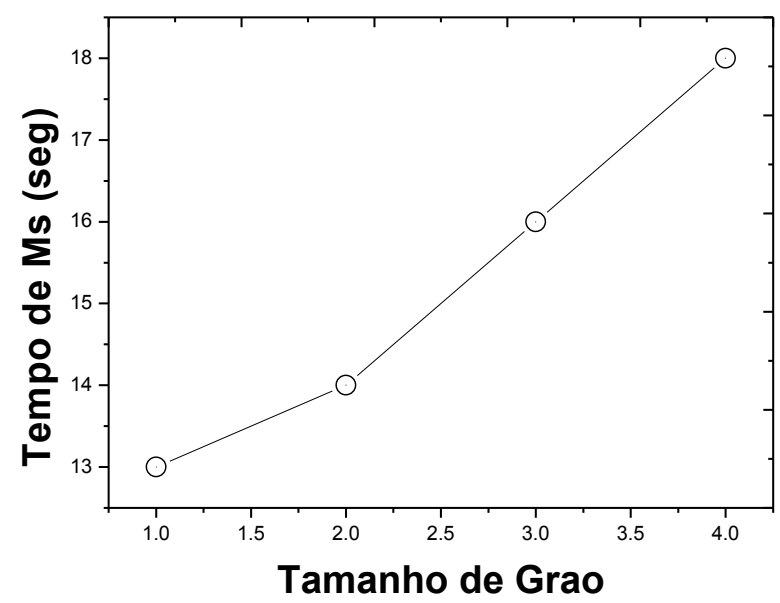

Figura 72 - Tempo de Ms em função do tempo.

Medidas de ruído de Barkhausen convencional, realizadas nos materiais com o menor tamanho de grão (01) até o maior tamanho (04), antes e depois da transformação são mostrados nos gráficos a seguir:
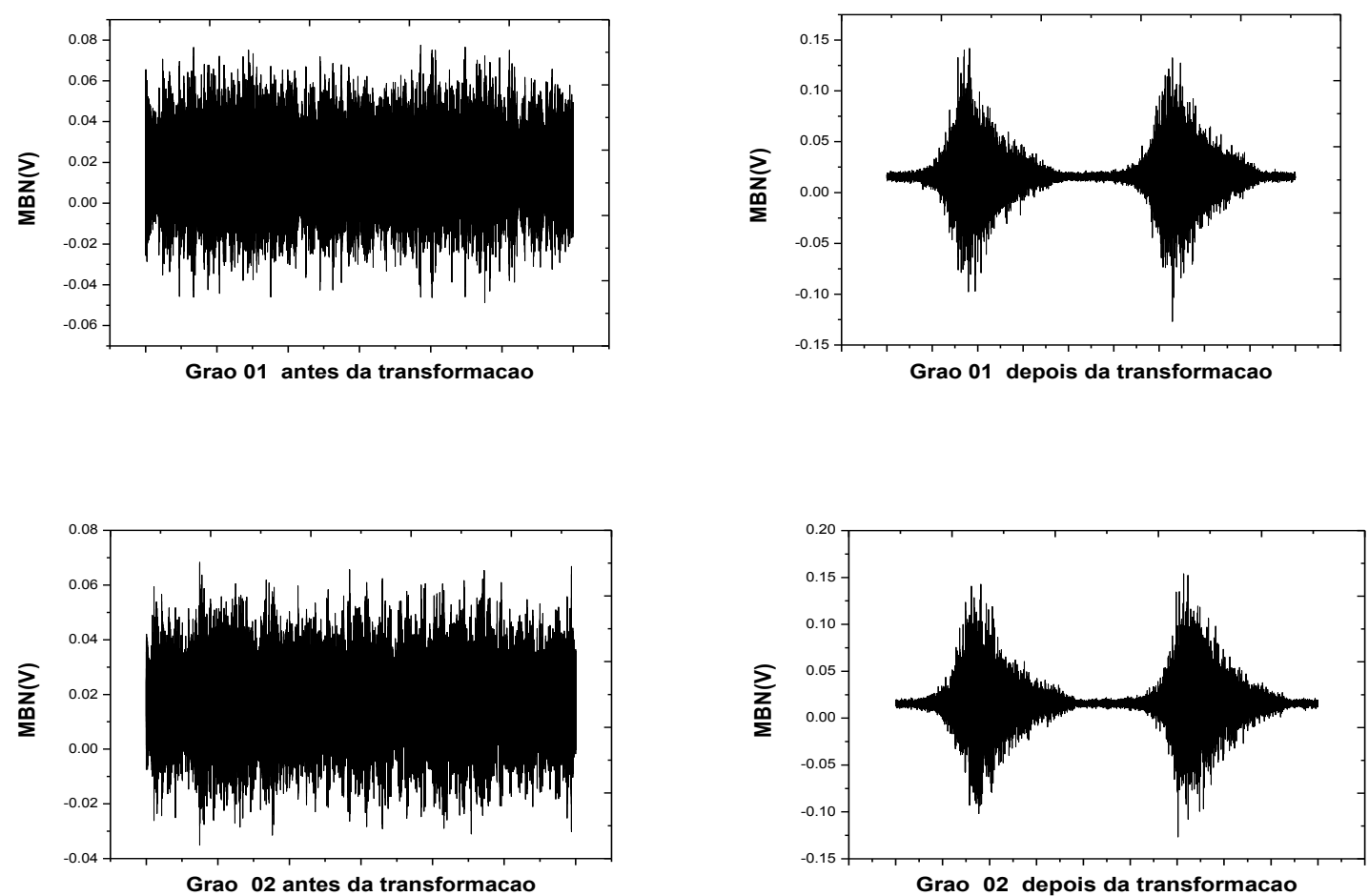


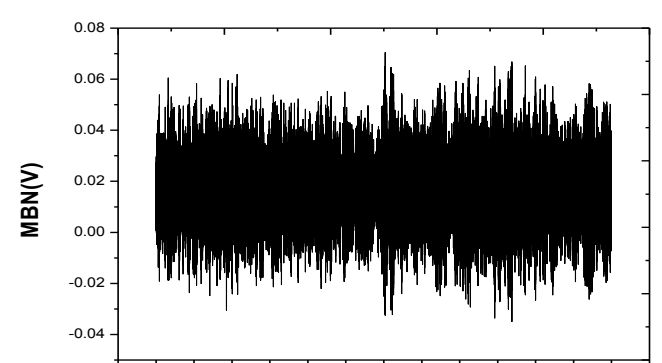

Grao 03 antes da transformacao

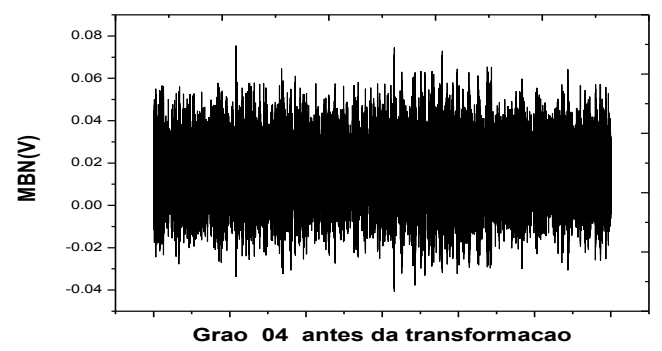

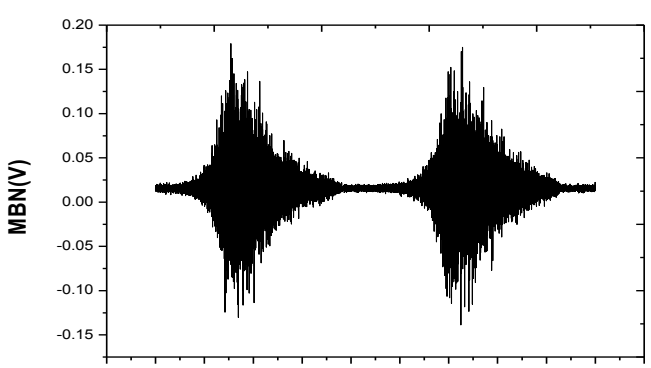

Grao 03 depois da transformacao

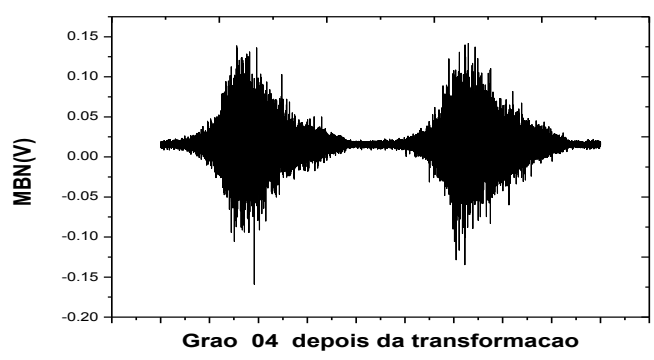

Figura 73 - MBN antes e depois da transformação em função do tamanho de grão austenítico.

Na Figura 74 é mostrado o MBN em função do tamanho de grão austenítico transformado.

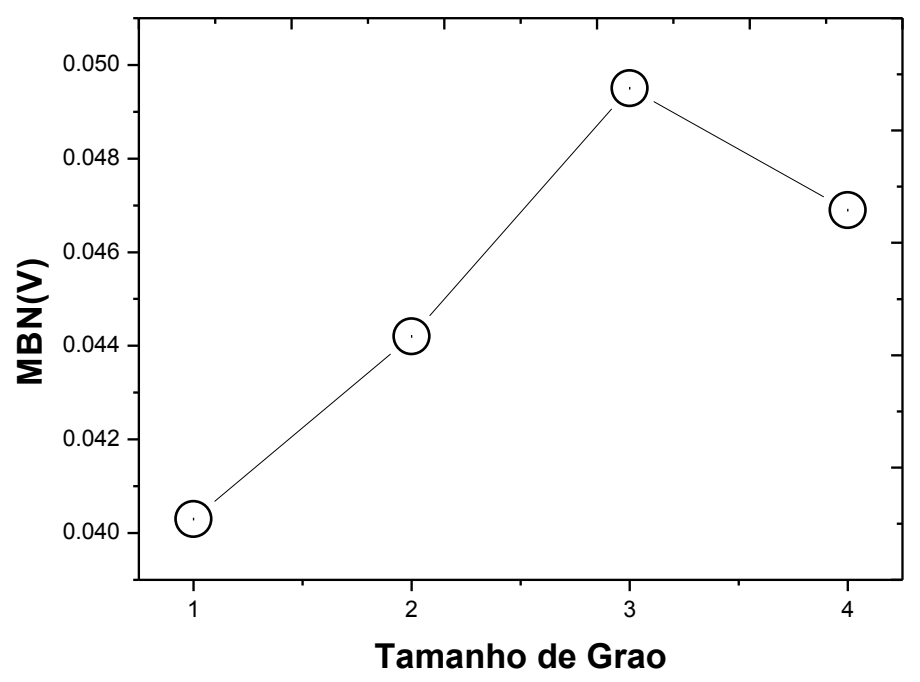

Figura 74 - MBN em função do tamanho de grão austenítico transformado. 
Observa-se aumento do MBN nos materiais com grãos maiores, indicando que a fração transformada para martensita é maior em materiais com grãos austeniticos maiores, como relatado na literatura (NISHIYAMA, 1978).

\subsection{Presença de martensita no aço AISI D2 temperado.}

$\mathrm{Na}$ temperatura de $1200^{\circ} \mathrm{C}$, observaram-se quantidades mínimas de martensita, mesmo à temperatura ambiente, apesar da temperatura Ms estimada ser de $-19^{\circ} \mathrm{C}$; esta martensita pode ser um fenômeno de superfície, nucleada pela preparação metalografica, ou pode realmente ser um fenômeno mais geral, nunca descrito anteriormente por que as técnicas convencionais de detecção da Ms exigem um volume mínimo transformado.
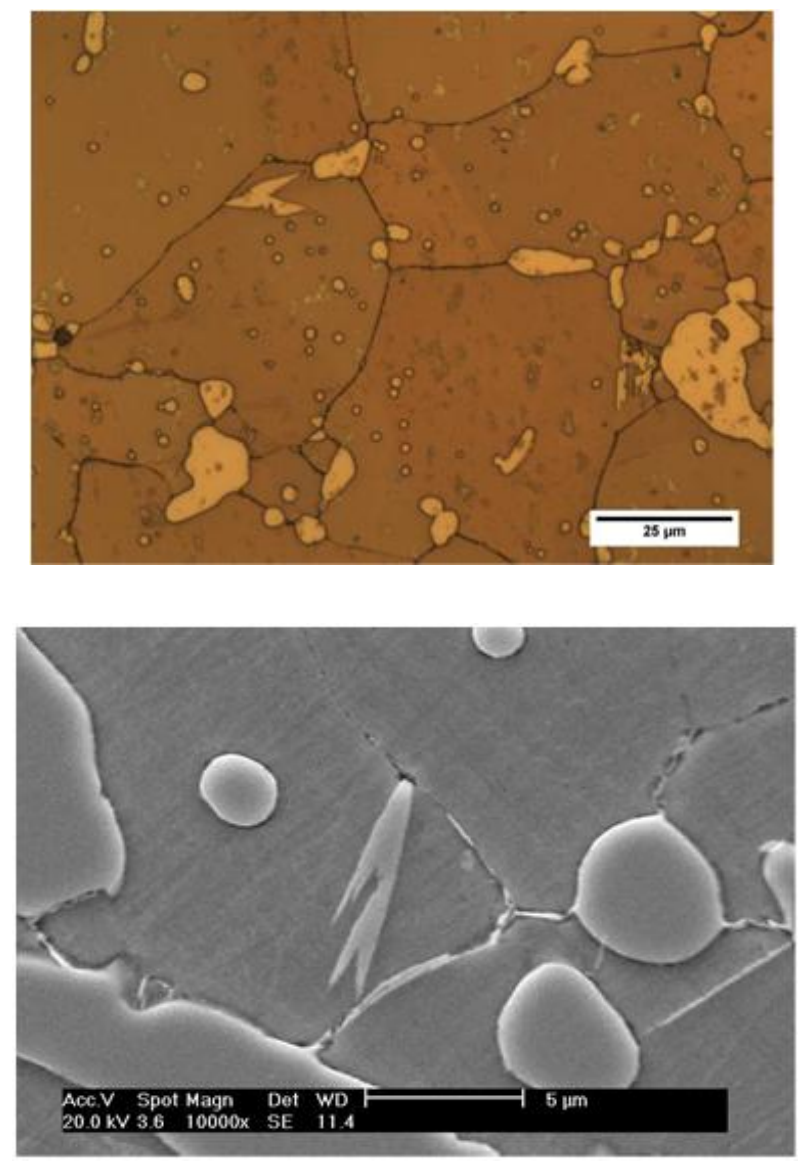

Figura 75 - Aço D2 solubilizadas a $1200^{\circ} \mathrm{C}$ e temperado em óleo com presença de martensita. 


\section{CONCLUSÕES}

Ruído magnético de Barkhausen convencional mostrou ser uma ferramenta útil para acompanhar a transformação da austenita em martensita durante o resfriamento a temperaturas sub-zero.

Experimentos executados com amostras de aço ferramenta AISI D2 recozido a $1200^{\circ} \mathrm{C}$, com temperaturas Ms abaixo de $0^{\circ} \mathrm{C}$ mostrou resultados compatíveis com medidas de resistividade obtidos simultaneamente durante o resfriamento.

A resistividade elétrica na transformação martensítica mostra melhores resultados quando são submetidos a correntes elevadas.

No aço AISI D2, A resistividade elétrica (Ms 230K), ruído de Barkhausen

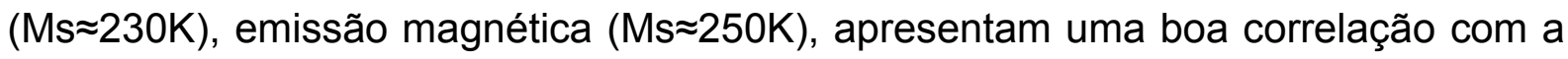
formula empírica de Andrews linear de Ms $\approx 245,03 \mathrm{~K}$, assim como o aço Fe-Ni-C a

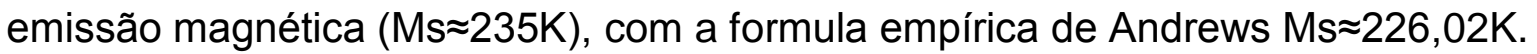

Foi reproduzido o experimento histórico de Okamura utilizando um campo fixo para registrar os pulsos magnéticos correspondentes aos eventos de crescimento individual de martensita (placa ou burts).

Um novo fenômeno, a emissão espontânea de pulsos magnéticos durante o resfriamento foi demonstrado pela primeira vez com o aço AISI D2 e confirmado com liga austenítica ferromagnética Fe-32,27\%Ni, 0,035\%C.

O novo método de medição Emissão Magnética (ME) promete ser uma ferramenta simples para explorar a transformação martensítica em ligas ferromagnéticas, propícios para a miniaturização e portabilidade do sensor, permitindo detectar o ME nas amostras de ensaios mecânicos, durante a observação no microscópio óptico e eletrônico equipado com fases de frio, durante a conformação a frio de aços TRIP, e em qualquer estrutura industrial contendo austenita retida.

Verificou-se a presencia de pulsos magnéticos no $\mathrm{ME}$, correspondentes à transformação martensítica. 
$\mathrm{Na}$ liga Fe-Ni-C a medida que o tamanho de grão da austenita o inicio da transformação martensítica o Ms diminui.

Mostrou um aumento do MBN em função do tamanho da austenita com a fase de martensita, que pode ser sensível à quantidade de martensita presente no material. 


\section{REFERÊNCIAS}

ALbeRTERIS, C. M.; CAPÓ, S. J.; PÉREZ, B. J.; PADOVESE, L. R. Characterization of the elastic-plastic region in AISI/SAE 1070 steel by the magnetic barkhausen noise. NDT\&E International, v. 41, p. 656-659, 2008.

ANDREWS, K. W. Empirical formulae for the calculation of some transformation temperatures. Journal of The Iron and Steel Intitute, v. 203, p. 721-727, 1965.

ANSELL, G. S.; DONACHIE, S. J.; MESSLER, JR. R. W. The Effect of Quench Rate on the Martensitic Transformation in Fe-C Alloys. Metallurgical Transactions, v. 2, p. 2443-2449, 1971.

BENZ, R.; ELLIOTT, J. F.; CHIPMAN, J. Thermodynamics of the carbides in the system Fe-Cr-C. Metallurgical and Materials Transactions B, v. 5, p. 2235-2240, 1974

BHADESHIA, H. K. D. H.; HONEYCOMBE, R.W.K. Steels Microstructure and Properties. Third edition. s.I. : ELSEVIER, 2006.

BLACHNIO, J. The effect of changing loads affecting the martensite steel on its structure and the Barkhausen noise level. NDT\&E International, v. 41, p. 273-279, 2008.

BLAOW, M.; EVANS, J. T.; SHAW, B. A. Magnetic Barkhausen noise: the influence of microstructure and deformation in bending. Acta Materialia, v. 53, p. 279-287, 2005.

BOZORTH, R. M. Ferromagnetism, Wiley-Blackwell; Reissue edition, 992p, 1993.

BUNSHAH, R. F.; MEHL, R. F. Rate of Propagation of Martensite. Transactions AIME, v. 197, p. 1251-1258, 1953.

CECH, R. E.; TURNBULL, D. Heterogeneous Nucleation of the Martensite Transformation. Transactions AIME, v. 206, p. 124-132, 1956.

CHEN, P.; CHEN, K.; WU, G. H.; ZHANG, X. X. Martensitic phase transformation in single crystal $\mathrm{Co}_{5} \mathrm{Ni}_{2} \mathrm{Ga}_{3}$. J. Mater. Sci., v. 43 p. 4226-4229, 2008.

COHEN, M. The Strengthening of Steel. Transactions of the Metallurgical Society of AIME, v. 224, p. 638-657, 1962.

CULLITY, B. D.; GRAHAM, C. D. Introduction to Magnetic Materials, 2 ed, IEEE PRESS, 2009.

GILBERT, A.; OWEN, W. S. Diffusionless Transformation in iron-nickel, ironchromium and iron-silicon alloys. Acta Metallurgica, v. 10, p. 45-54, 1962. 
GOODENOW, R. H.; HEHEMANN, R. F. Transformations in Iron and Fe-9 pct Ni Alloys. Transactions of the Metallurgical Society of AIME, v. 233, p. 1777-1786, 1965.

GUIMARÃES, J. R. C.; RIOS, P. R. Martensite start temperature and the austenite grain-size. Journal of Materials Science, v. 45, p. 1074-1077, 2010.

GUO, H.; ZHAO, J.; SHEN, B.; ZHAN, W. Martensitic transformation, thermomagnetic properties and electronic resistivity of amorphous alloys $\left(\mathrm{Fe}_{1}\right.$. $\left.{ }_{x} \mathrm{Ni}_{x}\right)_{84} \mathrm{~B}_{16}$ after crystallization. Chinese Physics Letters, v. 5, p. 553-556, 1988.

HILLERT, M. Impact of Clarence Zener upon metallurgy. American Institute of Physics, v. 60, p. 1868-1876, 1986.

HSU, T. Y.; JIAN, L.; ZHENPENG, Z. Effect of solution strengthening of austenite on martensite transformation in Fe-Ni-C alloys. Metallographycs, v. 19, p. 305-316, 1986.

HUALLPA, E. A.; FARINA, P. F.; CAPO, J.; GOLDENSTEIN, H.; PADOVESE, L. R. The use of Brakhausen noise to study the martensitic phase transformation. SolidSolid Phase Transformation in Inorganic Materials (PTM2010), Avignon, France, 2010.

JABLONSKA, A.; DABROWSKI, L.; SUWALSKI, J.; NEOV, S. Investigation of low temperature diffusion of carbon in martensite by Mössbauer spectroscopy and X-ray diffraction. NUKLEONIKA, v. 51, p. 101-104, 2006.

JILES, D.C. Dynamics of domain magnetization and the Barkhausen effect. Czechoslovak Journal Physics, v. 50, p. 893-988, 2000.

KAJIWARA, S.; KIKUCHI, T. On the abnormally large tetragonality of martensite in Fe-Ni-C alloys. Acta Metallurgica et Materialia, v. 39, p. 1123-1131, 1991.

KATSUYAMA, J.; ARAKI, H.; MIZUNO, M.; SHIRAI, Y. Pre-martensitic phenomena of thermoelastic martensitic transformation of NiTiCu alloys studied with positron annihilation lifetime spectroscopy. Science and Technology of Avanced Materials, v. 5, p. 41-45, 2004.

KAUFMAN, L.; COHEN, M. Thermodynamics and Kinetics of martensitic transformation. Progress in Metal Physics, v. 7, p. 165-246, 1958.

KELLY, P. M.; NUTTING, J. The Martensite Transformation in Carbon Steels. Mathematical and Physical, v. 259, 1296, p. 45-58, 1960.

KLEBER, X.; HUG-AMALRIC, A.; MERLIN, J. Evaluation of the Proportion of Phases and Mechanical Strength of Two-Phase Steels Using Barkhausen Noise Measurements: Application to Comercial Dual-Phase Steel. Metallurgical and Materials Transactions A, v. 39A, p. 1308-1318, 2008. 
KLEBER, X.; BARROSO, S. P. Investigation of shot-peened austenitic stainless steel 304L by means of magnetic Barkhausen noise. Materials Science and Engineering A, v. 527, p. 6046-6052, 2010.

KRAUSS, G. Martensite in steel: strength and structure. Materials Science and Engineering, v. A273-275, p. 40-57, 1999.

KUNG, C. Y.; RAYMENT, J. J. An Examination of the Validity of Existing Empirical Formulae for the Calculation of Ms Temperature. Metallurgical Transactions A, v. 13A, p. 328-331, 1982.

LITWINCHUK, A.; KAYSER, F. X.; BAKER, H. H. The Rockwell C hardness of quenched high-purity iron-carbon alloys containing 0.09 to $1.91 \%$ carbon. Journal of Materials Science, v. 11, p. 1200-1206, 1976.

LIU, C.; ZHAO, Z.; NORTHWOOD, D. O.; LIU, Y. A new empirical formula for the calculation of Ms temperatures in pure iron and super-low carbon alloy ateels. Journal of Materials Processing Technology, v. 113, p. 556-562, 2001.

MACKENZIE, J. K. Martensite: fundamentals and technology. Division of Chemical Physics, págs. 402-403, 1970.

MAKI, T.; TSUZAKI, K.; TAMURA, I. The Morphology of Microstructure Composed of Lath Martensites in Steels. The Iron and Steel Institute of Japan, v. 20, p. 207-214, 1980.

MAKITA, T.; KOBUKATA, M.; NAGASAWA, A. Electric resistivity anomaly and martensitic phase transformation in Cu-Al-Zn alloy. Journal of materials science, $\mathrm{v}$. 21, p. 2212-2216, 1986.

MÉSZÁROS, I.; KÁLDOR, M.; HIDASI, B.; VÉRTES, A.; CZAKÓ-NAGY, I. Micromagnetic and Mössbauer spectroscopic investigation of strain-induced martensite in austenitic atainless steel. Journal of Materials Engineering and Performance, v. 5, p. 538-542, 1996.

NISHIYAMA, Z. Martensitic Transformation, Academic Press, New York, NY, 1978.

OKAZAKI, T.; UENO, T.; FURUYA, Y.; SPEARING, M.; HAGOOD, N. W. Detectability of stress-induced martensite phase in ferromagnetic shape memory alloy Fe-30.2at.\%Pd by Barkhausen noise method. Acta Materialia, v. 52, p. 51695175, 2004.

OLSON, G. B.; TSUZAKI, K.; COHEN, M. Statistical Aspects of Martensitic Nucleation. Materials Research Society, v. 57, p. 129-148, 1987.

OWEN, W. S.; WILSON, E. A. Physical properties of martensite and bainite, Special Report No. 93. Iron and Steel Institute, p. 153-163, London, 1965. 
PATI, S. R.; COHEN, M. Nucleation of the isothermal martensitic transformation. Acta Metallurgica, v. 17, p. 189-199, 1969.

PORTER, D. A.; EASTERLING, K. E. Phase Transformation in Metals and Alloys. s.I. : CHAPMAN \& HALL, 1992.

STANDARD SPECIFICATION FOR TOOL STEELS ALLOY. ASTM INTERNATIONAL A681-08.

TAYLOR, K. A.; COHEN, M. Aging of Ferrous Martensites. Progress in Materials Science, v. 36, p. 225-272, 1992.

TROIANI, H. E.; SADE, M.; BERTOLINO, G.; BARUJ, A. Martensitic transformation temperatures and microstructural features of FeMnCr alloys. Esomat, v. 6002, p. 1-5, 2009.

TSCHIPTSCHIN, A. P.; GOLDENSTEIN, H.; SINÁTORA, A. Metalografia dos Aços, Associacao Brasileira de Metais - ABM, 1988.

VILLARES METALS. Aços Ferramenta para Trabalho a Frio. s.I. : Catálogo Técnico.

VINCENT, A.; PASCO, L.; MORIN, M.; KLEBER, X.; DELNONDEDIEU. Magnetic Barkhausen noise from strain-induced martensite during low cycle fatigue of $304 \mathrm{~L}$ austenitic stainless steel. Acta Materialia, v. 53, p. 4579-4591, 2005.

VINTAIKIN, E. Z.; NOSOVA, G. I. The founder of the theory of diffusionless (martensite) transformations in metallic alloys. Metal Science and Heat Treatment, v. 39, p. 70-76, 1997.

VOORT, G. F. V. Metallography and Microstructures. s.I. : ASM HANDBOOK. v. 9, p. 644-669, 2004.

VOORT, G. F. V. Martensite and retained austenite. Industrial Heating, p. 51-54, 2009.

WEISS, R. J. The Origin of the "Invar" Effect. Proceedings of the Physical Society, v. 82, p. 281-288, 1963.

YANG, H-S.; BHADESHIA, H. K. D. H. Austenite grain size and the martensite-start temperature. Scripta Materialia, v. 60, p. 493-495, 2009.

YIN, Y.; KAKESHITA, T.; CHOI, M.S.; FUKUDA, T.; XIA, T.D. Martensitic transformation and anomalies in resistivity of $(\mathrm{Ti}-50 \mathrm{Ni})_{1-\mathrm{x}} \mathrm{C}_{\mathrm{x}}(\mathrm{x}=0.1,0.5 \mathrm{at} . \%)$ shape memory alloys. Journal of Alloys and Compunds, v. 464, p. 422-428, 2008.

YU, Z-Z.; CLAPP, P. C. Growth Dynamics Study of the Martensitic Transformation in Fe-30 Pct Ni Alloys: Part I. Quantitative Measurements of Growth Velocity. Metallurgical Transactions, v. 20A, p. 1601-1615, 1989. 
ZENER, C. Kinetics of the Decomposition of Austenite. American Institute of Mining and Metallurgical Engineers, p. 1-34, 1946.

ZHANG, M.-X.; KELLY, P. M.; GATES, J. D. A model of stress induced martensitic transformation in Fe-Ni-C alloy. Materials Science and Engineering, v. A273-275, p. 251-256, 1999.

ZHAO, J. Continuous cooling transformations in steels. Materials Science and Technology, v. 8, p. 997-1003, 1992.

ZHAO, J.; NOTIS, M. R. Continuous cooling transformation kinetics versus isothermal transformation kinetics of steel: a phenomenological rationalization of experimental observations. Materials Sciencie and Engineering, v. R15, p. 135-208, 1995. 